\title{
Initial Performance Evaluation and Ranking of Thermal Energy Storage Options for Light Water Reactor Integration to Support Modeling and Simulation
}

Daniel Mikkelson, NCSU Konor Frick Ph.D., INL Shannon Bragg-Sitton Ph.D., INL Cristian Rabiti Ph.D., INL J. Michael Doster Ph.D., NCSU

November 2019

The INL is a U.S. Department of Energy National Laboratory operated by Battelle Energy Alliance 


\section{DISCLAIMER}

This information was prepared as an account of work sponsored by an agency of the U.S. Government. Neither the U.S. Government nor any agency thereof, nor any of their employees, makes any warranty, expressed or implied, or assumes any legal liability or responsibility for the accuracy, completeness, or usefulness, of any information, apparatus, product, or process disclosed, or represents that its use would not infringe privately owned rights. References herein to any specific commercial product, process, or service by trade name, trade mark, manufacturer, or otherwise, does not necessarily constitute or imply its endorsement, recommendation, or favoring by the U.S. Government or any agency thereof. The views and opinions of authors expressed herein do not necessarily state or reflect those of the U.S. Government or any agency thereof. 
INL/EXT-19-56504

Revision 0

\section{Initial Performance Evaluation and Ranking of Thermal Energy Storage Options for Light Water Reactor Integration to Support Modeling and Simulation}

Daniel Mikkelson, NCSU

Konor Frick Ph.D., INL

Shannon Bragg-Sitton Ph.D., INL

Cristian Rabiti Ph.D., INL

J. Michael Doster Ph.D., NCSU

November 2019

Idaho National Laboratory

Idaho Falls, Idaho 83415

http://www.inl.gov

Prepared for the

U.S. Department of Energy

Office of Nuclear Energy

Under DOE Idaho Operations Office

Contract DE-AC07-05ID14517 



\section{ABSTRACT}

This report provides an in-depth analysis of current thermal storage technologies in the marketplace as of 2019 and develops a phenomenological identification ranking table (PIRT) and Figure of Merit (FOM) study for near-term thermal energy storage technologies with light water reactor technology. Particular focus was given the NuScale reactor as part of the Joint Use Modular Plant (JUMP) program between INL, NuScale, and the Utah Associated Municipal Project (UAMPs).

It is fair to notice that the changes in the scope of the Integrated Energy System program led this report to focus more on thermal energy storage than on hydrogen as a form of local energy storage. This is due to LWRS (Light Water Reactor Sustainability) program picking up this area of research with an industrial partner as a part of a CRADA.

Moreover, instead of trying to develop few initial models of some storage technologies, it has been chosen to analyze a broader range of thermal storage technologies and models available in literature. This takes also in consideration that any new model development in modelica would become soon obsolete, giving the decision to reshape the hybrid ecosystem of modelica models, which is part of FY2020 effort.

Ancillary service industries and technologies are explored in detail to ascertain thermodynamic requirements for integration with thermal energy storage technologies. These industries include steel manufacturing, hydrogen production, desalination, pulp and paper manufacturing. It was determined that a large percentage of these industries can make use of existing nuclear output temperatures and pressures. Storage technologies that can maintain these values are advantageous for coupling purposes.

The report then analyzes ten thermal energy storage technologies, with thirteen specific systems discussed in detail regarding their potential to integrate with LWR technology. A ranking tool identified important characteristics of thermal storage and ranked each of the technologies. Concrete, molten salt, and thermal oil sensible heat storages, and steam accumulators evaluated highly. After including cost estimations and qualitatively comparing these technologies, it is recommended that either molten salt or thermal oil is used for implementation with the JUMP module. The TES project cost will likely cost between $\$ 14,000,000$ and $\$ 50,000,000$. The potential flexibility of a two-tank sensible heat storage system should be able to demonstrate various new uses for nuclear heat. From power peaking via steam or liquid air heat topping to process heat applications, a two-tank system should be able to best provide a constant power transfer capability to the auxiliary energy consumer.

Through commencement of this work, a more refined thermal storage selection process for Nuscale and existing nuclear power plants can be conducted. The ranking system developed here can be used to reevaluate the energy storage options periodically depending on the projected installation dates. Current results suggest two-tank thermal energy storage is the most relevant technology in the near-term. 


\section{CONTENTS}

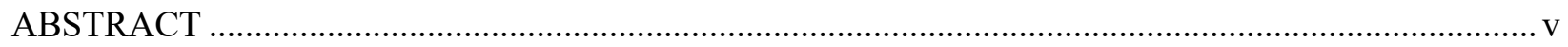

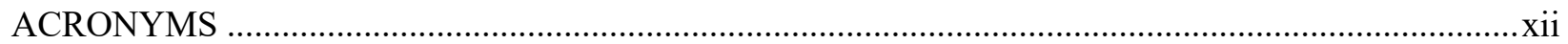

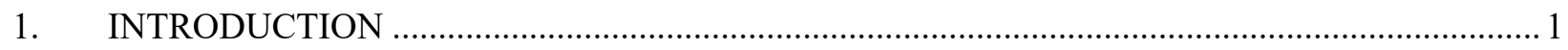

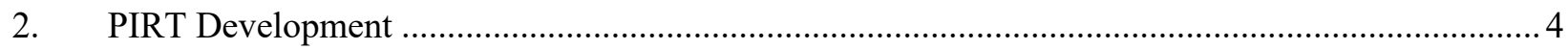

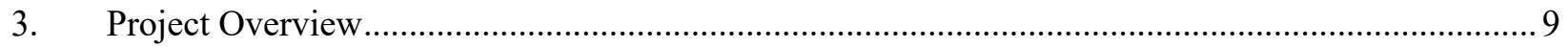

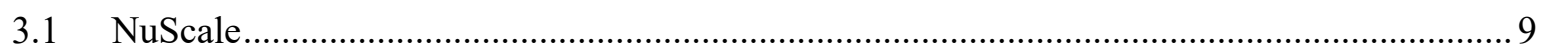

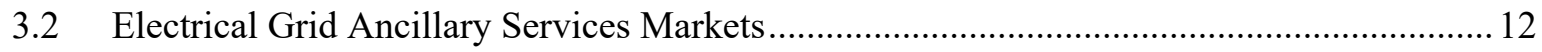

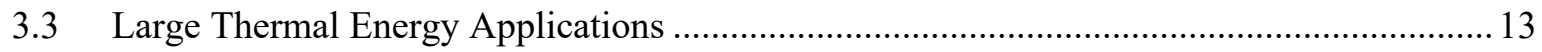

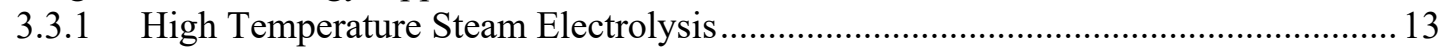

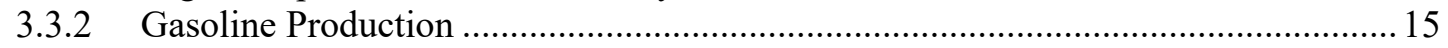

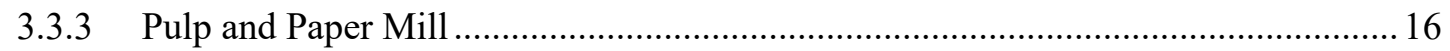

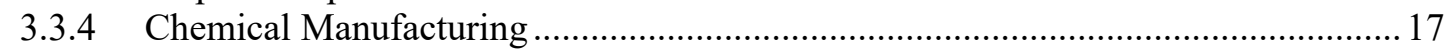

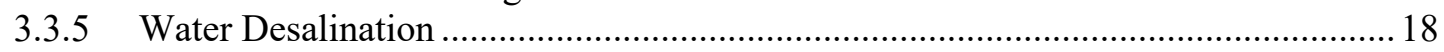

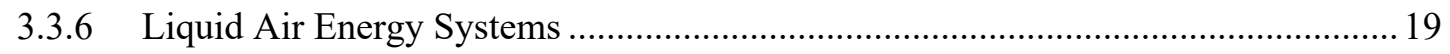

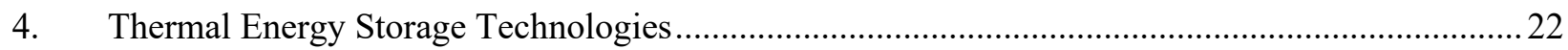

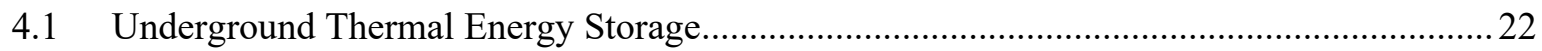

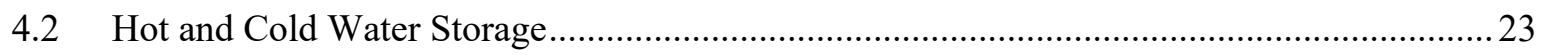

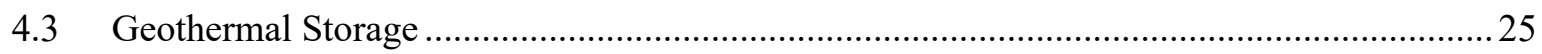

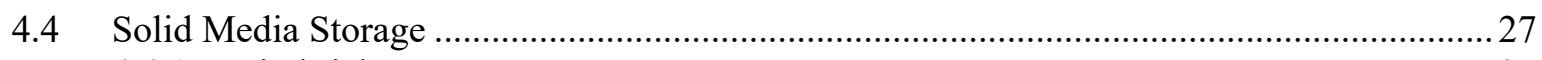

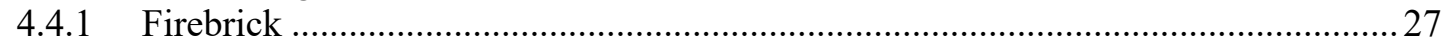

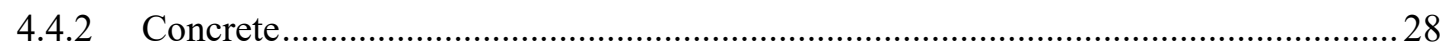

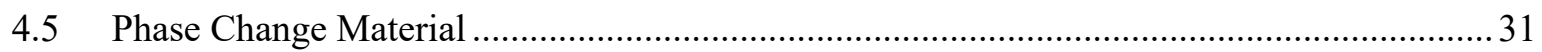

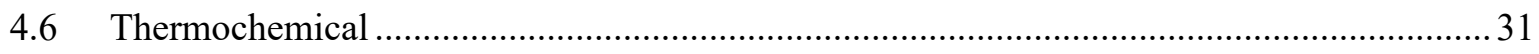

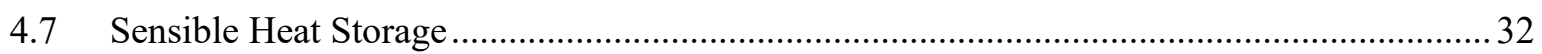

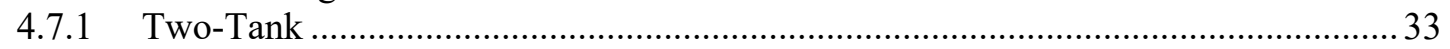

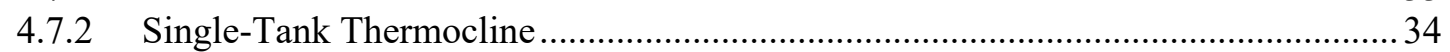

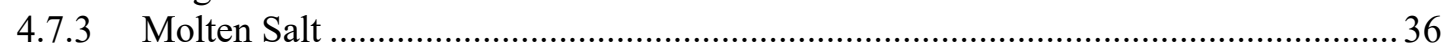

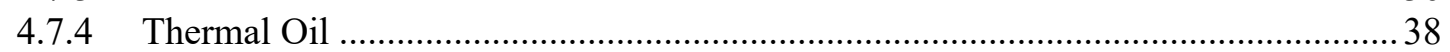

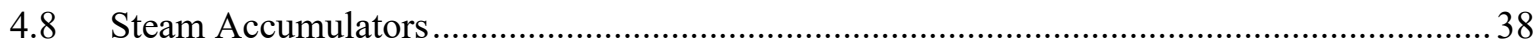

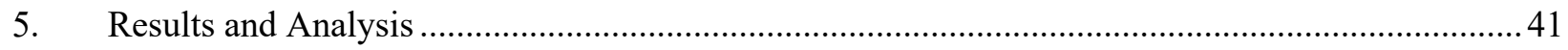

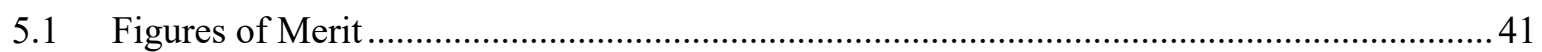

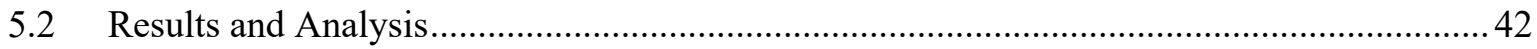

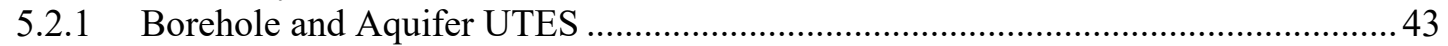

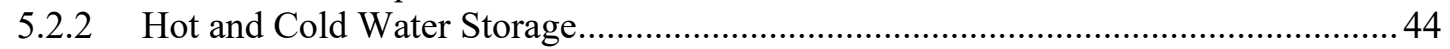

5.2.3 Concrete

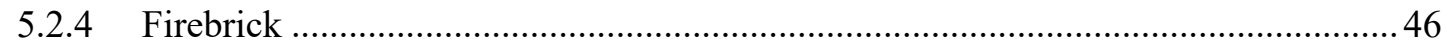

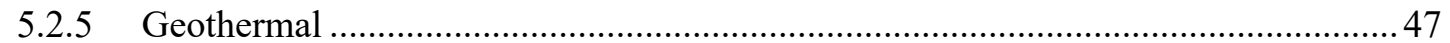

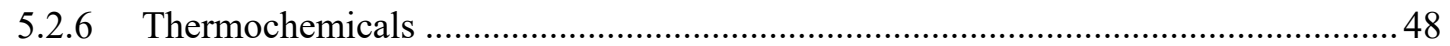

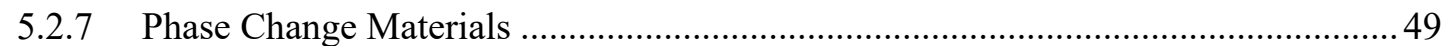

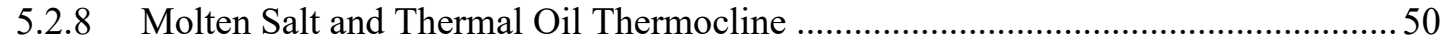


5.2.9 Two-Tank Molten Salt and Thermal Oil

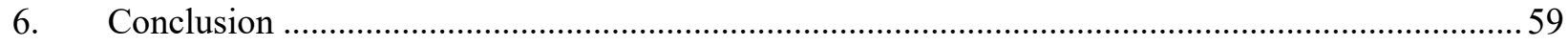

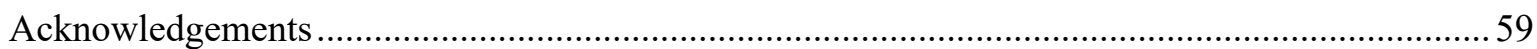

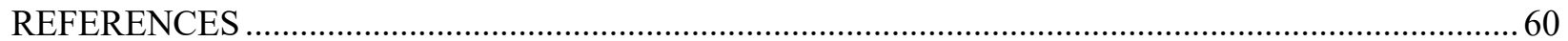




\section{FIGURES}

Figure 1. Major NPM components and flow path from NuScale [10].

Figure 2. Energy requirements of petroleum refineries; figure derived from [23]. All values along the energy path arrows are in tera-BTU The other values in the dark green, light brown, and mid-green boxes are emissions in $\mathrm{MMT} \mathrm{CO}_{2}$ offsite, onsite, and the added total

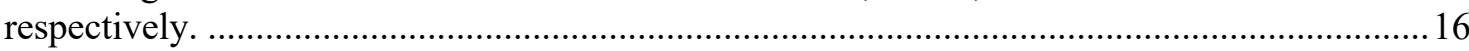

Figure 3. Liquor use in the Kraft recovery process, taken from [31] ................................................... 17

Figure 4. Energy use by thermal or electrical, from [24] ................................................................ 17

Figure 5. Water capacity and brine production by existing desalination techniques, from [32]................18

Figure 6. Specific energy consumption for various desalination technologies. Figure reproduced from [33] Table 1, where "Total Electric Equivalent" is equal to the electric consumption plus $45 \%$ of the thermal energy consumption, reflecting a standard conversion efficiency from thermal to electrical energy.

Figure 7. High level diagram of Highview Power LAES system [36] ...................................................20

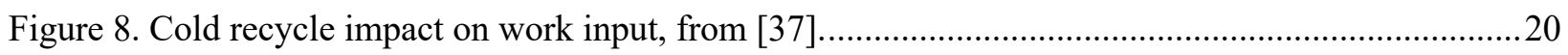

Figure 9. Impact of gas temperature on turbine output at 48 bar, extracted from [37] ...........................21

Figure 10. Impact of gas pressure on turbine output at $289 \mathrm{~K}$, from [37] ............................................21

Figure 11. LAES simulated efficiency versus number cycles, from [41] . .............................................22

Figure 12. Absorption chiller and SMR integration, from [47].........................................................24

Figure 13. Adapted representation of large-scale hot and cold water storage, from [48], [7]...................25

Figure 14. Design diagram for hot and cold well placement, from [50] .............................................26

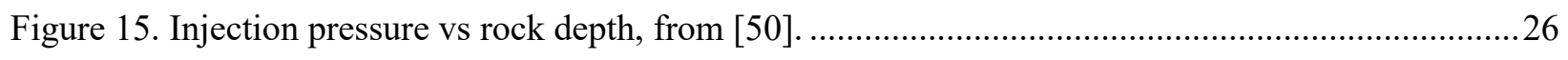

Figure 16. Geothermal energy storage potential design, adjusted from [50] ........................................27

Figure 17. Group of results of FIRES simulations. Outlet temperature, gas sweep fan power, discharge power, and various system temperatures [52]. ....................................................28

Figure 18. Cross section cut of HEATCRETE® material, reported in [55] ..........................................29

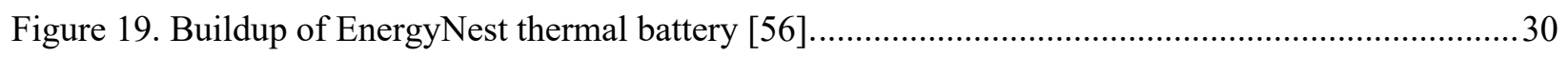

Figure 20. Example of graphite heat transfer structures application [57] .............................................30

Figure 21. Conceptual operation of thermochemical operation, from [4] ............................................. 32

Figure 22. Potential design of a two-tank sensible heat peaking unit integrated with a SMR [72]." ..........33

Figure 23. Design of a thermocline tank from HITEC, reproduced from [74]. .34

Figure 24. Dimensionless output temperature during discharge time for two thermocline Reynolds numbers $(\mathrm{Re})$ and various molten salt flow distances to particle diameter ratios $(\Psi)$ [74].

Figure 25. Discharge efficiency vs. dimensionless tank height for various internal Re numbers [75]. 35

Figure 26. Energy withdrawal comparison of two-tank vs. thermocline for a molten salt [73]................36

Figure 27. Relation between capital cost and temperature difference for various molten salts [78]..........37 


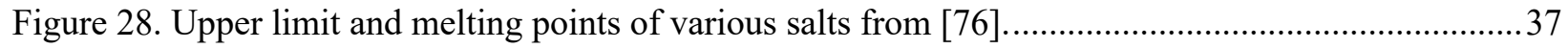

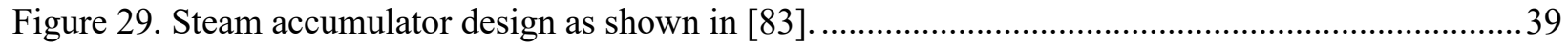

Figure 30. Density of steam discharged versus starting and ending pressure [83]. .................................39

Figure 31: Conceptual TES integration for JUMP project." ..................................................................58 


\section{TABLES}

Table 1. Technology Readiness Level Definitions, as defined in reference [84].....................................5

Table 2. Summary of PIRT assignments for the engineering questions. ............................................... 8

Table 3. Potential steam conditions at various turbine stage taps in present NuScale power conversion designs via design certification documents. ........................................................... 11

Table 4. Overview of ancillary services, extracted from [15] ............................................................ 12

Table 5. Presentation of spinning reserves market in different ISOs [15] ................................................ 13

Table 6. Free energy released during water production from hydrogen and oxygen, from [16] ...............14

Table 7. Inputs and outputs of HTSE using nuclear and electric heat, from [18]. Oxygen is in parenthesis because it is generally not collected as an output but rather is simply

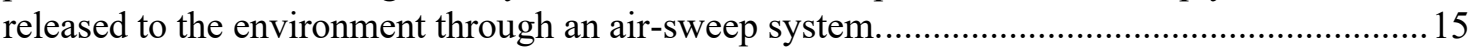

Table 8. Various heat transfer fluids for potential TES selection, from [72] ...........................................38

Table 9. Evaluation of Thermal Energy Storage Options. ........................................................................42

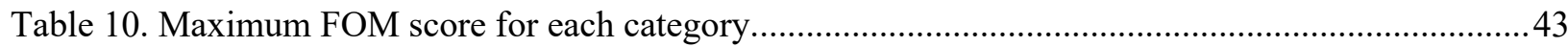

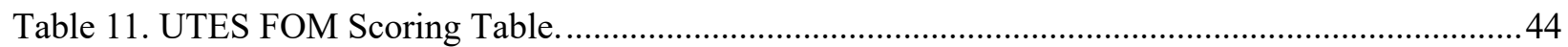

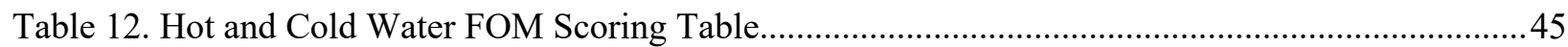

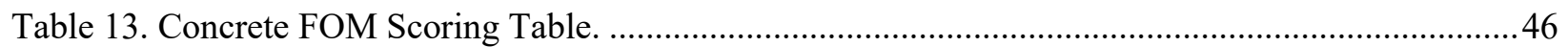

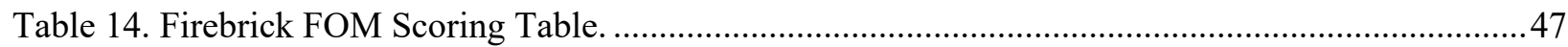

Table 15. Geothermal energy storage FOM Scoring Table.........................................................................48

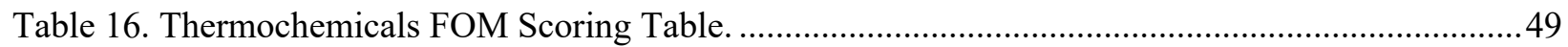

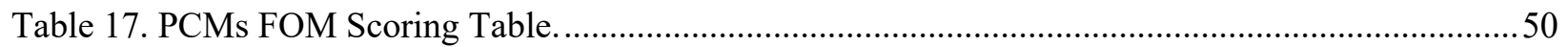

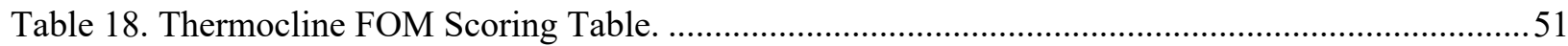

Table 19. Two-Tank Molten Salt/Thermal Oil FOM Scoring Table. .......................................................52

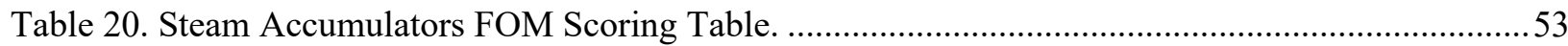

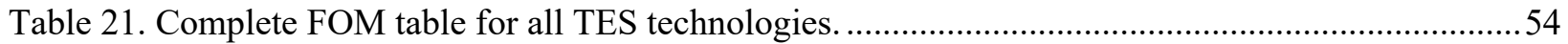

Table 22. Energy and Power Cost Estimates for Potential TES technologies. .........................................55

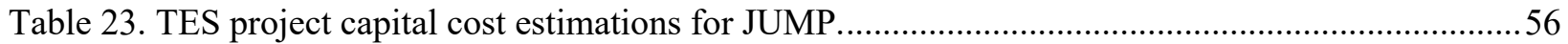




\section{ACRONYMS}

CFPP Carbon Free Power Project

CSP Concentrated Solar Power

FOM Figure of Merit

HCWS Hot and Cold Water Storage

HTF Heat Transfer Fluid

HTSE High Temperature Steam Electrolysis

INL Idaho National Laboratory

IPWR Integral Pressurized Water Reactor

JUMP Joint Use Modular Plant

LAES Liquid Air Energy Storage

LWR Light Water Reactor

LWRS Light Water Reactor Sustainability

MECS Manufacturing Energy Consumption Survey

NCSU North Carolina State University

NPM NuScale Power Module

PIRT Phenomenon Identification Ranking Table

PWR Pressurized Water Reactor

RO Reverse Osmosis

RTE Round Trip Efficiency

SMR Small Modular Reactor

SOEC Solid Oxide Electrolysis Cell

TES Thermal Energy Storage

UAMPS Utah Associated Municipal Power Systems

UTES Underground Thermal Energy Storage 


\section{INTRODUCTION}

Global electrical grids continue to integrate renewable energy sources alongside existing nuclear, coal, hydro, and natural gas generation. The influx of supply from solar and wind power has resulted in increased net demand variability on the grid. Selling electricity is becoming uneconomical for other baseload plants as the clearing price of electricity, set by the low marginal cost of variable renewable suppliers, is pressured downward. Because renewable energy is often incentivized and thus allows for profitable operation even at negative selling price, high penetrations of renewable energy can cause clearing prices to be very low or negative. This change in market dynamics requires a paradigm shift in the operations of baseload power plants to try to remain profitable. These price shifts are reflected both in daily prices and in the valuation of ancillary services such as spinning \& non-spinning reserves. Interest in energy storage is increasing with this new reality and government policy is also changing (FERC order 841) to accommodate industrial interest in energy storage. Electrical, mechanical, chemical, electro-chemical and thermal energy storage technologies are being researched globally in attempts to enhance their economic viability. Storage has long been seen as the "Holy Grail" for grid stability and integration of variable renewable generators, yet high costs have kept it just out of reach. The concentrated solar power (CSP) industry has increasingly used molten salt tank systems to flatten their power production profiles over daily cycles while still only collecting heat during daylight hours. In this way, CSP is overcoming the grid challenges of renewable intermittency by becoming as steady of a power source as possible. Other industries are looking to affect the inverse change: to produce power at constant rates and then distribute that energy during the intermittent lulls the grid is now experiencing.

In the U.S., nuclear energy has overwhelmingly been used to generate baseload electricity. While nuclear reactors are capable of providing flexible power output, given the general absence of variable costs, nuclear plant owners prefer to operate at maximum power as often as possible to recover the large capital costs incurred by their construction (assuming that the energy produced can be sold at non-negative electricity prices) [1] [2]. Economically, two-thirds of the cost of the electricity produced by a nuclear plant is due to the necessity to recover the up-front capital, with only about $12 \%$ appearing as variable fuel, operations, and maintenance [1]. Thus, the marginal income lost by reducing power or shutting down is not matched or reflected in reduced operating costs. EPRI has been conducting studies of plants that operate flexibly since approximate 2015 to determine if there are any increased operations and maintenance (O\&M) costs that derive from flexible power operations; to date, these additional costs appear to be minimal.

Various energy storage technologies are currently under development globally. An Idaho National Laboratory (INL) report from 2017 identified twenty-four mechanical, electrical, electrochemical, chemical, and thermal energy storage methods [8]. Nuclear reactors produce large amounts of thermal power that is transferred from the core at pressures and temperatures around 3.5-7 MPa and $290-345^{\circ} \mathrm{C}$. All steps of converting nuclear heat into energy consumed by another process incur system losses and thus additional economic cost. To minimize the number of energy transformations, thermal energy storage is pre-selected as the preferred energy storage option for nuclear energy systems. Thermal storage would introduce a new nuclear plant dynamic that is not currently practiced and could provide greater economic viability to nuclear power on the grid.

It is necessary to acknowledge that initially the assessment of using hydrogen, as storing medium for energy, has been considered as being part of this report. However, it has been decided to keep it out from this report. This choice came from considerations on the energy efficiency of this technology and the fact that this exact analysis will be undertaken by the Light Water Reactor 
Sustainability DOE Program in collaboration with an industrial partner as a part of a CRADA agreement.

INL is supporting research in integrated energy systems (IES) that investigates how nuclear energy can be used outside of traditional electricity generation [4]. One aspect of such research is the demonstration of IES technologies for small modular reactors (SMRs). This demonstration will be accomplished via the Joint Use Modular Plant (JUMP) program. The JUMP program proposes to use one module within a full 12-module, commercial NuScale Power plant for research, development, and demonstration (RD\&D) purposes. This collaboration between Idaho National Laboratory, NuScale, and Utah Area Municipal Power Systems (UAMPS) anticipates the JUMP module coming online around the beginning of fiscal year 2027. One primary goal of JUMP is to demonstrate thermal energy storage (TES) integration with an operating LWR in a real-world (commercial) environment. TES integration will allow for the demonstration of nuclear reactors operating in highly variable grids, such as small microgrid communities in remote destinations and in arenas where wind and solar generation cause significant grid net load reductions. ${ }^{1}$ Additionally, thermal energy storage integration allows the participation of nuclear reactors in ancillary service markets that can potentially increase profitability.

An intent of this research is both to support SMR deployment opportunities and inform the expansion of operating LWR capabilities. The JUMP program proposes to "dedicate for nuclear energy research the first reactor module planned for the Carbon Free Power Project (CFPP)... the plant will consist of 12 independent NuScale small modular reactors (SMRs) in a shared pool" [5]. Jess Gehin, Chief Scientist of the Nuclear Science \& Technology Directorate at INL indicates, "It would support research and development into the ability to utilize thermal energy storage, integration with other energy sources, and provide insights into other projects..." [5]. TES-related goals of the JUMP program are to demonstrate a variety of TES applications by using an energy storage system that is directly integrated into the secondary side (i.e., the thermal energy conversion system) of a NuScale Power Module (NPM). The relatively short timeline of the JUMP program incentivizes the need for energy storage selection mechanisms. Research and operational experience, which JUMP will provide, are needed to help integrate thermal storage into existing reactors. The heat stored in TES could be used for energy arbitrage or for load following. Energy arbitrage refers to storing or purchasing electricity when clearing prices are low and releasing or selling the electricity when clearing prices are high. In regulated markets that do not have a price for electricity it is better to describe the operational mode of the storage as load following. Load following is similar in concept to price arbitrage, but is motivated purely by shaving the peaks and valleys of net demand as opposed to taking advantage of changes in electricity pricing. Additionally, energy from a TES system can be used as process heat to drive a coupled industrial process. When TES is used for industrial process heat, it can serve as a buffer between the nuclear reactor and the industrial system, allowing for better coupling between subsystems that operate with different dynamic characteristics.

The JUMP program provides an opportunity to begin industry-wide discussions on the most important criteria for storage selection in nuclear power systems. Key characteristic questions that will be applicable to all storage applications must be identified to create a framework in which storage systems can be evaluated. Once this framework is established, application-specific figures of merit (FOM) analyses can be applied for future storage technology selection. Selected applications that could utilize stored heat are discussed in this report, including coal gasification, gasoline production, pulp and paper milling, chemical manufacturing, water desalination, high

\footnotetext{
${ }^{1}$ Net load or net demand refer to the remaining grid demand that must be met after renewable generation has been accounted.
} 
temperature steam electrolysis, liquid air energy storage, district heating, and power peaking units. Each of these applications maintain different thermal requirements and energy spectra that may favor different storage technologies.

Throughout this report, the terms charge and discharge of a TES system refer to the process of storing heat in the TES and removing it, respectively. During charging periods the amount of heat made available to electricity production would decrease. During the discharging phase, the opposite may be true depending on the application of the TES. A TES intended for use in power peaking would add stored energy to the power conversion system and thereby increase, for limited periods, electricity production.

TES options investigated in this report are: underground storage in aquifers or boreholes, hot and cold water storage, geothermal storage, solid media storage focusing on concrete, steam accumulators, thermochemicals, phase change materials (latent heat storage), and sensible heat storage focusing on molten salts and thermal oils.

While analyzing those TES options, consideration has been given to identify the necessary modeling information to couple these technologies with the modelica base model of the JUMP [6].

The next section discusses the phenomenon identification and ranking table for general thermal energy storage integration with nuclear reactors, presented as a series of engineering questions. This is followed by an overview of the JUMP program, including potential energy storage and use applications. This leads into a discussion on Figures of Merit for evaluation of coupled energy storage systems. Candidate thermal energy storage technologies are presented and evaluated, and a discussion of the effectiveness of the PIRT and subsequent FOM provide report conclusions. 


\section{PIRT Development}

To select a single thermal energy storage technology, it is important to make sure that all parameters are considered. While these may not be "phenomenon" in the traditional sense of the word, the phenomenon identification and ranking table (PIRT) method can be used to evaluate the various characteristics of storage technologies and their deployment. Each aspect of storage selection will be presented as an engineering design question.

The PIRT questions for thermal energy storage system evaluation include the following:

1. Is the storage technology deployable in an appropriate timeframe?

2. How compatible is the storage technology with the heat source?

3. Can the storage technology effectively store energy for a future application?

4. Can the storage technology allow for increased market penetration and operational flexibility?

5. Can the storage technology allow for a sufficient capacity of storage?

6. What is the time required to switch between operational modes (charge/discharge) for this storage technology?

7. How often can the storage technology be used and cycled?

8. Will the dynamics of the storage technology lead to periods of unavailability?

9. How much does the storage technology cost (capital and O\&M)?

10. What is the lifetime of the storage technology, especially when compared to the heat source and energy applications?

11. Will the storage technology increase the geographical requirements of the system?

12. Will the storage technology add to the concerns identified in the environmental evaluation of the system?

13. How long can the storage technology remain unused between cycles before it requires some form of intervention?

14. Are any regulatory challenges anticipated?

Each of the PIRT criteria will be evaluated with categorizations of every $(\mathrm{E})$, frequent $(\mathrm{F})$, and rarely $(\mathrm{R})$, that will indicate how often a specific application will need to include that question in its figure of merit study. The importance of the various contributors is then left up to those FOM studies.

1) Is the storage technology deployable in an appropriate timeframe? The technology readiness levels reference used later in this study is from the Technology Readiness Assessment Guide distributed by the Department of Energy in 2011 [85]. A summary of the technology readiness levels (TRL) is provided in Table 1. 


\begin{tabular}{|c|c|c|}
\hline $\begin{array}{c}\text { Relative Level of } \\
\text { Technology Development }\end{array}$ & $\begin{array}{l}\text { Technology Readiness } \\
\text { Level }\end{array}$ & TRL Definition \\
\hline System Operations & TRL 9 & $\begin{array}{c}\text { Actual system operated over the full range of expected mission } \\
\text { conditions. }\end{array}$ \\
\hline \multirow{2}{*}{ System Commissioning } & TRL 8 & $\begin{array}{c}\text { Actual system completed and qualified through test and } \\
\text { demonstration. }\end{array}$ \\
\hline & TRL 7 & $\begin{array}{l}\text { Full-scale, similar (prototypical) system demonstrated in } \\
\text { relevant environment }\end{array}$ \\
\hline Technology Demonstration & TRL 6 & $\begin{array}{l}\text { Engineering/pi lot-scale, similar (prototypical) system } \\
\text { validation in relevant environment }\end{array}$ \\
\hline Technology Development & TRL 5 & $\begin{array}{c}\text { Laboratory scale, similar system validation in relevant } \\
\text { environment }\end{array}$ \\
\hline Technology Development & TRL 4 & Component and/or system validation in laboratory environment \\
\hline \multirow{2}{*}{$\begin{array}{l}\text { Research to Prove } \\
\text { Feasibility }\end{array}$} & TRL 3 & $\begin{array}{l}\text { Analytical and experimental critical function and/or } \\
\text { characteristic proof of concept }\end{array}$ \\
\hline & \multirow[t]{2}{*}{ TRL 2} & \multirow[t]{2}{*}{ Technology concept and/or application formulated } \\
\hline \multirow[t]{2}{*}{$\begin{array}{l}\text { Basic Technology } \\
\text { Research }\end{array}$} & & \\
\hline & TRL 1 & Basic principles observed and reported \\
\hline
\end{tabular}

Table 1. Technology Readiness Level Definitions, as defined in reference [85].

For near-term deployment, a candidate technology must be relatively high on the TRL scale. For a longer-term project, such as generation IV reactors initially deployed independent of storage in 2030, a storage technology may not need to be fully viable yet to be the expected preferred choice [7]. It is expected that every project will need to evaluate storage options based on their current and likely TRL level at the desired time of deployment. Therefore, a value of $\mathrm{E}$ is assigned for the PIRT on this criterion.

2) How compatible is the storage technology with the heat source? Candidate technologies must be compatible with nuclear-generated steam pressures and temperatures. Light water cooled nuclear reactors produce energetic steam at pressures of 3.5-7 $\mathrm{MPa}$ (500-1000 psia), at temperatures approaching $315^{\circ} \mathrm{C}\left(600^{\circ} \mathrm{F}\right)$, with possible steam superheat of about $55^{\circ} \mathrm{C}\left(100^{\circ} \mathrm{F}\right)$. An ideal energy storage characteristic is the ability to utilize this heat as directly as possible. It is important to keep in mind that the storage medium, containment, and heat exchange components must all be re-evaluated for each technology to ensure compatibility. As more storage systems are deployed, theoretical matching of characteristics will be replaced with libraries of experiential knowledge for storage technologies. Every project will need to ensure that the selected storage technology can effectively charge with the heat source, so a PIRT of E is assigned for this criterion.

3) Can the storage technology effectively store heat for the future application? This question can be broken down into two sub-questions for a given application. First, can the storage technology 
effectively store heat over the given time period needed by the application? And second, is there a good discharge mechanism to move the energy into the specific application? A storage technology may be able to maintain a large amount of energy without major losses for a great deal of time, but have no efficient manner of applying the stored energy. Likewise, other storage technologies may be highly efficient over short time periods but will incur losses if stored for longer time frames. The storage timeframe for the application and the economics associated with the storage efficiencies will drive the importance of these criteria to each application. While question (2) deals with compatibility of the storage with the energy source, question (3) ensures that the compatibility with the energy application is addressed. Once again, it is expected that all applications will need to address this question, and so a PIRT of $\mathrm{E}$ is assigned.

4) Can the storage technology allow for increased market participation and operational flexibility? Increased ancillary services market participation may arise from the introduction of energy storage systems by allowing a power producer to create operational reserve capacity. Spinning and non-spinning reserve markets are location-specific and will change with every new system competing for its remunerations. In this case, operational flexibility is the ability of the power producer to alter its production stream in order to change its market participation in response to market conditions: storing energy to create capacity credits or to avoid selling at a loss, or discharging to earn reserve credits and to sell energy for higher profits. This question deals very specifically with the engineering application, and may be avoided depending on the system setup. For systems looking to provide a buffer between the heat generation source and energy user it may not be practical to investigate any increased market participation as the system goal shifts from electricity production. Therefore, a value of $\mathrm{F}$ is assigned to the PIRT for this category. If the market shifts for nuclear heat demand toward using it for more process heat in the future, this value may shift to R.

5) Can the storage technology provide a sufficient storage capacity? While many storage technologies may be built in parallel or series in order to increase the overall storage size, there may still be technical limits that exist. For instance, the size of a pumped hydro storage facility is generally capped when the physical size and weight of the stored water becomes economically infeasible to maintain. Salt storage tanks face similar challenges, and their heights and diameters become limited by material considerations in the pumps and storage tanks themselves. Other storage technologies, such as concrete, expect to be limited only by the amount of land available, as they are designed and implemented in a modular fashion. Ensuring that enough storage can be created is essential for large applications. A PIRT of E is assigned for this category.

6) What is the time required to change between operational modes when using this storage technology? This can also be called "ramp time." This question is application dependent, and the requirements could change rapidly. Additionally, the question implies that there is a time required to change between charging and discharging operational modes, which may not be the case depending on the storage technology. In systems where the heat transfer fluid charging or discharging the systems runs in different directions depending on the system operational state, a change will be necessary. In other systems, charging and discharging may be able to occur simultaneously, such as in two-tank sensible heat systems or in steam accumulators. Even in these systems, however, the time associated with switching from not-charging or not-discharging to charging or discharging will likely need to be considered. In seasonal storage systems, this will not likely be a significant concern as the power of the system will be much smaller than the energy content of the system. A PIRT of $F$ is assigned in this category.

7) How often can the storage technology be used and cycled? Cycle frequency can dictate what kinds of storage technologies can be used for short-cycle applications. The difference between this 
question and the question of ramp time is in the storage technology's potential need to completely discharge or charge in order to be useful again. System characteristics may cause significant thermal stresses while cycling that may need to be mitigated simply by being offline for a time. Similar to ramp time, whether there are such concerns is dependent on the application. Due to systems that will be able to ignore this criterion, a PIRT of $\mathrm{F}$ is assigned in this category.

8) Will the dynamics of the storage technology lead to periods of unavailability? This question pertains to system realignment due to non-linearities in the storage system. An example of this is a thermocline tank in which the thermocline layer has expanded, creating a more isothermal system than is desired. By not having hot and cold sections set in the tank, the storage tank now becomes ineffective until these two distinct sections can be re-established. Again, systems with long cycle lengths may be able to ignore questions of temporary unavailability, while it may be of great importance to short cycle systems. A PIRT of F is assigned in this category.

9) How much does the storage technology cost? There are two overall cost figures that must be calculated in storage systems: $\$ / \mathrm{kWh}$ and $\$ / \mathrm{kW}$. The first is associated with the amount of money per unit of stored energy available to the power producer. This figure should always be calculated with as much information as possible. For instance, in a sensible heat system, this cost value is useless without also indicating the storage medium temperature change. When it comes to calculating power costs, the cycle frequency may play a significant role, as energy losses cause the amount of power output available to decrease. Further, it should be recalled during design that there are no $100 \%$ efficient systems, and that system losses occur. Therefore, the same storage technology may have different cost values depending on its usage frequency as system losses vary with cycle frequency. Every project must thoroughly evaluate costs, so a PIRT of E is assigned in this category.

10) What is the lifetime of the storage technology, especially when compared to the heat source and applications? The technology lifetime is linked with the technology cost, and how this question is approached will also be engineering team dependent. For instance, most current thermochemical studies show that they have limited cycles before too many pollutants arise in the reactant-product chain. In this case, at least the thermochemical media must be replaced in order to continue to effectively store energy. Whether this should be considered a storage technology lifetime or simply considered a refueling cost will likely be application dependent. As storage is already an economic challenge, storage systems that are long-lasting will likely be the priority in order to avoid incurring additional costs. A PIRT of $\mathrm{E}$ is assigned to this category.

11) Will the storage technology increase the geographical requirements of the system? There are two potential geographical challenges associated with energy storage. The first is the question of a particular geographical feature required to build the storage facility itself. Underground energy storage often requires specific geology depending on the storage technique in order to site properly. The second geographical requirement is the physical footprint required for the storage. The challenges herein may include the physical space required for storage as well as the challenges of transporting energy between the power producer, storage, and energy applications. A PIRT of E is assigned in this category.

12) Will the storage technology add to the concerns raised in environmental evaluation of the system? Energy storage is being investigated not only for potential economic benefit but more so for its ability to help curb harmful emissions in the energy sector. Therefore, the storage itself should be investigated on its environmental impact. It is not expected that many storage technologies will cause great concern in this area, but it will be a requirement for every application. Therefore, a PIRT of E is assigned in this category. 
13) How long can the storage technology remain unused between cycles before requiring intervention? Storage technologies may require some amount of constant energy or priming in order to remain useful. A system that is constantly used will not need to address this concern, while systems with longer cycles may need to address this. This question is application and technology specific, and as such will not be as much of a focus as some of the previous questions. A PIRT of $\mathrm{R}$ is assigned in this category.

14) What kinds of regulatory challenges are expected? The nuclear power industry is especially concerned with regulatory oversight. Energy storage will bring in more than just nuclear regulators in nearly all applications. The electrical grid is also a highly regulated system due to its significant complexity, relative fragility, and direct impact on society. The first-of-a-kind storage implementations that use nuclear subsystems will likely pave the way for future implementations with regard to regulatory issues. Because of this learning curve that should develop, a PIRT of $F$ is assigned in this category.

15) How will ownership, liability, and revenue-sharing be divided among the power producer, storage, and energy user? One may argue, with merit, that this is a legal issue and not an engineering issue. However, when evaluating a storage system and making the business case for it, this question has a significant impact on the economic evaluation. Furthermore, the expected agreements between energy producers, storage, and users, may impact the energy distribution priorities and thus the profitability and market potential of systems with storage. In some systems, there may only be one or two parties involved. Therefore, a PIRT of F is assigned in this category.

Overall, 15 significant engineering design questions have been proposed as widely relevant to using energy storage integrated with nuclear power systems. Each has been evaluated based on the frequency with which they will appear as a major decision point in the engineering design process. This paper investigates such an engineering design process and figure of merit discussion based on these investigative questions. Table 2 summarizes the PIRT evaluation.

\begin{tabular}{|c|c|c|c|}
\hline Engineering Design Question & $\begin{array}{c}\text { PIRT } \\
\text { Value }\end{array}$ & Engineering Design Question & $\begin{array}{c}\text { PIRT } \\
\text { Value }\end{array}$ \\
\hline Technology readiness? & E & Storage Cost & E \\
\hline Heat Source Compatibility & E & Storage Lifetime & E \\
\hline Effective Heat Storage & E & Geographical Requirements & E \\
\hline Market Participation and Operational Flexibility & F & Environmental Concerns & E \\
\hline Storage Size & E & Necessary Interventions & R \\
\hline Ramp Time & F & Regulatory Challenges & F \\
\hline Cycle Frequency & F & Ownership Dynamic & F \\
\hline Unavailability Frequency & F & & \\
\hline
\end{tabular}

Table 2. Summary of PIRT assignments for the engineering questions. 


\section{Project Overview}

As discussed in the introduction, INL is collaborating with NuScale and UAMPS on the JUMP program for RD\&D purposes. One research component of JUMP is to demonstrate integrated energy systems (IES). The full JUMP IES will include a NPM, thermal energy storage, and the ability to maneuver thermal energy streams between multiple applications. A FOM study on the thermal energy storage technology is done for the future JUMP system. The next section will introduce components of the JUMP IES and the thermal energy storage technologies that will be evaluated.

\subsection{NuScale}

The NuScale Power Module is an integral pressurized water reactor (IPWR) small modular reactor designed to operate over its full $200 \mathrm{MWt}$ range cooled by natural circulation. The NPM is intended to be a safe-by-design nuclear reactor that is cost competitive with other energy sources while providing power generation without $\mathrm{CO}_{2}$ emissions. While the project is based on existing pressurized water reactor (PWR) operations in order to expedite the licensing timeline for this project, the NuScale design includes enhanced safety features. Safety features include indefinite, operator-free (natural circulation) cooling without using power or additional water during shutdown conditions, redundant passive decay heat removal systems, fewer large pipes, and an elimination of reactor coolant pumps. NuScale boasts the first reactor "proven to not require power to be safe" [9]. The Nuclear Regulatory Commission (NRC) completed its Phase 1 review process in 2018, marking NuScale as the first SMR to achieve this level of certification in the U.S. [10].

The NuScale reactor is cooled via natural circulation wherein the primary cooling water rises from the bottom and flows upward through the core, up through a tall riser, before "falling" on the outside of this structure and flowing over the steam generators [11]. This process allows for buoyancy forces to drive the coolant flow in all power conditions and eliminating reactor coolant pumps. Heat is transferred to the secondary side via two helical coil steam generators utilizing feedwater and steam plenums at each end to equalize the fluid conditions. Simplified graphics of the core and primary coolant system are shown in Figure 1. 


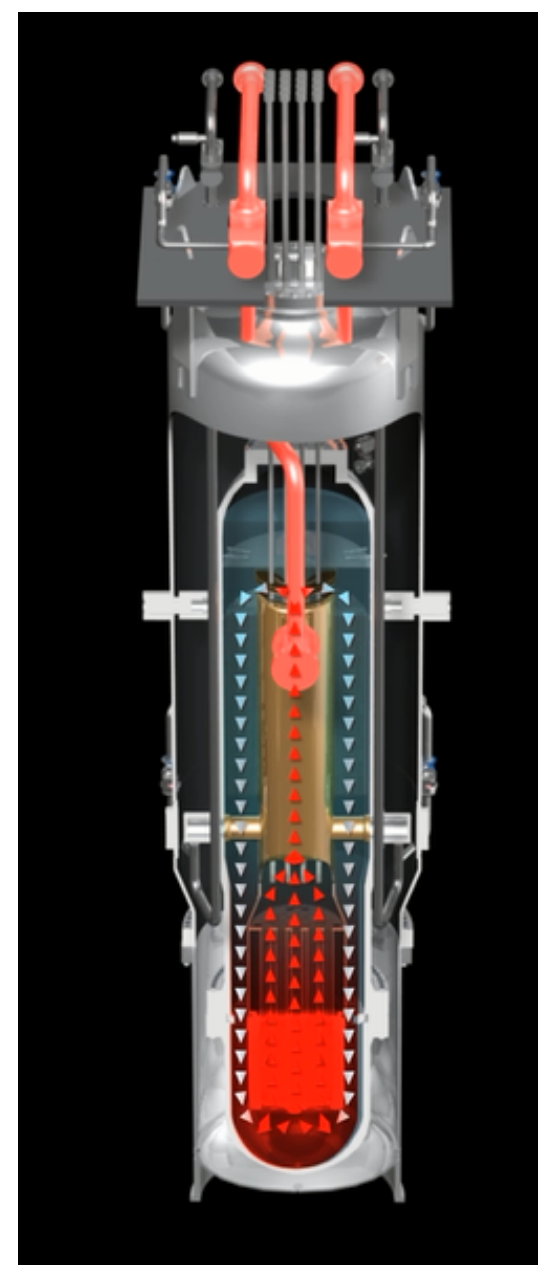

Figure 1. Major NPM components and flow path from NuScale [11].

Each reactor module operates at $200 \mathrm{MWt}$ using $<5 \%$ enriched fuel on a two years refueling cycle [12]. The primary coolant is designed to operate at $12.5 \mathrm{MPa}(1850 \mathrm{psia})$, at a hot leg temperature of around $310^{\circ} \mathrm{C}\left(590^{\circ} \mathrm{F}\right)$ [14]. This temperature and pressure, along with the efficient helical coil steam generator, leads to secondary loop design pressure, temperature, and flow rates of $3.4 \mathrm{MPa}(500 \mathrm{psia}), 302^{\circ} \mathrm{C}\left(575^{\circ} \mathrm{F}\right)$, and $295,200 \mathrm{~kg} / \mathrm{hr}(650,800 \mathrm{lbm} / \mathrm{hr})$, respectively [15].

Design documents submitted to the NRC show the currently planned standard secondary side design of the NuScale reactor. Two different operational states were submitted, evaluating the same design at approximately $159 \mathrm{MWt}$ and $162 \mathrm{MWt}$ [10]. The design schematic shows many expected fluid states across the secondary side of the NuScale plant.

This design elucidates the steam conditions that exist downstream of the turbine control valve, capable of charging a TES system, as well as the expected conditions at potential steam reintroduction points and feedwater heat exchangers [15]. These data points are useful for comparing INL-developed dynamic models and NuScale models, and they can also guide design decisions introduced by TES that are not necessary for a standard module dedicated to electricity production. Information from this design leads to the data in Table 3 for the currently estimated conditions. 


\begin{tabular}{cccc}
\hline $\mathbf{k P a}$ & ${ }^{\circ} \mathbf{C}$ & psia & ${ }^{\circ} \mathbf{F}$ \\
\hline $\mathbf{3 1 7 0}$ & 303 & 460 & 578 \\
\hline $\mathbf{2 6 1 3}$ & 283 & 379 & 542 \\
\hline $\mathbf{5 2 4}$ & 153 & 76 & 308 \\
\hline $\mathbf{2 5 5}$ & 128 & 37 & 262 \\
\hline $\mathbf{1 3 8}$ & 109 & 20 & 228 \\
\hline $\mathbf{6 3}$ & 87 & 9.2 & 189 \\
\hline $\mathbf{5 2 . 4}$ & 83 & 7.6 & 181 \\
\hline $\mathbf{2 6}$ & 67 & 3.9 & 152 \\
\hline
\end{tabular}

Table 3. Potential steam conditions at various turbine stage taps in present NuScale power conversion designs via design certification documents.

Introduction of TES into this system will introduce dynamic behavior as steam is diverted out of the normal turbine generator train and towards the TES module. If the TES application is used to provide peak heating, then re-introducing steam back into the system will also alter the fluid conditions in the system. Because feedwater heating uses steam taps from various turbine stages, any change in the flow rate passing through that turbine stage will affect the feedwater conditions re-entering the steam generator [13]. Reactor operations could be more sensitive to off-design conditions in the feedwater due to the dependence on natural circulation in the NPM.

TES integration with the NPM will provide insight into future TES applications with existing fleet LWRs. While steam production in the NPM heat exchangers occurs at a lower pressure of about $3.5 \mathrm{MPa}$, versus $7.0 \mathrm{M}$ Pa for a standard PWR, the steam temperatures are very similar: $300^{\circ} \mathrm{C}$ $\left(575^{\circ} \mathrm{F}\right)$ in the NPM and about $285^{\circ} \mathrm{C}\left(545^{\circ} \mathrm{F}\right)$ in PWRs. NPMs using helical coil steam generators allows for the creation of superheated steam, while the use of U-tube steam generators in most U.S. PWRs produces saturated steam. Both the NPM and typical LWR designs use turbine steam taps and moisture separators to remove some steam from the turbine-generator train in order to preheat feedwater entering the steam generator. Experience gained by integrating TES with NuScale should be applicable to LWRs due to the similarities in the reactor designs and system conditions. Of particular value will be a greater understanding of specific control schemes and feedback mechanisms using TES with a nuclear reactor, as well as practical sizing experience for future TES modules.

INL, NuScale, and UAMPS are collaborating to build its first 12-module plants on Department of Energy property near INL. INL researchers working on JUMP will collaborate with NuScale designers to design a TES system specifically for integration with the NPM. Any necessary design modifications will be determined with NuScale input and concurrence. 


\subsection{Electrical Grid Ancillary Services Markets}

Power producers can earn credits by participating in electrical grid ancillary markets. Participation is dependent on a site's abilities to provide frequency control and supply to an operating grid. The exact values and requirements of ancillary market participation is based on the rules of the specific interconnect. Demonstration of ancillary market service capabilities will result from JUMP research; hence, this topic is addressed here.

Power producers may also participate in the power reserves market. Reserve credits compensate power producers that can produce electricity with certain requirements but are actively not producing it. The reserves market is split into two regimes: spinning and non-spinning reserves. Spinning reserves are producers that are operating and loaded on the grid but can increase their supply onto the grid. Non-spinning reserves are producers that presently are unsynchronized from the electrical grid but can initiate operation and become synchronized in a relatively brief time. The most stringent requirements to obtain reserves credits are to be capable of increasing to rated reserve power within ten minutes and to be able to maintain that level for two hours [16]. An Argonne National Laboratory report from January of 2016 detailed the ancillary services of seven transmission operators in the United States, summarized in Table 4. Operator requirements to participate in ancillary services and remunerations for said service were detailed in the report. Table 5 provides mean prices in $\$ / M W h$ for spinning reserves in various markets, and the requirements to participate in them.

\begin{tabular}{|llll|}
\hline CAISO & Spinning Reserves & Non-spinning Reserves & $\begin{array}{l}\text { Regulation } \\
\end{array}$ \\
& Spinning & Non-spinning & $\begin{array}{l}\text { Regulation-up } \\
\text { Regulation-down } \\
\text { Regulation Mileage-up } \\
\text { Regulation Mileage-down }\end{array}$ \\
\hline ERCOT & Responsive & Non-spinning & $\begin{array}{l}\text { Regulation-up } \\
\text { Regulation-down }\end{array}$ \\
\hline ISO-NE & Ten-minute Synchronized & Ten-minute Non-synchronized & Regulation \\
& & Thirty-minute Operating & Regulation \\
\hline MISO & Spinning & Supplemental & Regulation \\
\hline NYISO & Ten-minute Spinning & Ten-minute Non-synchronized & Regulation \\
\hline PJM & Thirty-minute Spinning & Thirty-minute Non-synchronized & Regulation-up \\
\hline SPP & Synchronized & Primary & Regulation-down \\
\hline
\end{tabular}

Table 1-1 Overview of the ancillary services offered by each ISO/RTO

Table 4. Overview of ancillary services, extracted from [16]. 


\begin{tabular}{|c|c|c|c|c|}
\hline Market Operator & $\begin{array}{c}\text { Reserve Response } \\
\text { Time }\end{array}$ & $\begin{array}{l}\text { Reserve Min. } \\
\text { Oper. Time }\end{array}$ & $\begin{array}{l}2014 \text { Mean Price } \\
\text { (\$/MWhe) }\end{array}$ & $\begin{array}{l}2014 \% \text { \%ours of } \\
\text { \$0 Price }\end{array}$ \\
\hline $\begin{array}{l}\text { California Independent } \\
\text { System Operator }\end{array}$ & $10 \mathrm{~min}$ & $2 \mathrm{hr}$ & 3.34 & $0.0 \%$ \\
\hline $\begin{array}{c}\text { Electric Reliability of } \\
\text { Texas }\end{array}$ & "Within a few min" & $1 \mathrm{hr}$ & 14.15 & $0.0 \%$ \\
\hline $\begin{array}{c}\text { Independent System } \\
\text { Operator - New } \\
\text { England }\end{array}$ & $10 \mathrm{~min}$ & N/A & 2.53 & $82.7 \%$ \\
\hline $\begin{array}{l}\text { New York Independent } \\
\text { System Operator }\end{array}$ & $10 \mathrm{~min}$ & N/A & $\begin{array}{l}6.49,4.07 \\
\text { (East, West) }\end{array}$ & $69.3 \%, 87.6 \%$ \\
\hline $\begin{array}{c}\text { Midcontinent } \\
\text { Independent System } \\
\text { Operator }\end{array}$ & $10 \mathrm{~min}$ & N/A & 2.58 & $0.0 \%$ \\
\hline PJM & $10 \mathrm{~min}$ & N/A & 4.21 & $62.6 \%$ \\
\hline Southwest Power Pool & $10 \mathrm{~min}$ & N/A & 7.46 & $0.0 \%$ \\
\hline
\end{tabular}

Table 5. Presentation of spinning reserves market in different ISOs [16].

From Table 5, it is apparent that there is market potential in being capable of increasing power output. Systems operating with integrated TES could be able to participate in spinning reserves markets during any time in which the TES is charging or charged. During charging, the heat into the TES could be credited as spinning reserves; once charged, a TES capable of ramping within ten minutes would be able to claim that stored energy as reserve capacity as well. The maximum spinning reserves values were as high as $\$ 1285.73 /$ MWhe among the seven markets, with the peak price simple average at $\$ 660.23 / \mathrm{MWhe}[16]$.

\subsection{Large Thermal Energy Applications}

Thermal energy storage can be used as a buffer system between a nuclear reactor and a high energy input thermal application. Several systems are investigated in this section including high temperature steam electrolysis, coal gasification, gasoline production, pulp and paper milling, general chemical manufacturing, and water desalination. By targeting industries that use large quantities of steam at LWR temperatures and pressures, the portfolio of applications for nuclear energy can expand. Some of these applications may be possible to integrate with the JUMP module for research purposes, while others are included in this discussion for general LWR consideration.

\subsubsection{High Temperature Steam Electrolysis}

Growing global demand and interest in Hydrogen is increasing. Its potential use as a clean fuel has driven development of hydrogen-based fuel cell technology. Hydrogen is also used in oil refining and chemical production, and is being investigated for use in natural gas distribution. 
Hydrogen is pursued due to its abundance, high available energy density, and clean burning (no $\mathrm{CO}$ or $\mathrm{CO}_{2}$ emission). One $\mathrm{H}_{2}$ production method is high temperature steam electrolysis (HTSE). In this process, electricity and high temperature steam chemically split water into hydrogen and oxygen. The hydrogen is then captured for future use in ammonia production, steel manufacturing, hydrogen fuel cells, and several other applications. Hydrogen fuels are based on the exothermic reaction that produces free energy $\Delta g_{f}$, with values presented in Table 6:

$$
H_{2}+\frac{1}{2} O_{2} \rightarrow H_{2} O+\Delta g_{f}
$$

\begin{tabular}{lll}
\hline Form of water product & Temperature $\left({ }^{\circ} \mathrm{C}\right)$ & $\boldsymbol{\Delta} \overline{\boldsymbol{g}}_{f}\left(\mathbf{k J \mathbf { m o l }} \mathbf{1}^{\mathbf{1}}\right)$ \\
\hline Liquid & 25 & -237.2 \\
Liquid & 80 & -228.2 \\
Gas & 80 & -226.1 \\
Gas & 100 & -225.2 \\
Gas & 200 & -220.4 \\
Gas & 400 & -210.3 \\
Gas & 600 & -199.6 \\
Gas & 800 & -188.6 \\
Gas & 1000 & -177.4 \\
\hline
\end{tabular}

Table 6. Free energy released during water production from hydrogen and oxygen, from [17].

Hydrogen presents a possible clean fuel to replace carbon-emitting fuels such as petroleum and gasoline. Unfortunately, creation of pure hydrogen gas from other materials is a highly energy intensive process. As early as 2001, there was an understanding that nuclear energy would be capable of playing a role in the production of hydrogen either through thermo-chemical splitting or through electrolysis [18]. HTSE is a well-developed technology, with lab-scale projects already underway, including one at INL. Advanced, dynamic modeling of HTSE provides a clear picture of the energy requirements for HTSE processes, as summarized in Table 7 [19]. Present energy requirements for HTSE processes are about $170 \mathrm{MJ} / \mathrm{kg}$ of $\mathrm{H}_{2}$ produced [19]. 


\begin{tabular}{|c|c|c|c|c|}
\hline & \multicolumn{2}{|l|}{ Description } & Unit & Value \\
\hline \multirow[t]{2}{*}{ Inputs } & \multicolumn{2}{|l|}{ Water } & $\mathrm{kg} \mathrm{s}^{-1}\left[\right.$ metric ton $\left.\mathrm{yr}^{-1}\right]$ & $4.48[141]$ \\
\hline & \multicolumn{2}{|l|}{ Air } & $\mathrm{kg} \mathrm{s}^{-1}\left[\right.$ metric ton $\left.\mathrm{yr}^{-1}\right]$ & $23.3[734]$ \\
\hline \multirow[t]{3}{*}{ Outputs } & \multirow{2}{*}{\multicolumn{2}{|c|}{$\begin{array}{l}\text { Hydrogen } \\
\text { (Oxygen) }\end{array}$}} & $\mathrm{kg} \mathrm{s}^{-1}\left[\right.$ metric ton $\left.\mathrm{yr}^{-1}\right]$ & $0.4015[12.7]$ \\
\hline & & & $\mathrm{kg} \mathrm{s}^{-1}\left[\right.$ metric ton $\left.\mathrm{yr}^{-1}\right]$ & $3.186[100]$ \\
\hline & \multicolumn{2}{|l|}{$\mathrm{CO}_{2}$} & $\mathrm{~kg} \mathrm{~s}^{-1}\left[\right.$ metric ton $\left.\mathrm{yr}^{-1}\right]$ & $0[0]$ \\
\hline \multirow{7}{*}{$\begin{array}{l}\text { Utility } \\
\text { summary }\end{array}$} & \multirow{5}{*}{$\begin{array}{l}\text { Power } \\
\text { consumption }\end{array}$} & Total & $\mathrm{MW}_{\mathrm{e}}\left[\mathrm{MW}_{\mathrm{th}}\right]$ & $61.2\left[192.5^{\mathrm{a}}\right]$ \\
\hline & & Electrolyzer & $\mathrm{MW}_{\mathrm{e}}\left[\mathrm{MW}_{\text {th }}\right]$ & $45.5\left[143.2^{\mathrm{a}}\right]$ \\
\hline & & MSCS & $\mathrm{MW}_{\mathrm{e}}\left[\mathrm{MW}_{\text {th }}\right]$ & $10.1\left[31.6^{\mathrm{a}}\right]$ \\
\hline & & FWP & $\mathrm{MW}_{\mathrm{e}}\left[\mathrm{MW}_{\mathrm{th}}\right]$ & $0.0127\left[0.0401^{\mathrm{a}}\right]$ \\
\hline & & ETHs & $\mathrm{MW}_{\mathrm{e}}\left[\mathrm{MW}_{\mathrm{th}}\right]$ & $5.61\left[17.7^{\mathrm{a}}\right]$ \\
\hline & $\begin{array}{l}\text { Power } \\
\text { generation }\end{array}$ & SGT & $\mathrm{MW}_{\mathrm{e}}\left[\mathrm{MW}_{\mathrm{th}}\right]$ & $7.89\left[24.8^{\mathrm{a}}\right]$ \\
\hline & Nuclear proce & s heat & $\mathrm{MW}_{\text {th }}\left[\mathrm{MW}_{\mathrm{e}}\right]$ & $14.6\left[4.63^{b}\right]$ \\
\hline
\end{tabular}

Table 7. Inputs and outputs of HTSE using nuclear and electric heat, from [19]. Oxygen is in parenthesis because it is generally not collected as an output but rather is simply released to the environment through an air-sweep system.

HTSE uses steam between $600^{\circ} \mathrm{C}-850^{\circ} \mathrm{C}$ as an input into the solid-oxide electrolysis cells (SOEC), depending on fuel cell design. LWR peak steam temperatures are closer to $300^{\circ} \mathrm{C}$. However, it has been shown that nuclear energy is capable of providing the latent heat to vaporize the water and produce the steam input, and electric topping heaters (or another source of heat) could be employed to provide the remainder of the necessary temperature peaking [19]. This combined thermal and electric process could be entirely provided by a nuclear power plant such as an SMR, or potentially substantiated by multiple sources in a hybrid (i.e. multi-generator) energy configuration.

It is possible that nuclear energy could be used in other hydrogen production processes, such as reformation. Reformation is the process of isolating hydrogen out of hydrocarbon gases, usually natural gas $\left(\mathrm{CH}_{4}\right)$. The process does result in some carbon monoxide or carbon dioxide production, which is one reason HTSE has been highlighted. The production of $\mathrm{H}_{2}$ by nuclear-generated heat and electricity would produce no additional carbon gases during the various process stages, making it a completely carbon-free energy production process. Results from a recent INL study suggest that the coupling of existing of LWRs to HTSE could be a highly economical endeavor in certain regions of the United States [20]. In addition, a recent funding opportunity award by the U.S. DOE to an industry-led team that includes First Energy (lead), Xcel Energy, and Arizona Public Serve will support demonstration of hydrogen production at an existing nuclear facility in the next couple of years [21].

\subsubsection{Gasoline Production}

Producing gasoline from crude oil requires a large amount of both thermal and electric energy. Petroleum refining plants produce some of the required steam and electric power directly on site. Figure 2 summarizes the total energy requirements of the petroleum sector in 2006 . The values seen along the arrows in the graphic show the energy requirements in TBTU (Tera-BTU). The values in the dark green boxes are the present emissions associated with the energy produced offsite in $\mathrm{MMT} \mathrm{CO}_{2}$. The light brown boxes in the right half of the figure show the emissions in onsite 
production, and the values in the mid-green boxes are the total emissions associated with each phase of gasoline production [24].

\section{Total \\ Energy}

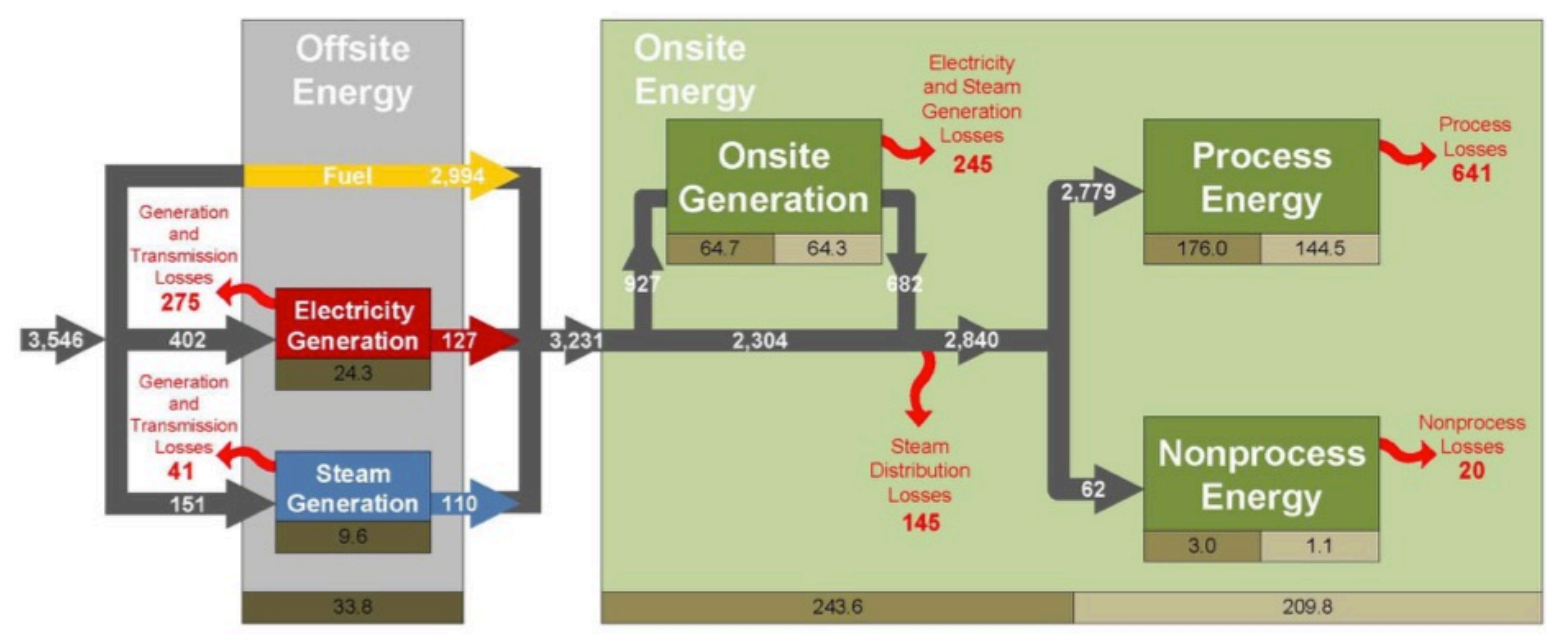

Figure 2. Energy requirements of petroleum refineries; figure derived from [24]. All values along the energy path arrows are in tera-BTU The other values in the dark green, light brown, and midgreen boxes are emissions in $\mathrm{MMT} \mathrm{CO}_{2}$ offsite, onsite, and the added total respectively.

Nuclear-generated heat and electricity can be used to provide the $9.6 \%$ of required input steam generation, and the $24.3 \%$ of required electricity. The relative amounts of electrical and heat energy required, as depicted in Figure 2, are about $54 \%$ and $46 \%$ of the non-fuel offsite energy requirements. Over half of the steam requirements of petroleum refineries are below $2 \mathrm{MPa}(300$ psig), below the steam discharge pressure of LWRs [25]. SMR deployment to support petroleum plant needs has been previously researched in the context of nuclear-renewable hybrid energy systems. This work found that integration of nuclear energy into this process is possible and can provide generation stability and economic benefit [26] [27].

\subsubsection{Pulp and Paper Mill}

The pulp and paper industry is one of the largest users of process steam in the U.S. The 2014 Manufacturing Energy Consumption Survey (MECS) data shows that $11 \%^{2}$ of manufacturing energy was used by the pulp and paper industries [28]. MECS data also shows that over $50 \%{ }^{3}$ of this energy was produced off-site [29]. Around $20 \%$ of the energy consumed in this industry is derived from natural gas [28], which could be replaced by nuclear heat. Pulp and paper mills primarily require process steam at temperatures and pressures that LWRs can provide. Kraft pulping, sulfite pulping, washing, refining, bleaching and drying processes all use steam pressures between $200-1000 \mathrm{kPa}(30-150 \mathrm{psia})$ and temperatures below $175^{\circ} \mathrm{C}\left(350^{\circ} \mathrm{F}\right)$ [25]. Paper mills produce on-site power via recovery boilers burning black liquor, a byproduct of wood digestion and washing. The processes in the recovery boiler use black liquor and produce smelt that becomes

\footnotetext{
${ }^{2}$ MECS Table 1.2, Total Energy by NAICS code 312 divided by reported total in Table 1.2

${ }^{3}$ Fraction derived by dividing value of "off-site produced fuel consumption" by "first use of energy for all purposes"
} 
green liquor. This green liquor is combined with lime to produce white liquor, which is input with wood into the digester. Figure 3 shows this process diagram [32].

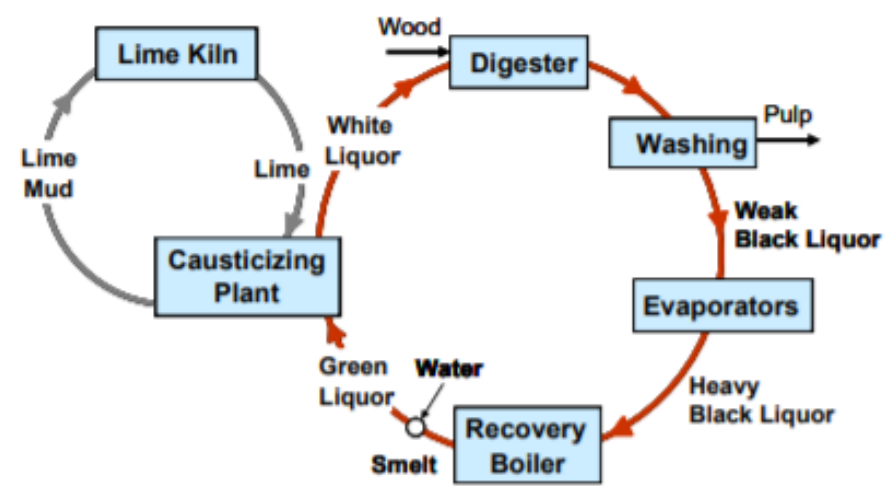

Figure 3. Liquor use in the Kraft recovery process, taken from [32].

The power produced from the recovery boilers could be used for any high pressure and high temperature demands that the mill may have, using the nuclear-generated heat input for lower pressure and temperature processes. Figure 4 presents the thermal and electrical energy requirements in a pulp and paper mills.

\section{Table 3.1-1. Energy Use at Integrated Pulp and Paper Mills [1]}

\begin{tabular}{|lcc|cc|cc|}
\hline & \multicolumn{2}{c}{ Thermal } & \multicolumn{2}{c|}{ Electrical } & \multicolumn{2}{c|}{ Total } \\
Process Energy for Integrated Mills & Min. & Max. & Min. & Max. & Min. & Max. \\
\hline Chemical (Kraft and Sulfite) & 16,000 & 33,000 & 2,400 & 5,500 & 18,400 & 38,500 \\
\hline Mechanical & 8,000 & 25,000 & 6,500 & 17,200 & 14,500 & 42,000 \\
\hline Sulfite Semichemical & 17,000 & 35,000 & 4,100 & 6,800 & 21,000 & 41,800 \\
\hline Chemi-Thermomechanical & 9,000 & 25,000 & 7,500 & 16,400 & 16,500 & 41,400 \\
& & & & & & Thousand Btu/ton \\
\hline
\end{tabular}

Figure 4. Energy use by thermal or electrical, from [25].

Large thermal and electrical requirements at appropriate LWR steam pressures and temperatures make pulp and paper mills great candidates for cogeneration integration with SMRs or LWRs buffered by TES. Integrating LWR power into pulp and paper mills would allow for the substitution of non-recovery power generation that is currently provided by natural gas, replacing a $\mathrm{CO}_{2}$-emitting energy source with a carbon-free source.

\subsubsection{Chemical Manufacturing}

Chemical manufacturing processes use steam for stripping, fractionation, power generation, mechanical drive, quenching, dilution, process heating, vacuum draw, injection, and process water requirements [25]. Ethylene, ammonia, urea, styrene, polystyrene, sodium hydroxide, PVC, acetone, benzene, toluene, xylene, sodium carbonate, polybutadiene rubber, styrene butadiene rubber, and butyl rubber manufacturing processes all use steam within NuScale design pressure [25]. MECS data shows that in 2014, chemical manufacturing accounted for about $33 \%$ of the total manufacturing energy use [28]. Further, MECS data states that more than $60 \%$ of offsite energy 
production was provided by natural gas; these energy sources could be replaced by nucleargenerated heat from LWRs, reducing emissions from the chemical manufacturing sector [29]. A report from INL and the National Renewable Energy Laboratory presented an in-depth look at chemical manufacturing cogeneration opportunities for nuclear and renewable resources. [30]

\subsubsection{Water Desalination}

Water desalination is a growing global need, as clean water demand exceeds natural production [31]. Clean water makes up only about $2.5 \%$ of water on earth, with only around $1 \%$ of that being easily accessible. Nearly two-thirds of people on earth will soon live in water stressed or water scarce regions. To fight against this pending crisis, clean water needs to be produced from salty water, either from brackish areas or from seawater. Desalination is accomplished primarily through thermal distillation methods (boiling water and reducing the salt content) or through forced osmosis (forcing water through semipermeable membranes). In the latter half of the 1900s, distillation methods were the primary choice for desalination. As the turn of the century approached, improvements in reverse osmosis (RO) technology led to increases in RO installations. By the year 2000, water production from RO and thermal distillation methods was nearly equal [33]. RO plants now account for around $69 \%$ of global water production, and as such most of this section will be focused on this dominant technology.

Reverse osmosis plants have become the lead desalination method due to their low energy requirements for water production. Figure 6 presents the energy requirements of various desalination technologies. At a reported minimum energy requirement of $0.5 \mathrm{kWh} / \mathrm{m}^{3}$ of clean water produced, RO technology is normally the lowest cost available [34]. It also produces a smaller amount of brine compared to other technologies, making the plants more environmentally friendly, as shown in Figure 5 [33]. RO plants do require feed water preconditioning and are reasonably sensitive to inlet conditions of the feed stream [35]. Many variables impact energy requirements for RO plants including water flow rates, total dissolved solids in the feed and product streams, pressure, temperature, and age of plant components [34].

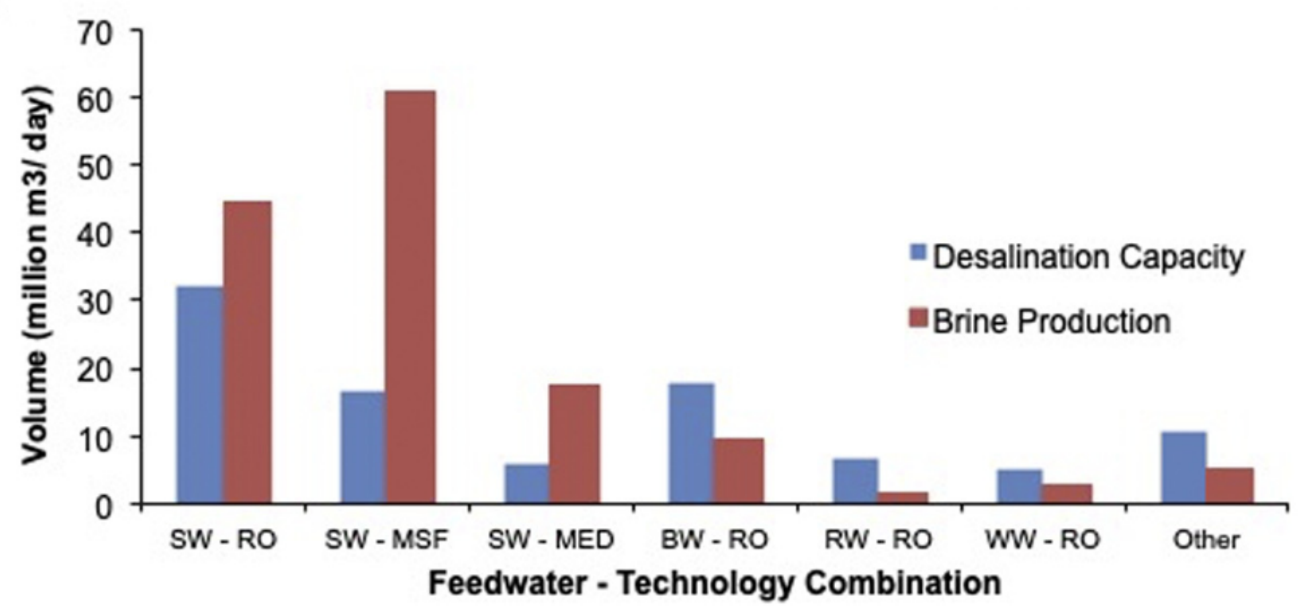

Figure 5. Water capacity and brine production by existing desalination techniques, from [33]. ${ }^{4}$

\footnotetext{
${ }^{4} \mathrm{SW}$ - seawater, BW- brackish water, RW- river water, WW- waste water, MSF- multistage flash, MED- multiple effect distillation
} 


\begin{tabular}{cccc}
\hline \multirow{2}{*}{ Technology } & \multicolumn{3}{c}{ Specific Energy Consumption $\left(\mathrm{kWh} / \mathrm{m}^{3}\right)$} \\
\cline { 2 - 4 } & Electric & Thermal & Total Electric Equivalent \\
\hline BWRO & $0.5-3$ & - & $0.5-3$ \\
SWRO & $3-6$ & - & $3-6$ \\
ED & $1-3.5$ & - & $1-3.5$ \\
EDR & $1-2$ & - & $1-2$ \\
MVC & $7-15$ & - & $7-15$ \\
FO & $0.2-0.5$ & $20-150$ & $10-68$ \\
MD & $1.5-4$ & $4-40$ & $3-22$ \\
MSF & $2.5-5$ & $40-120$ & $21-59$ \\
MED & $2-2.5$ & $30-120$ & $15-57$ \\
MEB & 2 & 60 & 30
\end{tabular}

Notes: $\mathrm{BWRO}=$ brackish water reverse osmosis; $\mathrm{SWRO}=$ seawater reverse osmosis; $\mathrm{ED}=$ electrodialysis; $\mathrm{EDR}=$ electrodialysis reversal; $\mathrm{MVC}=$ mechanical vapor compression; $\mathrm{FO}=$ forward osmosis; $\mathrm{MD}=$ membrane distillation; $\mathrm{MSF}=$ multi-stage flash; $\mathrm{MED}=$ multiple effect distillation; $\mathrm{MEB}=$ multi-effect boiling.

Figure 6. Specific energy consumption for various desalination technologies. Figure reproduced from [34] Table 1, where "Total Electric Equivalent" is equal to the electric consumption plus 45\% of the thermal energy consumption, reflecting a standard conversion efficiency from thermal to electrical energy.

Current market conditions and technological developments favor reverse osmosis methods for water desalination. That being considered, integrated a RO plant with a nuclear reactor does invite separate possibilities that are beyond the scope of this report but could be worth investigating in future cogeneration systems. As nuclear plants produce large amounts of heated steam, determining where steam driven motors and pumps could be used in place of electric counterparts may be worthwhile to future projects. Overall, water desalination is an energy intensive process but is a significantly growing need across the planet. For thermal distillation processes, nuclear heat is capable of fulfilling feedstock preheating requirements of around $120^{\circ} \mathrm{C}$ [36]. In fact, these temperatures correspond to waste heat temperatures in nuclear facilities making it an easy-win for nuclear systems.

\subsubsection{Liquid Air Energy Systems}

Liquid air energy storage (LAES) is an energy storage technology using the Claude process to liquefy air, store this air in tanks, and then use heat to expand the air through turbines to produce power on demand. Presently, there is a "grid-level" (5 MWe/15 MWh) LAES plant commissioned by Highview Power that began operation in April 2018 in England [37]. Figure 7 shows a highlevel diagram of a Highview process. Highview Power publishes that their systems can produce from 10-200 MWe, and store 40-2000 MWh. Their designs using waste heat claim 70\% round trip efficiency (RTE) for AC to AC power. Because the power production is based on gas expansion through the Brayton cycle, increased heat input should result in higher efficiencies. While Highview Power's designs include cold storage for continued use in the plant, if a source of waste cold is available, their efficiencies can increase to $100 \% \mathrm{AC}$ to $\mathrm{AC}$ power due to a reduction in refrigeration needs during the liquefaction process, an impact seen in Figure 8 [37]. 


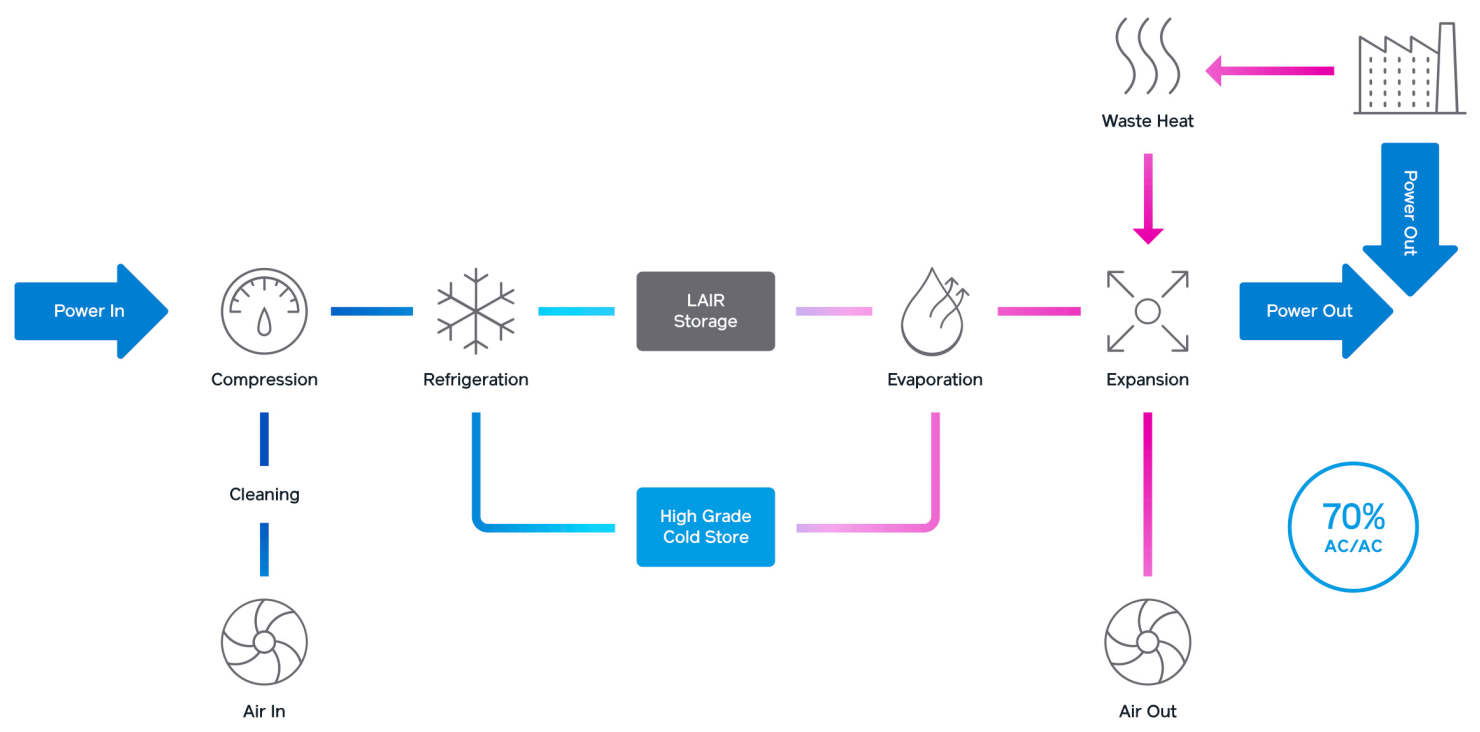

Figure 7. High level diagram of Highview Power LAES system [37].

The initial pilot plant by Highview Power achieved just an $8 \%$ efficient cycle. At the time, the highest maximum efficiency predicted for the "best build" was approximately $60 \%$ [38]. One study further investigating potential LAES arrangements researched the impact of a cold box storage on the system. Using ambient heating while discharging, and obtaining some power out of the system via a cryoturbine, they computed a potential efficiency of 56.3\% [39]. By introducing nuclear topping heat it is possible to achieve a theoretical $71.3 \%$ round trip efficiency [40]. Specific LAES configurations can cause efficiencies to vary between $68-90 \%$. Efficiency variations for individual designs depend on assumptions, which can cause as much as $20 \%$ change [41]. Some parameter impacts are shown in Figure 9 and Figure 10. Other research indicates that utilizing a pebble bed cold box recovery component into LAES will increase the efficiency during successive cycling to a theoretical limit, as shown in Figure 11. This is in contrast to some other TES uses or applications, in which there is degradation over time [42].

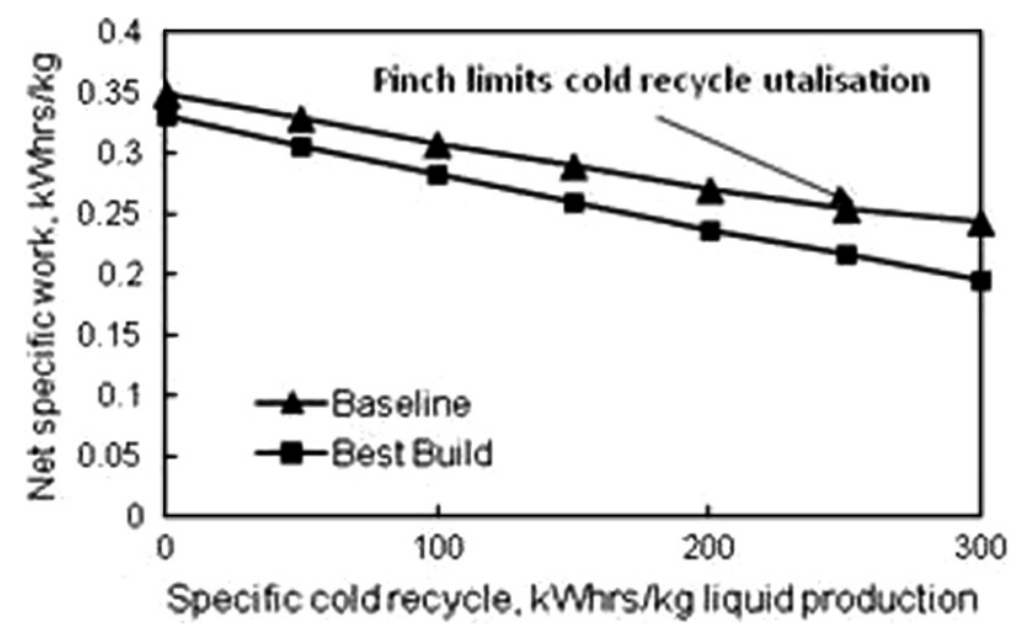

Figure 8. Cold recycle impact on work input, from [38]. 


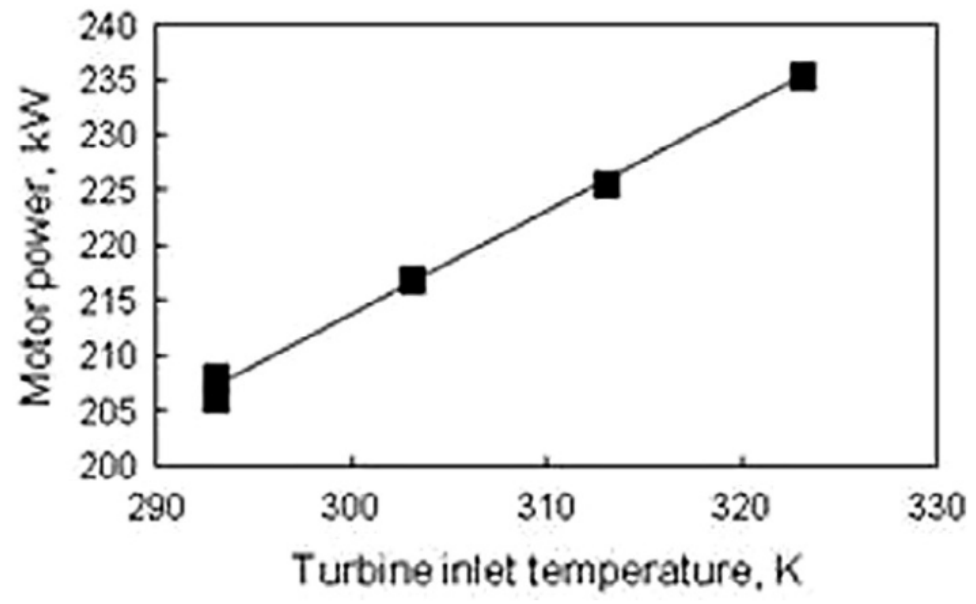

Figure 9. Impact of gas temperature on turbine output at 48 bar, extracted from [38].

Figure 8 to Figure 9 show some of the behavioral impact of system parameters on LAES performance. Cold bed integration is part of the development by Highview power to obtain $70 \%$ RTE AC to AC [37]. Figure 11 shows how the efficiency of LAES should be constant once the system is fully operational. Figure 9 and Figure 10 combine to demonstrate the nonlinear combination of discharge gas pressure and temperature impacts of an actual operating LAES plant. The combination presents how a LAES system would utilize nuclear heat to aid in its discharge process. Further thermal integration into the LAES process may be possible if steam driven compressor trains can be used in the charging process, but that is outside the scope of the current research.

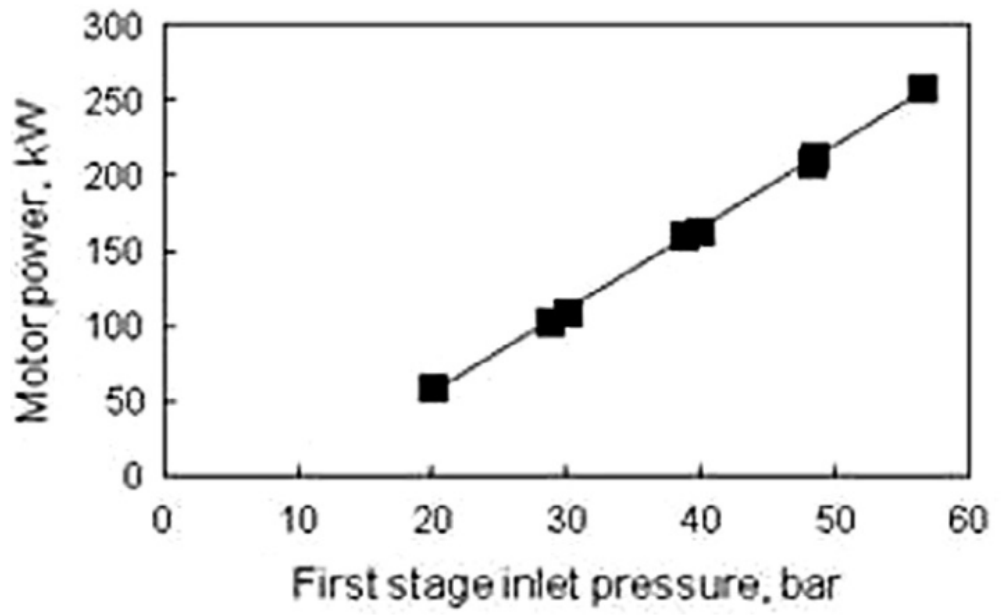

Figure 10. Impact of gas pressure on turbine output at $289 \mathrm{~K}$, from [38]. 


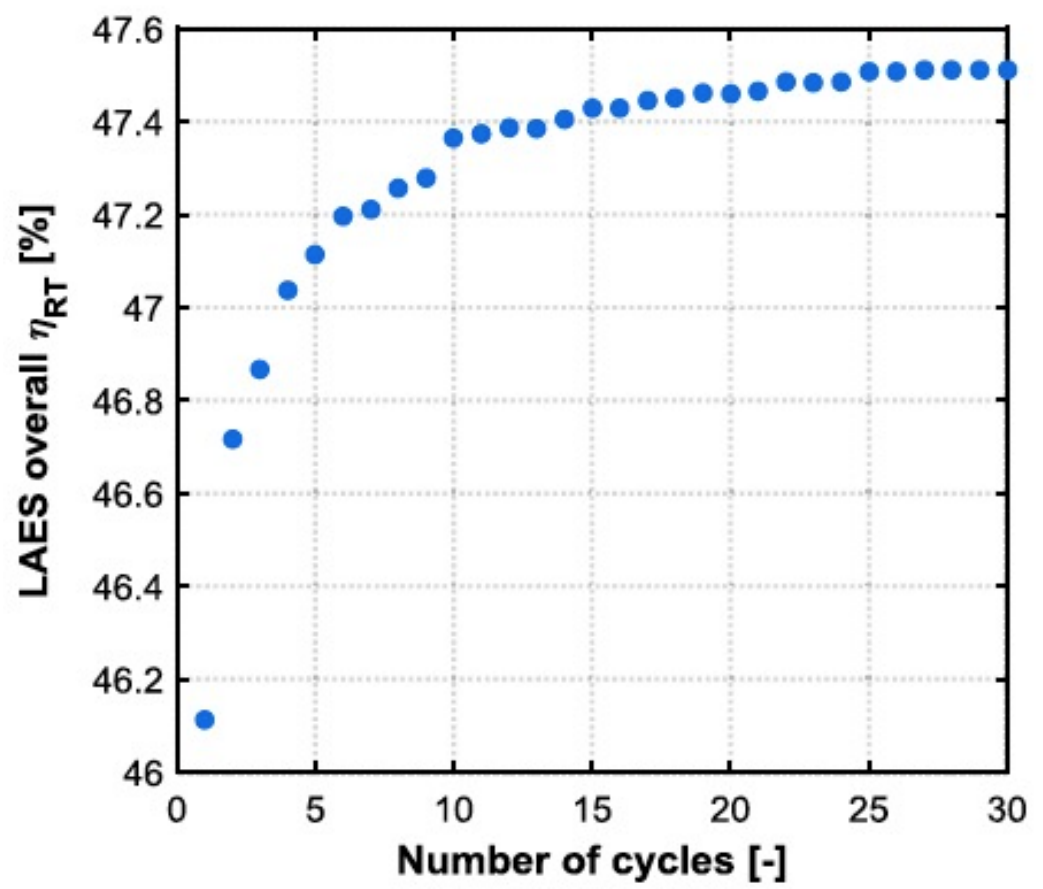

Figure 11. LAES simulated efficiency versus number cycles, from [42].

LAES has been included as a potential power boosting application for nuclear generated heat, particularly for integration with existing LWRs. Because the system as currently designed is mostly uncoupled from nuclear heat input, it would likely require less licensing oversight and less direct thermal integration to mix the technologies relative to other ancillary processes.

\section{Thermal Energy Storage Technologies}

This chapter provides an in-depth look at the thermal energy storage technologies currently available in the marketplace. Technologies presented take advantage of sensible heat, latent heat, and thermochemical storage capabilities. Information provided here is the latest information readily available as of August 2019

\subsection{Underground Thermal Energy Storage}

Underground thermal energy storage (UTES) includes two different technologies: aquifer and borehole storage. Both technologies store energy directly as heat, but the storage medium is different. Experience with both technologies has been in seasonal heat storage.

Aquifer energy storage uses separate cold and warm water wells. During summer and winter months, water is moved from one well to the other and used for heating or cooling. In the summer, water is moved from the cold store to the hot store after it is used for cooling. In the winter, water is used for heating and subsequently moved to the cold well [43]. This practice is common in some European countries such as the Netherlands and the Scandinavian countries. Geographic requirements are the biggest inhibitors against installing aquifer energy storage. European aquifers are built into beds of sand, chalk, or sand/gravel [44]. Aquifers are used for seasonal building heating and cooling at reduced cost as compared against on-demand HVAC mechanisms. 
Borehole storage involves creating thermal loops for the working fluid. The hot charging fluid transfers heat to the underground rock, sand, and soil via long piping systems dug into the ground. These boreholes allow for the heat to be transferred from the working fluid into the surrounding ground [45]. The heat then conducts through the storage area, allowing for the working fluid to use the stored energy by removing heat at a later time. Borehole storage is used in locations incapable of supporting aquifers [46].

UTES is a fully developed technology used to mediate building temperatures by seasonally storing cold and warm thermal masses. Thus far, there are no UTES charging methods that involve media other than liquid water. Any interface with steam produced by nuclear generated heat would require new heat exchange methods. Additionally, current experience does not indicate that high storage temperatures would be possible.

\subsection{Hot and Cold Water Storage}

Hot and cold water storage, or chilled water storage, is a common thermal energy storage method in locations with peak demands on heating and cooling systems. The process involves storing chilled or heated water in a thermocline tank or in multiple tanks during low electricity price and demand periods in order to provide cooling or heating during periods of high prices and demands. This is commonly done for HVAC systems at large office buildings, campuses, or district networks. Many traditional systems use electric chillers, and there has been research regarding how absorption chillers could be thermally integrated with SMR technology [47]. One integration option is shown in Figure 12. 


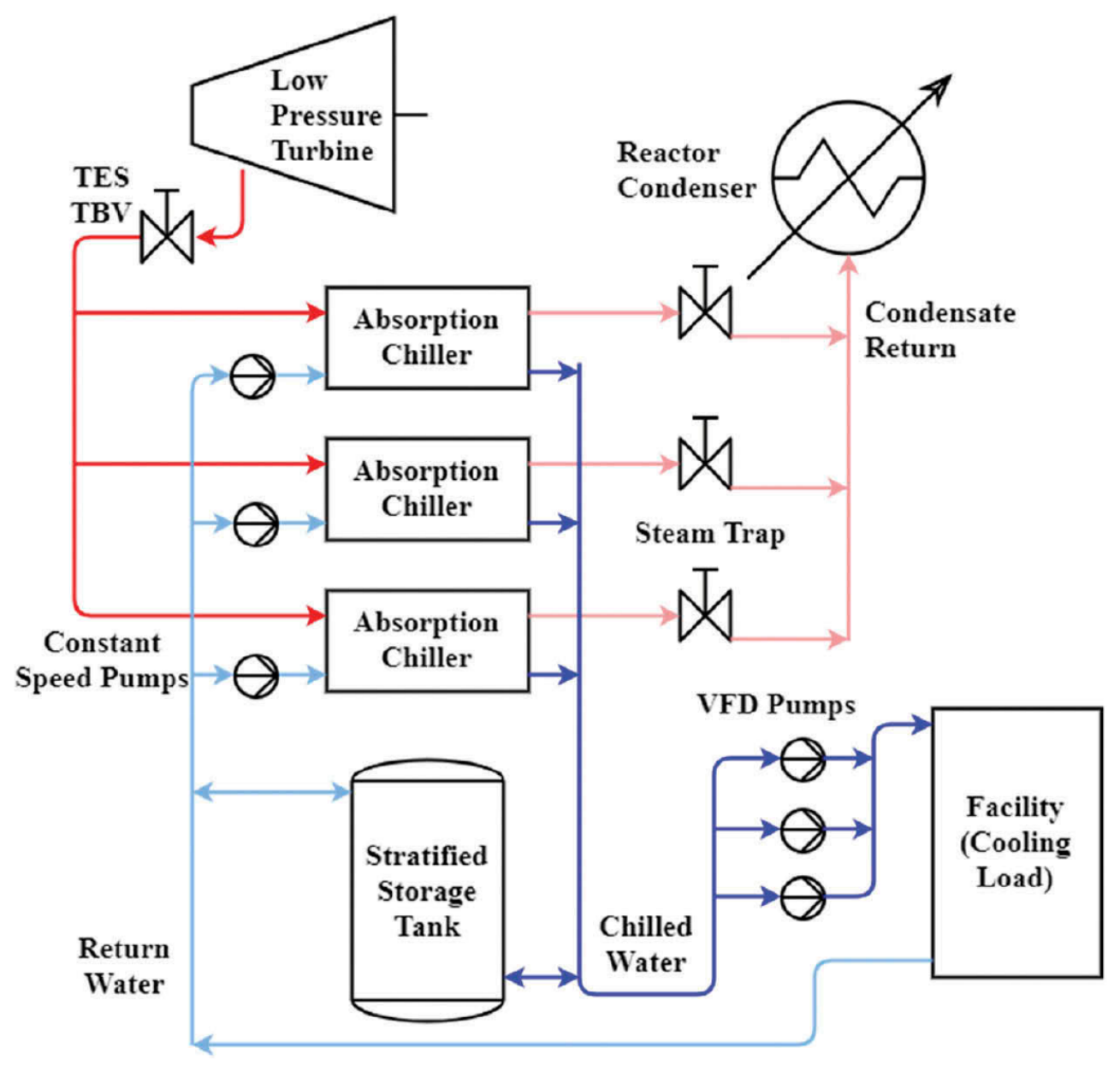

Figure 12. Absorption chiller and SMR integration, from [48]. ${ }^{5}$

This integration technique with a nuclear reactor would allow one to derive use out of heat that might otherwise be wasted during time of low load. Steam discharge from the low pressure turbine can be used in chillers to offset future energy costs in the surrounding area. A large hot and coldwater storage project was recently completed at Stanford University (non-nuclear); a representative diagram is shown in Figure 13. Additional work at North Carolina State University demonstrated that by coupling a thermal storage system with a small modular reactor, high quality waste heat can be used to simultaneously drive absorption chillers [48].

\footnotetext{
${ }^{5} \mathrm{TBV}=$ Turbine Bypass Valve; VFD $=$ Variable Frequency Drive
} 


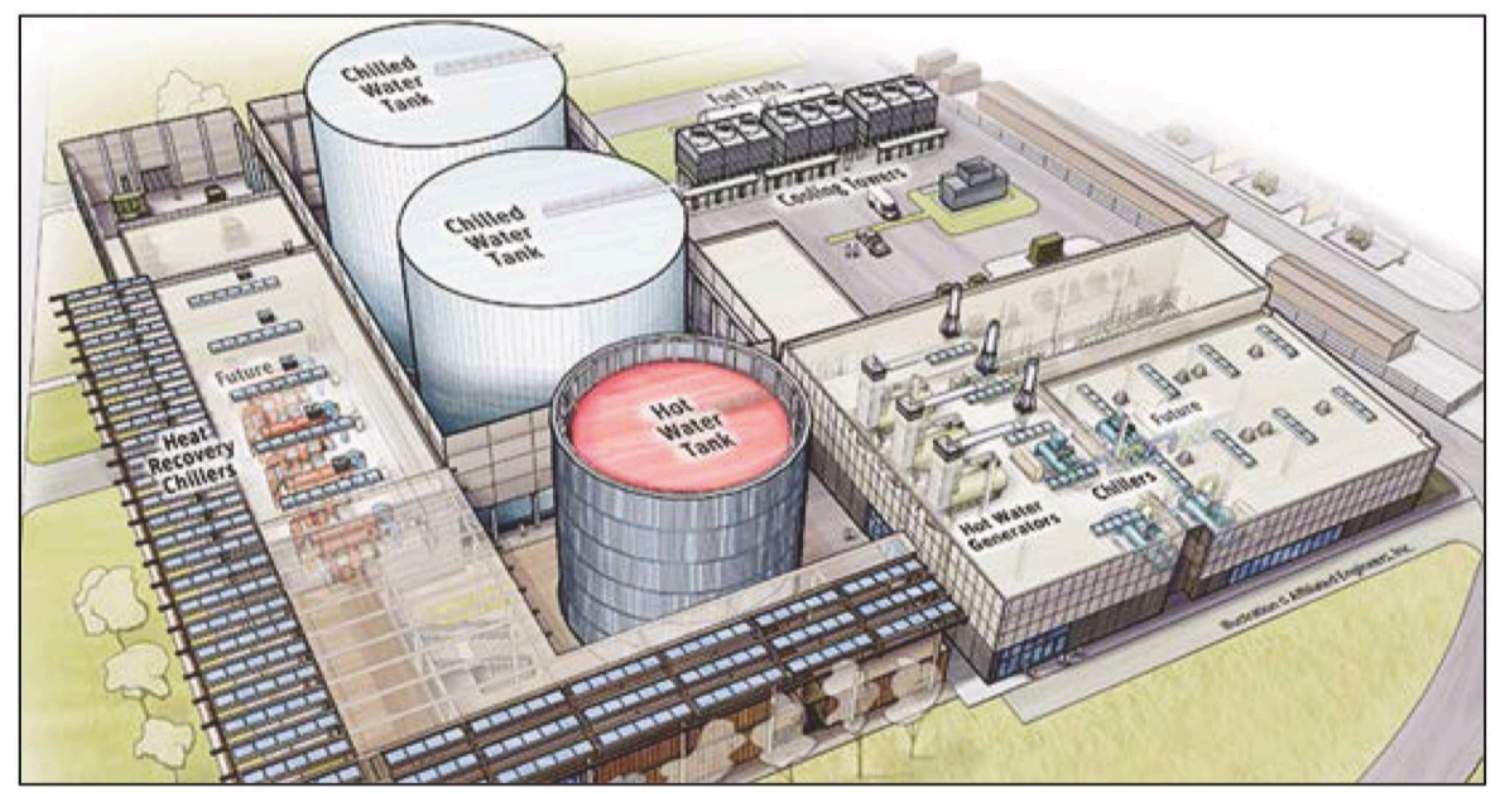

Figure 13. Adapted representation of large-scale hot and cold water storage, from [49], [8].

Because water has a large density change with temperature, coupled with a relatively low thermal conductivity, it is possible to have a single thermocline tank with the hot water at the top of the storage tank and the cold water at the bottom. A thin, high gradient, thermocline layer is established between the hot and cold storage sections. Temperatures in these water storage tanks are heavily pressure dependent, and it has not been economical to increase the potential hot water temperatures due to the requirements on the tank materials. Using increased pressures will be covered in the later section on steam accumulators, as hot and cold water, or chilled water, storage is colloquially associated with HVAC-type applications. The largest chilled water storage project in the DOE Global Energy Storage Database is a $1 \mathrm{GWh}$ facility in Jacksboro, Texas that is used to cool inlet air for a gas turbine [50].

\subsection{Geothermal Storage}

Geothermal energy storage involves hybridizing underground thermal energy storage techniques with geothermal power plant concepts. Initial research into this storage method involves designing a checkerboard-like configuration shown in Figure 14 for hot and cold wells at deep locations (around 1,219m [4,000ft].) [51]. Hot wells accept heated, pressurized water during storage charging times, and after discharging the water it is returned to cold wells. 


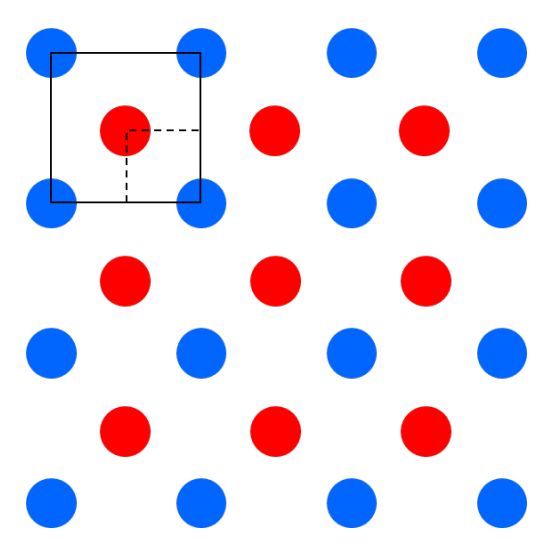

Figure 14. Design diagram for hot and cold well placement, from [51].

This project initially investigated interconnections with a parabolic solar trough plant, capable of heating water to an appropriate $250^{\circ} \mathrm{C}\left(480^{\circ} \mathrm{F}\right)$ temperature, which requires a minimum storage pressure of $4 \mathrm{MPa}$ (580 psia). This pressure is needed to maintain liquid water in the system. An LWR would also be able to operate in conjunction with this system, as LWR secondary steam pressures are around 3.5 $\mathrm{MPa}$ [51]. Other research has been conducted supporting solar heat systems integrated with geothermal technologies, investigating how solar preheating can be integrated with existing geothermal plants [52].

Ambient pressure increases with rock depth. In order to ensure that coolant injection does not fracture the surrounding sediment, injection pressures need to be lower than the rock pressures, as shown in Figure 15. Figure 16 shows a cross section design of how the hot and cold wells would operate in sedimentary formations.

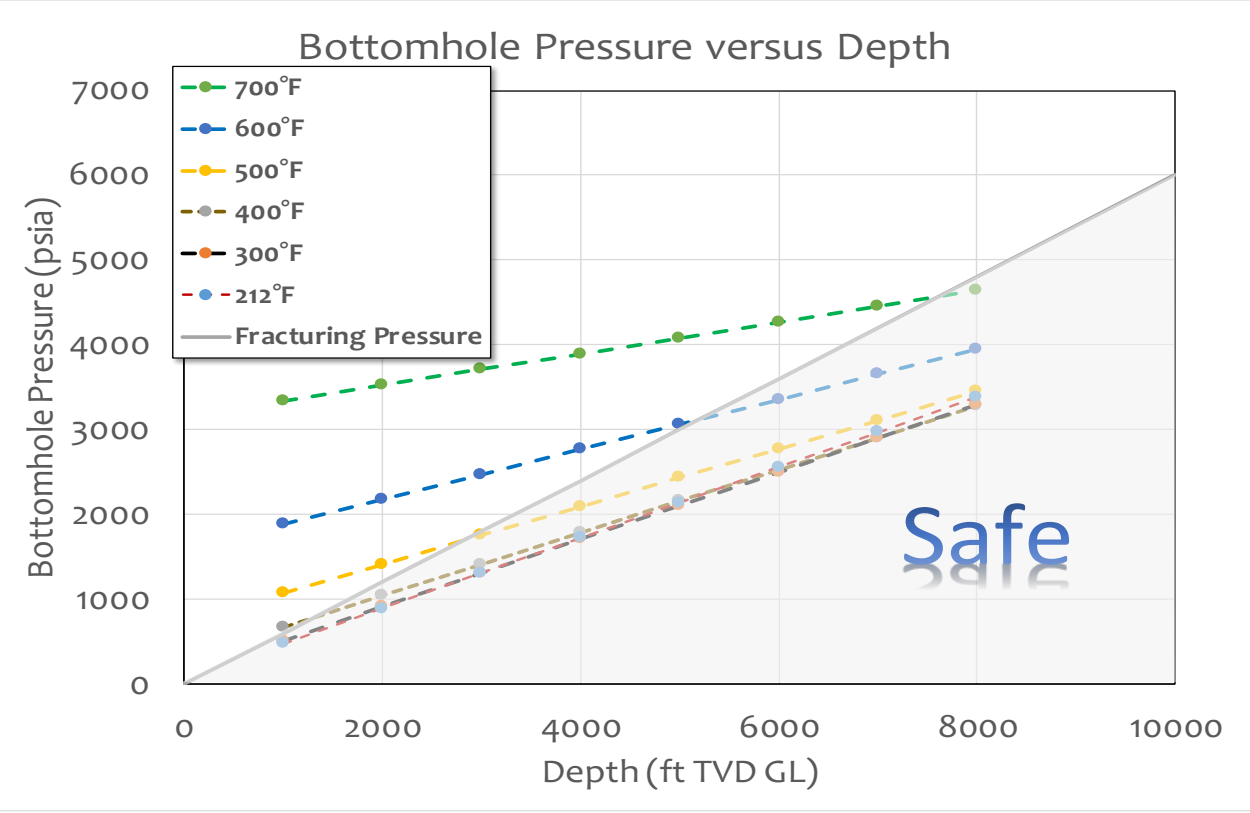

Figure 15. Injection pressure vs rock depth, from [51]. 


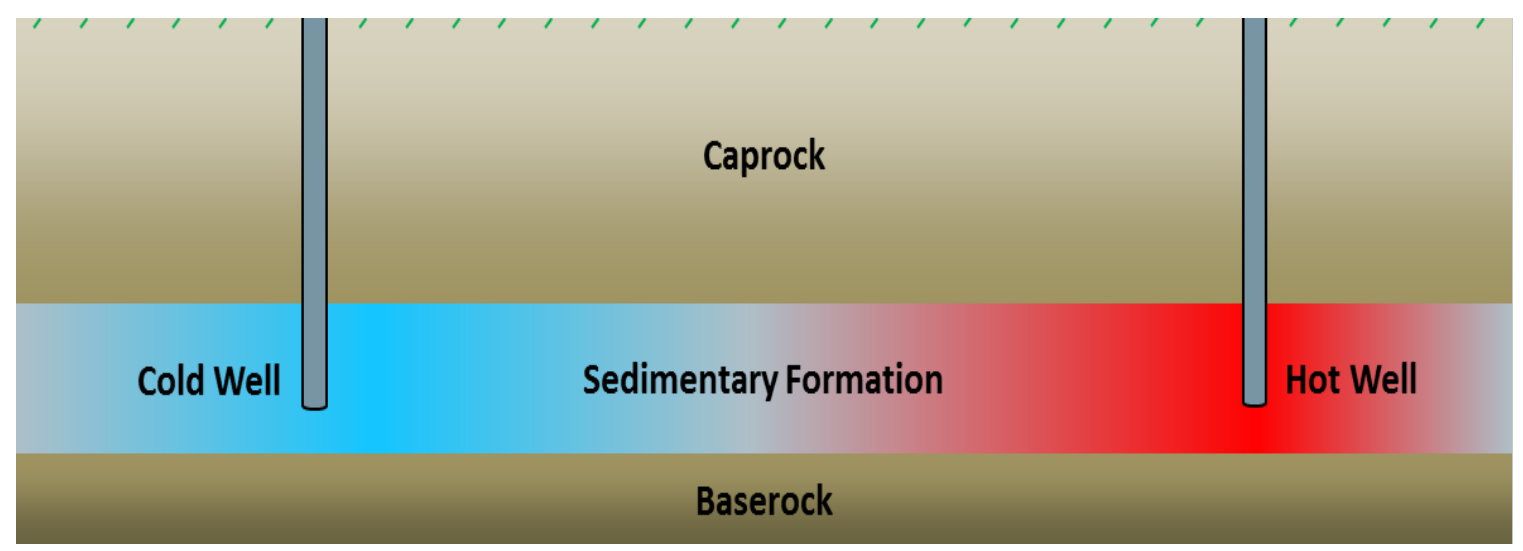

Figure 16. Geothermal energy storage potential design, adjusted from [51].

Overall, geologic thermal energy storage is a new technology based on some of the concepts that govern geothermal energy. The mechanisms for storage are similar to aquifer or borehole thermal energy storage, but by storing at large depths, the resulting hydrostatic pressure allows for high temperature storage.

\subsection{Solid Media Storage}

Solid media storage is a form of sensible heat storage using a solid structure. The heat is directly stored via temperature increase in the structure. A significant design issue that must be addressed in solid media is the material stress added via thermal expansion and contraction. Two forms of solid media storage are investigated in this report. The first is firebrick thermal energy storage, which uses electrical resistance heating to obtain very high temperatures. The second form of solid media storage is concrete thermal storage. Concrete will be used as a representation of thermally integrated solid material storage.

\subsubsection{Firebrick}

Firebrick thermal energy storage uses electrical energy at low prices to resistively heat a ceramic material that later discharges heated air at high temperatures. The high temperatures necessitate that the material is some form of ceramic such as $\mathrm{Al}_{2} \mathrm{O}_{3}, \mathrm{MgO}$, or $\mathrm{SiC}$ [53]. The firebrick FIRES (Firebrick Resistance-Heated Energy Storage) system is designed to be heated to 1000$1700^{\circ} \mathrm{C}$ for gas applications at high temperatures. Applications could include providing peak heating to nuclear reactors, although temperature limitations in heat exchangers may force this technology to have to wait for gas reactors [54]. The technology is based on regenerative Cowper stoves and brick stacks, which are used to recover large amounts of gas heat in other industrial applications. Storage capacity is approximately $0.5-1.0 \mathrm{kWh} / \mathrm{m}^{3}-\mathrm{K}$ [54]. Due to power and energy interdependency in solid media storage systems, firebrick needs to be sized no smaller than $3 \mathrm{x}$ the power capacity needed from the application (Figure 17) [55]. Additionally, heat losses are estimated at around 3\%/day with insulation [55]. Continued research into this technology is needed, especially with regards to avoiding thermal shock in high power firebrick systems [53]. The material choices presented exhibit maximum temperature gradients that are approached or exceeded by current proposed designs, especially at the cooling flow inlet where the discharge air is the coldest. Existing firebrick systems have peaked at $10 \mathrm{MWh}$, and there have not yet been any builds of larger systems [53].

Figure 18 contains four graphs showing simulation results of a FIRES system. The upper left plot shows the gas exit temperature during a storage discharge cycle. The required turbine gas temperature is marked on the graph using the red line to indicate where additional heating is 
required for continued use of the FIRES system. The lower left plot shows the possible power out of the FIRES system during a discharge while the upper right plot similarly shows the required fan power to obtain the output power. The fan power demand increases as the output temperature decreases in the system. The lower right plot shows the system temperatures at various heights along the discharge channels, where the temperature profile which starts effectively as a gradual thermocline becomes nearly isothermal at the point where the required temperature is no longer met. The combination of these plots supports the observation that a FIRES system must be oversided to individually meet a required power or energy rating, and that its maximum available discharge power will always be significantly less than the system input power [55].
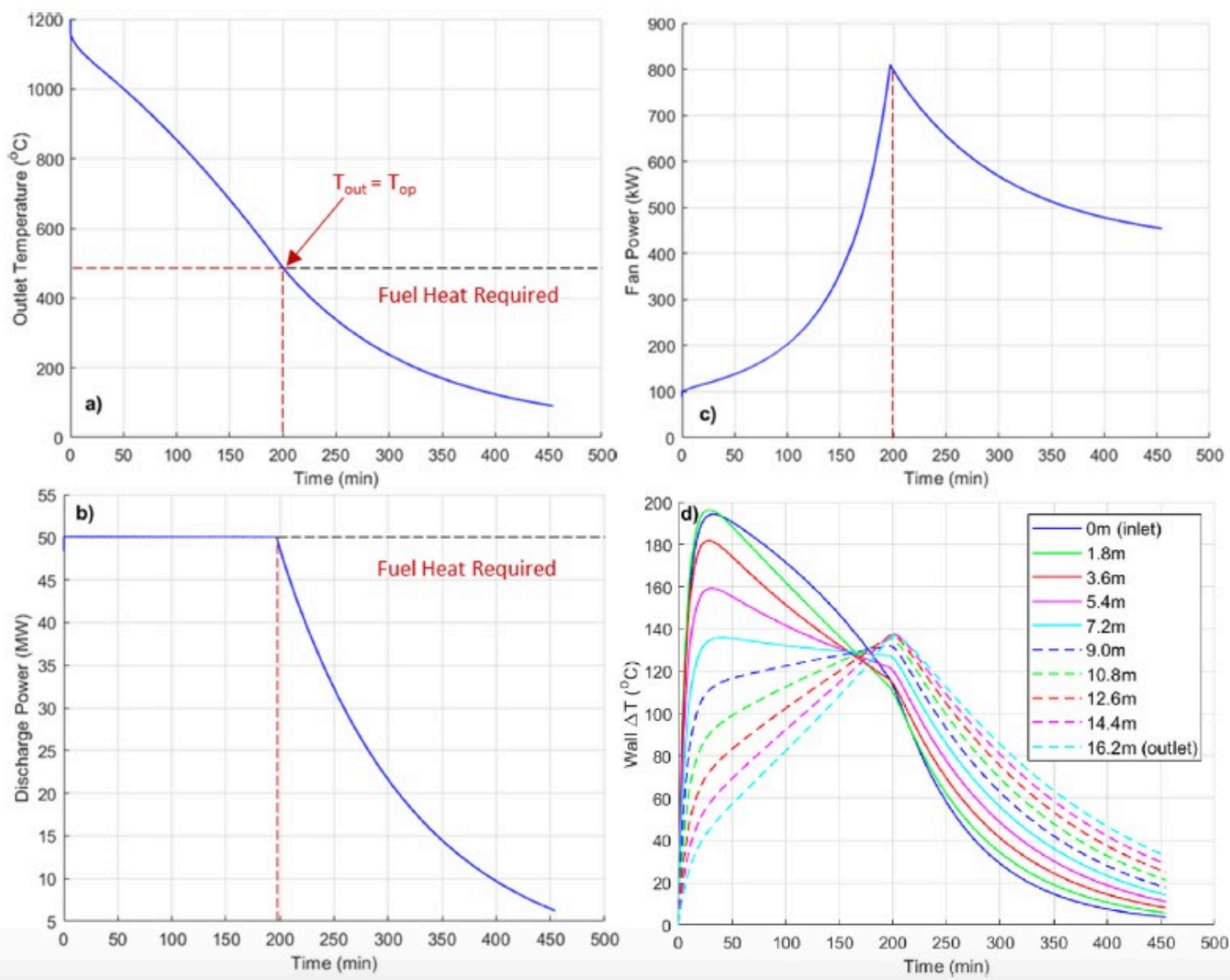

Figure 17. Group of results of FIRES simulations. Outlet temperature, gas sweep fan power, discharge power, and various system temperatures [53].

\subsubsection{Concrete}

Concrete thermal energy storage is at near-deployment stage of development. Similar to LAES, there are a few companies prepared to make a leap into deploying their technology. EnergyNest is a company that has publicly developed a solid media thermal energy storage module based on a proprietary advanced concrete material HEATCRETE®. The first commercially deployed EnergyNest module has been compared against models and observed while connected at the Masdar Institute of Science \& Technology Solar Platform [56]. Dowtherm-A heat transfer fluid (HTF) was used to move heat between electric heaters and the concrete storage. The EnergyNest design uses HTF flowing through U-tube steel pipes into the HEATCRETE® to deposit or withdraw heat. The overall design of the full storage module is to stack individual "thermal 
batteries" and interconnect them for charging and discharging purposes. A cross-section of one of these "batteries" is shown in Figure 18. EnergyNest indicates that the storage life of this system will exceed 30 years, and more likely 50 years [57]. Other concrete technologies similarly discuss steel piping frames encased in the concrete storage medium. The system charges when steam flows through the internal steel pipes. The system discharges by feeding cold water through the steel pipes in the reverse direction.

HEATCRETE® was designed specifically to maintain concrete's structural advantages while improving some of its thermal disadvantages. By increasing the thermal conductivity and the heat capacity, HEATCRETE® maintains a higher energy storage density $\left(43.3 \mathrm{kWh} / \mathrm{m}^{3}\right.$, approximately $0.7 \mathrm{kWh} / \mathrm{m}^{3}-\mathrm{K}$, including piping) than standard concrete $\left(0.6 \mathrm{kWh} / \mathrm{m}^{3}-\mathrm{K}\right)$ [58]. Additionally, the material has been selected due to its thermal expansion coefficient that is nearly identical to steel, allowing the entire system to expand or contract without adding internal stress or losing heat transfer capability (see system cross section in Figure 18).

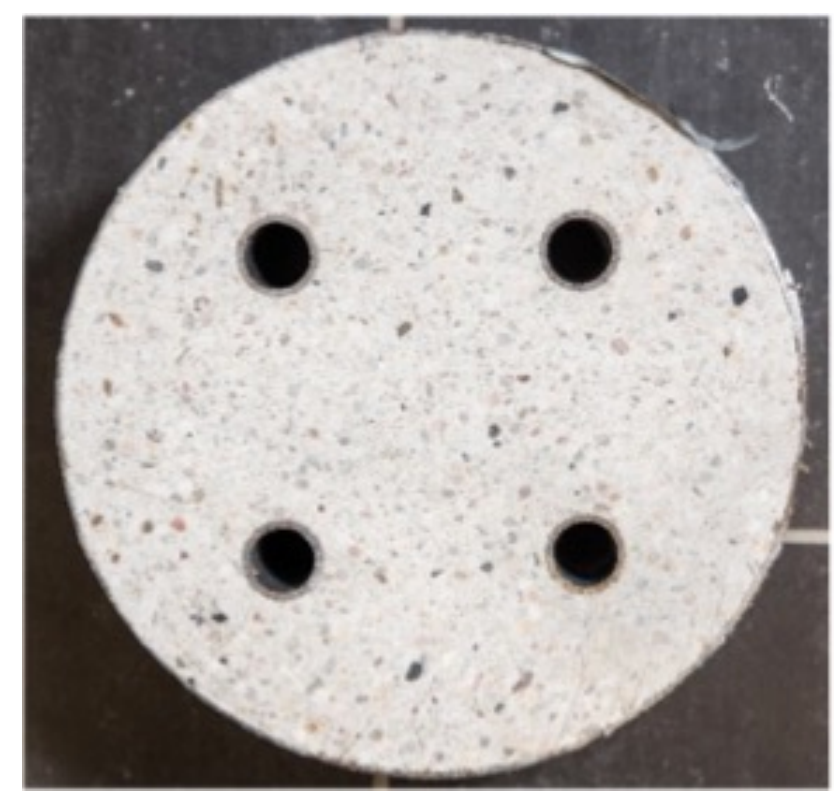

Figure 18. Cross section cut of HEATCRETE® material, reported in [56].

EnergyNest believes that their thermal battery system could cost as low as $\$ 25 / \mathrm{kWh}$ depending on how expensive it is to source the construction materials [57]. Thus far, the storage has been modeled successfully, with the only differences between predicted and actual results being tied to the heat transfer fluid source temperature rather than any systematic modeling error [56]. The system is touted to store at temperatures up to $450^{\circ} \mathrm{C}$ without material degradation, which is seen at higher temperatures, indicating that HEATCRETE® systems should integrate well with LWR technology. The EnergyNest thermal battery configuration is shown in Figure 19. 

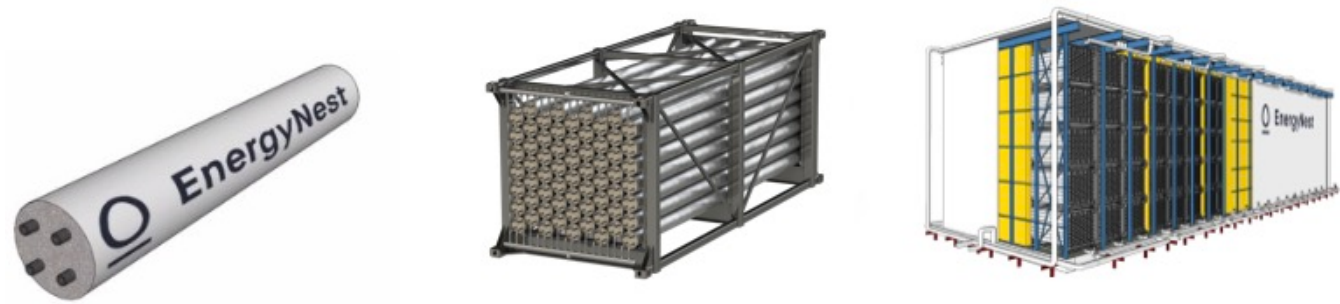

Figure 19. Buildup of EnergyNest thermal battery [57].

Previous concrete storage research at the Institute of Technical Thermodynamics began in May 2008 [58]. Results include material impacts, charging and discharging details, specific heat, and cycling data. After water evaporation during the first few cycles, material properties stayed consistent as long as the temperatures stayed below $500^{\circ} \mathrm{C}$. A major design concern is storage efficiency, or the amount of heat recovered as a fraction of heat deposited. In tests conducted in Stuttgart, Germany between 2006 and 2010, $1518 \mathrm{kWht}$ of heat was repeatedly transferred during a 37-hour charging period, while only $950 \mathrm{kWht}$ were extracted [58]. No explanation was included regarding this decrease in discharge vs. charge, but the behavior is likely similar to that of firebrick in Figure 17. Research focused on increasing the heat transfer rates in and out of concrete found that heat insertion and removal rates could be increased by adding heat transfer structures such as graphite foils as seen in Figure 20.

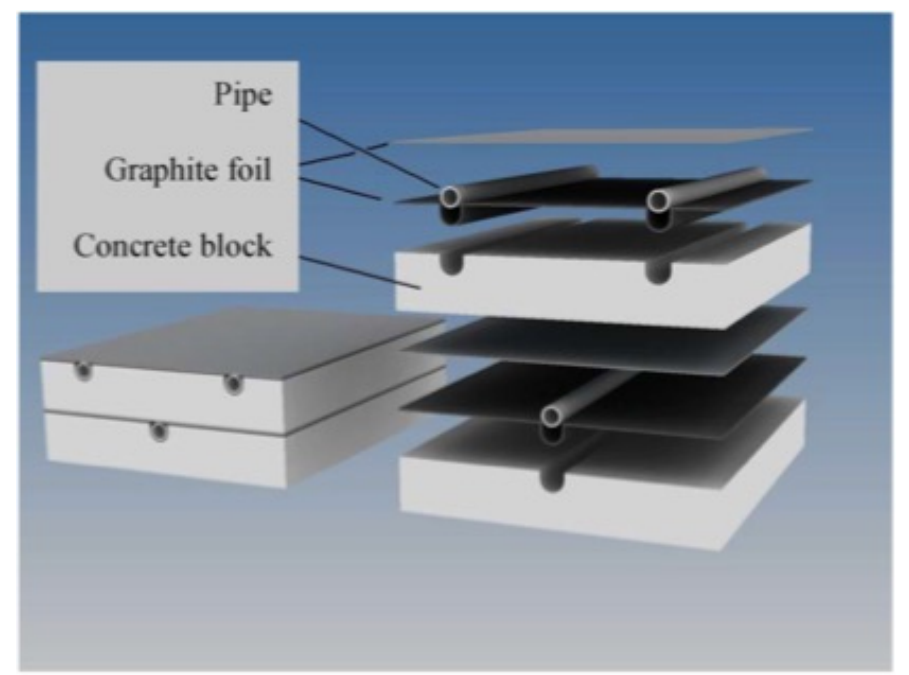

Figure 20. Example of graphite heat transfer structures application [58].

The temperature is restricted to lower than $450^{\circ} \mathrm{C}$ due to the material constraints for concrete. Unfortunately, there are questions regarding the ability of concrete to provide discharge energy that is similar to the amount of energy deposited during charging. Concrete could be a very inexpensive TES method due to the simplicity and cost of its components. Other companies are also investigating concrete thermal energy storage, but as of right now do not have publicly available materials to include in this report. 


\subsection{Phase Change Material}

Phase change materials store energy in the form of latent heat between two phases: most commonly a solid phase heated to a liquid phase. The heat storage capacity and density of phase change materials is higher than sensible heat systems due to the latent heat of phase transition. Phase change material selection involves careful investigation of thermal, physical, kinetic, and chemical properties [59].

Thermal considerations include a melting temperature in the desired operating range, high phase transition latent heat, high specific heat in each phase, and high thermal conductivity of both phases [59]. Desired physical properties include small change in specific volume between phases, favorable phase equilibrium, congruent melting, and high density [59]. Kinetically, there should be no supercooling, a high nucleation rate, and an adequate rate of crystallization [59]. Finally, chemical considerations focus on the long-term stability of the material, completely reversible freezing and melting cycles, safety, and compatibility with other construction materials [59].

Many materials have been investigated for use as phase change materials. PCMs can be solidgas, solid-liquid, liquid-gas, and solid-solid, with solid-liquid as the most common PCM. Melting temperatures for some PCMs can be as low as $0^{\circ} \mathrm{C}[60]$. Organic compounds and salt hydrates have relatively low transition temperatures between $0-150^{\circ} \mathrm{C}\left(32-302^{\circ} \mathrm{F}\right)$ [59] [60]. Many organic compounds have very low thermal conductivities, requiring expensive and creative geometry designs for heat transfer enhancement [60]. Salt hydrates maintain higher but still low thermal conductivities. For higher temperature PCM applications, inorganic compounds such as metals, salts, or eutectic salts are used. The melting points of eutectic salt range from around $50^{\circ} \mathrm{C}$ (more commonly $100^{\circ} \mathrm{C}$ ) to $369^{\circ} \mathrm{C}$ [61] [60]. Eutectic salts tend to have crystallization fronts during freezing, and thus may lose some liquid properties at temperatures above their melting/freezing point. Other inorganic compounds have melting points at even higher temperatures, much out of the range of applicable light water nuclear heat temperatures.

Phase change materials are still in early research and development stages. Laboratory experiments have demonstrated different PCM features, but there have not been laboratory scale demonstrations of PCM storage technology. Each of the main proposed PCMs, namely organics, salt hydrates, and inorganic compounds, have specific challenges that prohibit their present use. Organic compounds are based on carbon compounds, and have safety and flammability issues along with degradation challenges. Salt hydrates suffer from storage capacity reduction over time, and advanced methods for increasing heat transfer in materials, such as encapsulation, requires extensive energy input that increases as storage size increases [62] [63]. Other inorganic salts have high specific volume changes, insufficient thermal properties data, or exhibit supercooling effects [64]. Additionally, these materials suffer from cycling degradation with respect to hydration or other key properties within just a few heating and cooling cycles [65].

Overall, phase change materials are theoretically well suited for thermal energy storage applications at effectively any design temperature. However, there are currently many materials issues that have precluded PCMs from attaining any production beyond small experiments.

\subsection{Thermochemical}

Thermochemical energy storage involves reversible chemical reactions in which energy is stored via an endothermic reaction occurring at a trigger point, to be released by the reverse exothermic reaction. A conceptual process diagram is presented in Figure 21 and equations 1 and 
2, where $A$ and $B$ represent constituent reversible reactants. Many chemical reactions are temperature dependent for reaction initiation and subsequent reaction rates. There exists a significant research base into thermochemical energy storage from the solar energy community, as the field seeks to provide an intermediary between solar energy production and consumption. Thermochemical storage is mostly being investigated for seasonal storage [66] [67] [68] .

$$
\begin{aligned}
& A B+\text { heat } \rightarrow A+B \text { at high temperature } \\
& A+B \rightarrow A B+\text { heat at low temperature }
\end{aligned}
$$

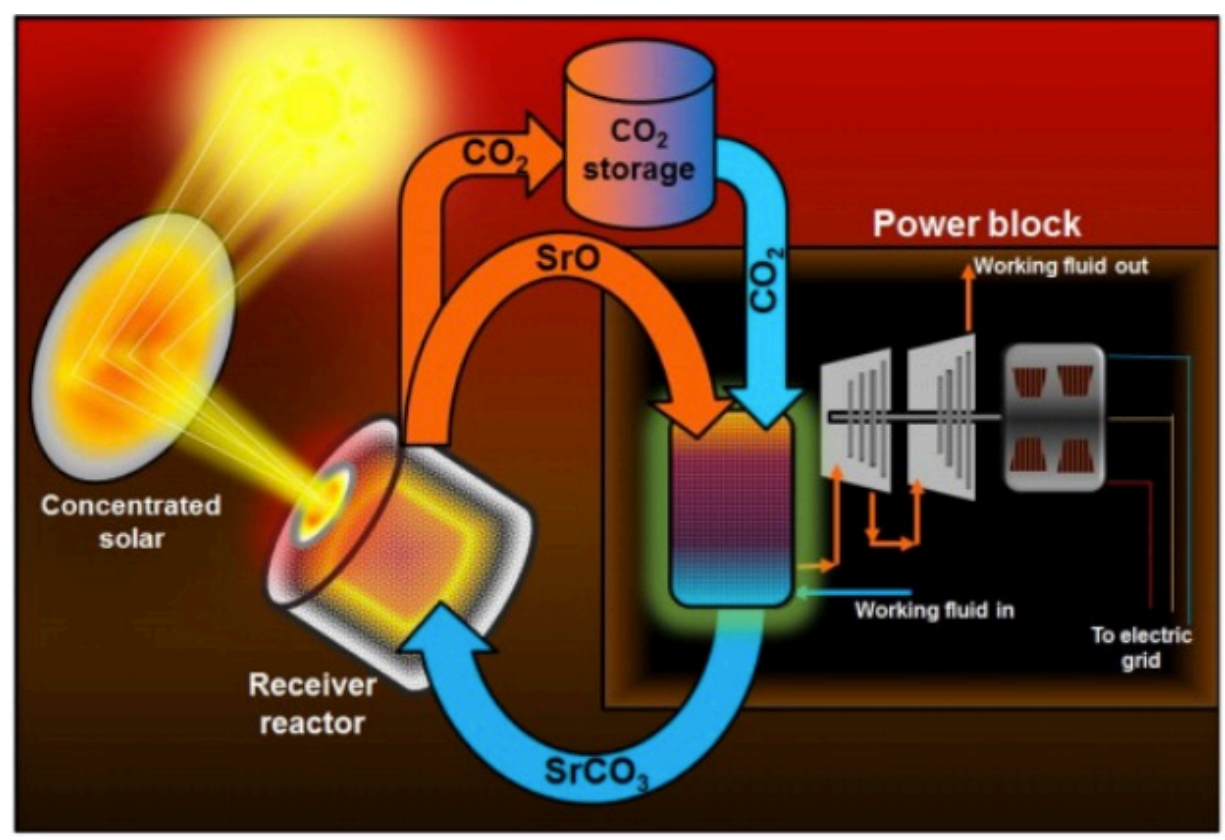

Figure 21. Conceptual operation of thermochemical operation, from [4].

Thermochemical storage has the highest theoretical energy density capability of any thermal storage technology. However, there are significant challenges with regards to the cyclability of reactions [69]. While there is ongoing research into molecular level stabilization methods, this specific technology is still only at the laboratory experiment stage. Chemical reactor design is also difficult, and researchers note the need for continued investigation into heat removal from these kinds of systems [70]. Material selection is also a significant hurdle in thermochemical storage due to multiple stages with separate material needs [66]. Hydrogen production is involved in the goal of many high temperature thermochemical reactions, which may make thermochemicals more attractive in the future if the associated process can inherently aid in $\mathrm{H}_{2}$ production [71]. Research thus far has focused on concentrated solar power storage, due to its need for energy storage to increase capacity factors. Thermochemicals are still in theoretical design and laboratory experiment stages.

\subsection{Sensible Heat Storage}

Sensible heat storage is the process of storing heat through a temperature increase in the storage medium. The difference between sensible heat storage and solid media storage in this paper is the transport of the storage medium that takes place in sensible heat storage. In this section, two 
different system types and two materials will be discussed. The system designs are either two tank or thermocline, and material types discussed are restricted to molten salt and thermal oil.

\subsubsection{Two-Tank}

Two-tank sensible heat storage is the most common form of large-scale thermal energy storage [72]. The process involves two large tanks, each capable of handling the entire storage mass. One tank is kept cold, and the other is kept hot. During charging, storage mass is pumped from the cold tank, through the heat exchanger, and then stored in the hot tank. During discharge, the reverse is done. Figure 22 shows an example potential two-tank design.

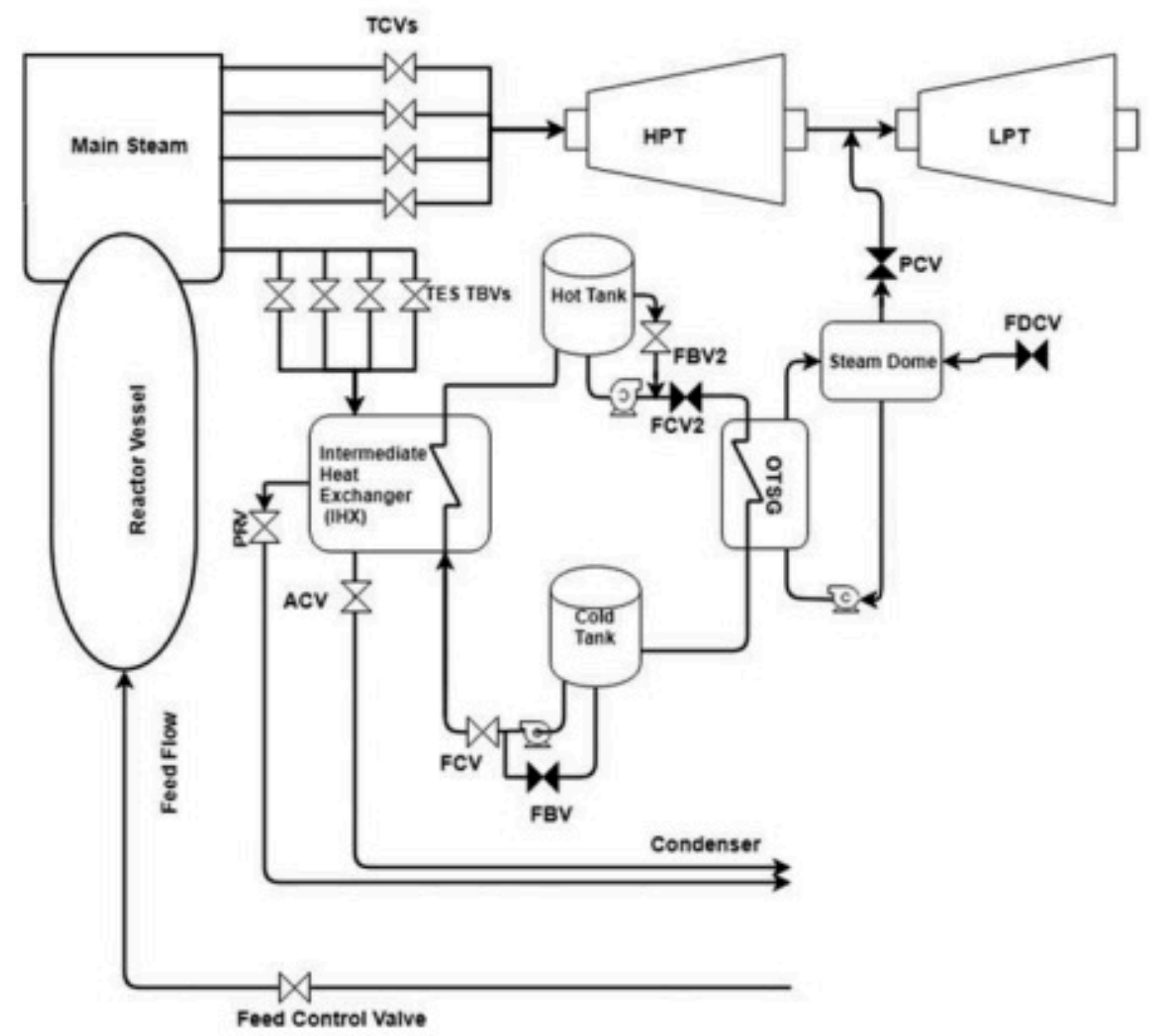

Figure 22. Potential design of a two-tank sensible heat peaking unit integrated with a SMR $[73] .{ }^{6,7,8}$

By completely separating the hot and cold storage masses, it is possible to have constant temperature discharge of all stored heat [74]. This simple system is currently used in many solar systems using molten salt or thermal oils [72]. The largest concern or drawback from this system

${ }^{6}$ HPT - High Pressure Turbine, LPT - Low Pressure Turbine, OTSG - Once through Steam Generator

${ }^{7}$ PCV - Pressure Control Valve, TCV - Turbine Control Valve, FCV - Flow Control Valve

${ }^{8}$ PRV - Pressure Relief Valve, ACV - Auxiliary Control Valve, FDCV - Feed Control Valve 
is the capital cost associated with making two tanks large enough to handle the entire required storage mass. The capital cost of a single thermocline tank system is approximately two-thirds of a similar two-tank system [74]. However, there is an increase in efficiency in two-tank systems, making it a back and forth between the two that becomes highly dependent on operational strategy.

\subsubsection{Single-Tank Thermocline}

A single-tank thermocline stores heat storage mass separated by a thin thermocline region. Large buoyancy changes and low internal thermal conductivity are very desirable for these systems in order to maintain the smallest thermocline region possible. A cheaper filler material is used to increase the storage density via higher heat capacity values and to decrease the cost of the storage system [75]. Internal flow characteristics as well as structural and filler designs have significant impact on thermocline thickness. Unfortunately, molten salt thermoclines have a technical height limit of $14 \mathrm{~m}$ due to available pump sizes [74]. Creating larger storage then must be accomplished by increasing storage diameters, which can lead to material failures from excess thermomechanical stress. Figure 23-Figure 25 show thermocline design and its impact on the thermocline behavior. In addition, Figure 26 illustrates that thermocline tanks suffer reduced useful energy storage when compared with two-tank systems due in part to thermal mixing in the tank, as well as "defocusing," or the phenomenon in which the raise in temperature at the outlet of the thermocline during the charging process reduces the amount of power able to be extracted from power collectors [74]. Lower thermal salt Reynolds numbers, relatively taller tanks, and smaller particle bed sizes lead to improved discharge efficiencies [76]. Most research available focuses on molten salt storage due to its higher temperature capabilities and solar energy applications.

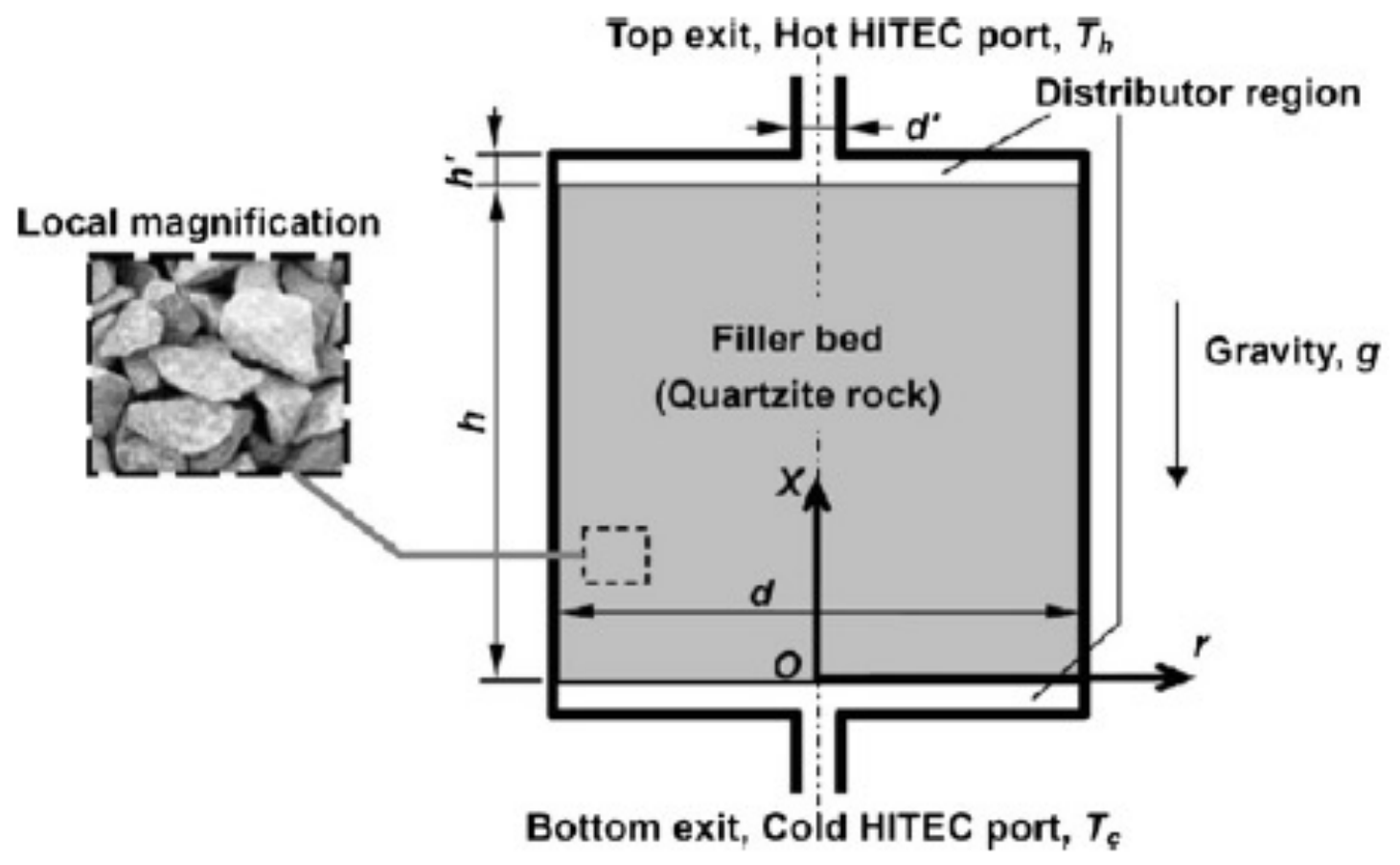

Figure 23. Design of a thermocline tank from HITEC, reproduced from [75]. 


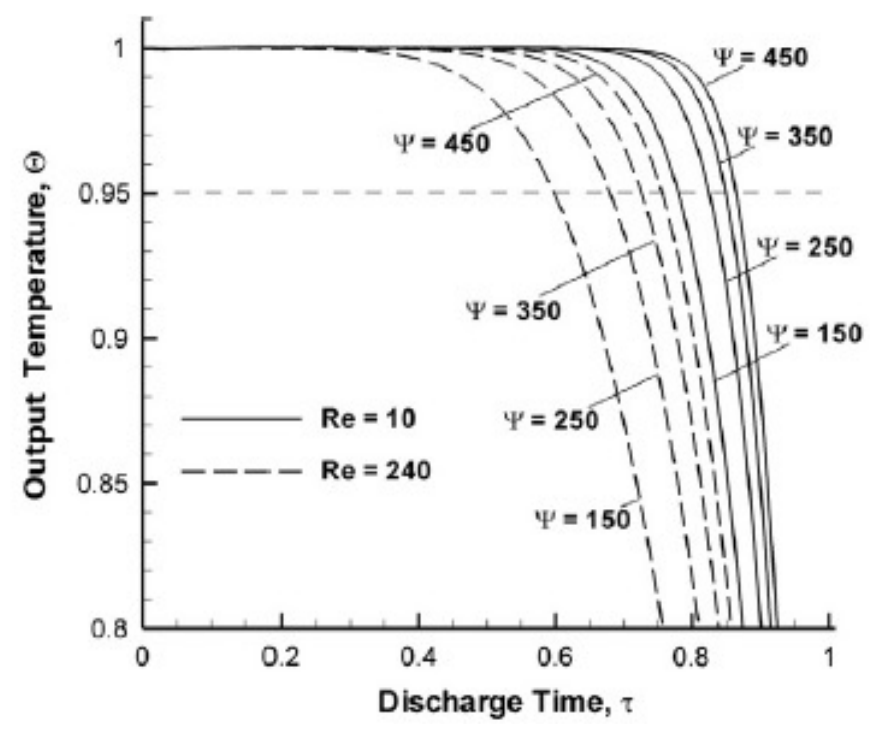

Figure 24. Dimensionless output temperature during discharge time for two thermocline Reynolds numbers $(\mathrm{Re})$ and various molten salt flow distances to particle diameter ratios $(\Psi)$ [75].

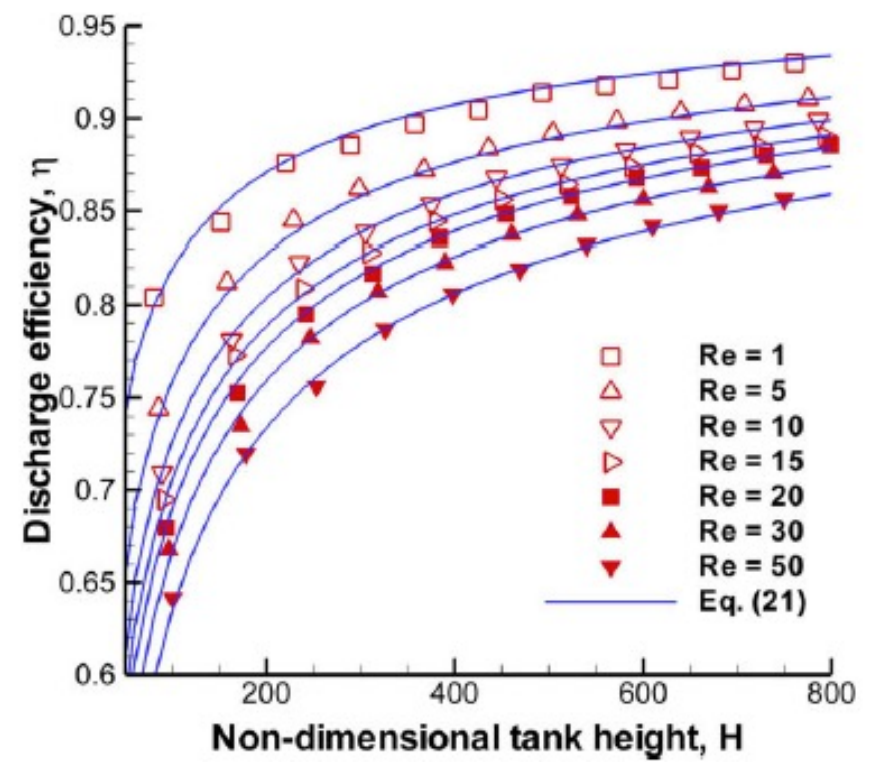

Figure 25. Discharge efficiency vs. dimensionless tank height for various internal Re numbers [76]. 


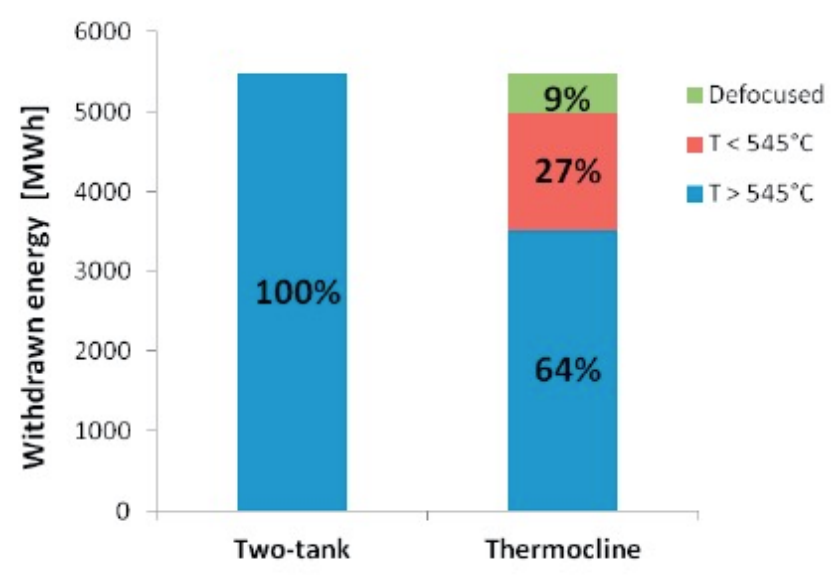

Figure 26. Energy withdrawal comparison of two-tank vs. thermocline for a molten salt [74].

\subsubsection{Molten Salt}

Molten salts are liquefied salts characterized by high melting and boiling points, and attractive physical properties for heat transfer. Salt must be liquid in order to be pumped. Unlike pure materials, which typically operate as a liquid to the material melting point, salts used in storage are eutectic and can exhibit precipitation at temperatures above their initial melting point, at a liquidus temperature [61]. Salt choice will be especially important if linked to a LWR system, as the liquidus temperature will dictate the minimum temperature while the LWR secondary side steam temperature will set the maximum storage temperature. Figure 27 shows how cost is related to storage temperature differences. A large temperature difference is desired in order to minimize the storage volume. The minimum liquidus temperature salt in 2008 was $52^{\circ} \mathrm{C}$, a $\mathrm{KNO}_{3}-\mathrm{NH}_{4}-\mathrm{AgNO}_{3}$ eutectic that the authors note is prohibitively expensive due to the silver nitrate component [61]. Figure 28 shows possible operating temperatures of a variety of salts, with the lowest salt melting point corresponding to a five-component eutectic nitrate-nitrite mixture $\mathrm{LiNO}_{3}-\mathrm{NaNO}_{3}-\mathrm{KNO}_{3}$ $\mathrm{NaNO}_{2}-\mathrm{KNO}_{2}$ with a melting point at $74.4^{\circ} \mathrm{C}$ [77]. There is a quaternary Ca-Li-Na-K nitrate mixture with a liquidus point of $95^{\circ} \mathrm{C}$, also a reasonably low temperature [78].

As seen in Figure 28, the maximum temperature of most salts is around $500^{\circ} \mathrm{C}$, after which point the salts degrade [79] [77] [78]. Specific salt selections must include a great deal of material considerations, only increasing with more salt compounds that make up a eutectic salt. One significant advantage to using molten salts as energy storage media is the low pressure and inherent safety of the material. Salts solidify when they leak, leading to safer accident conditions. 


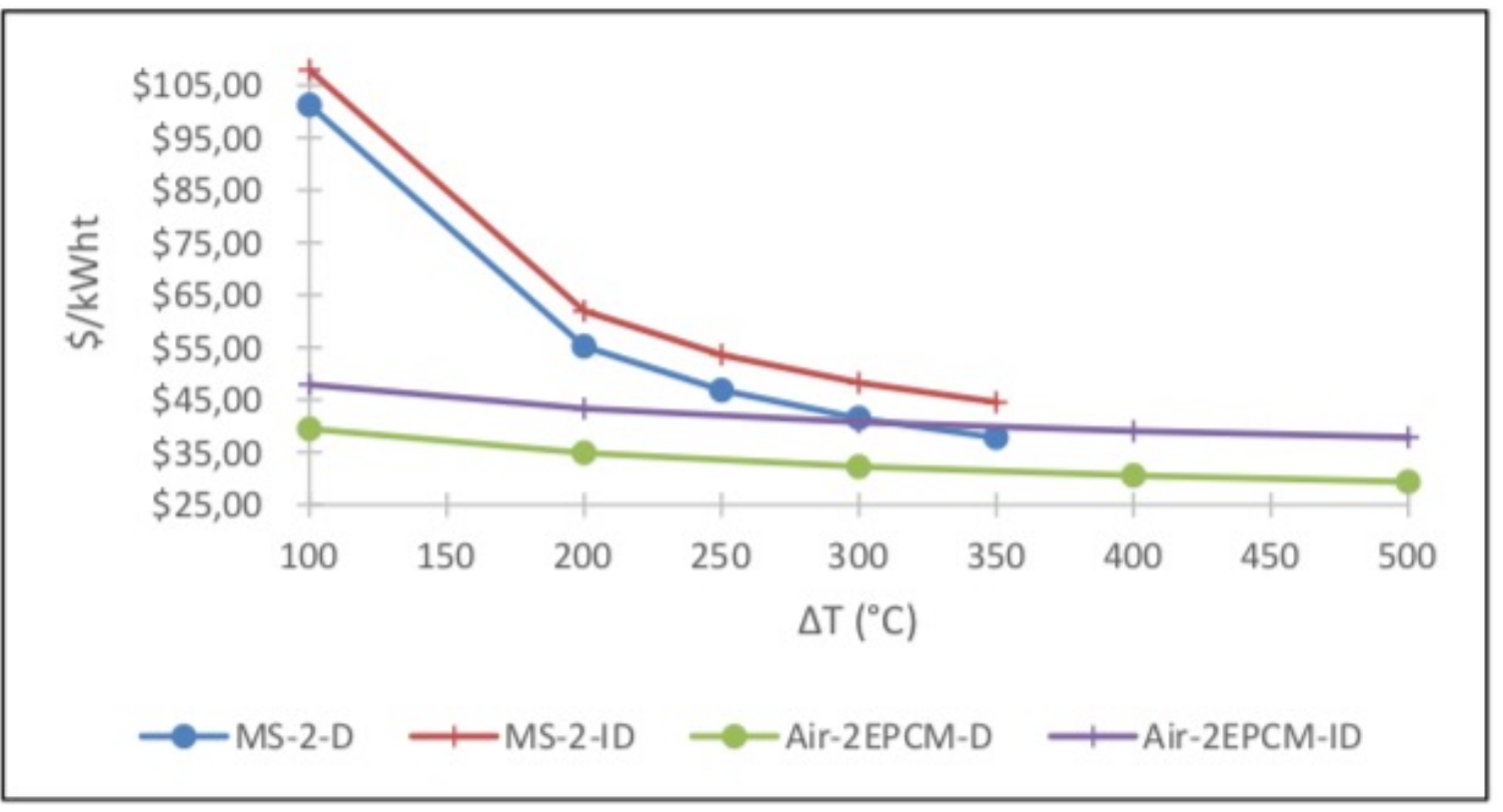

Figure 27. Relation between capital cost and temperature difference for various molten salts [79].

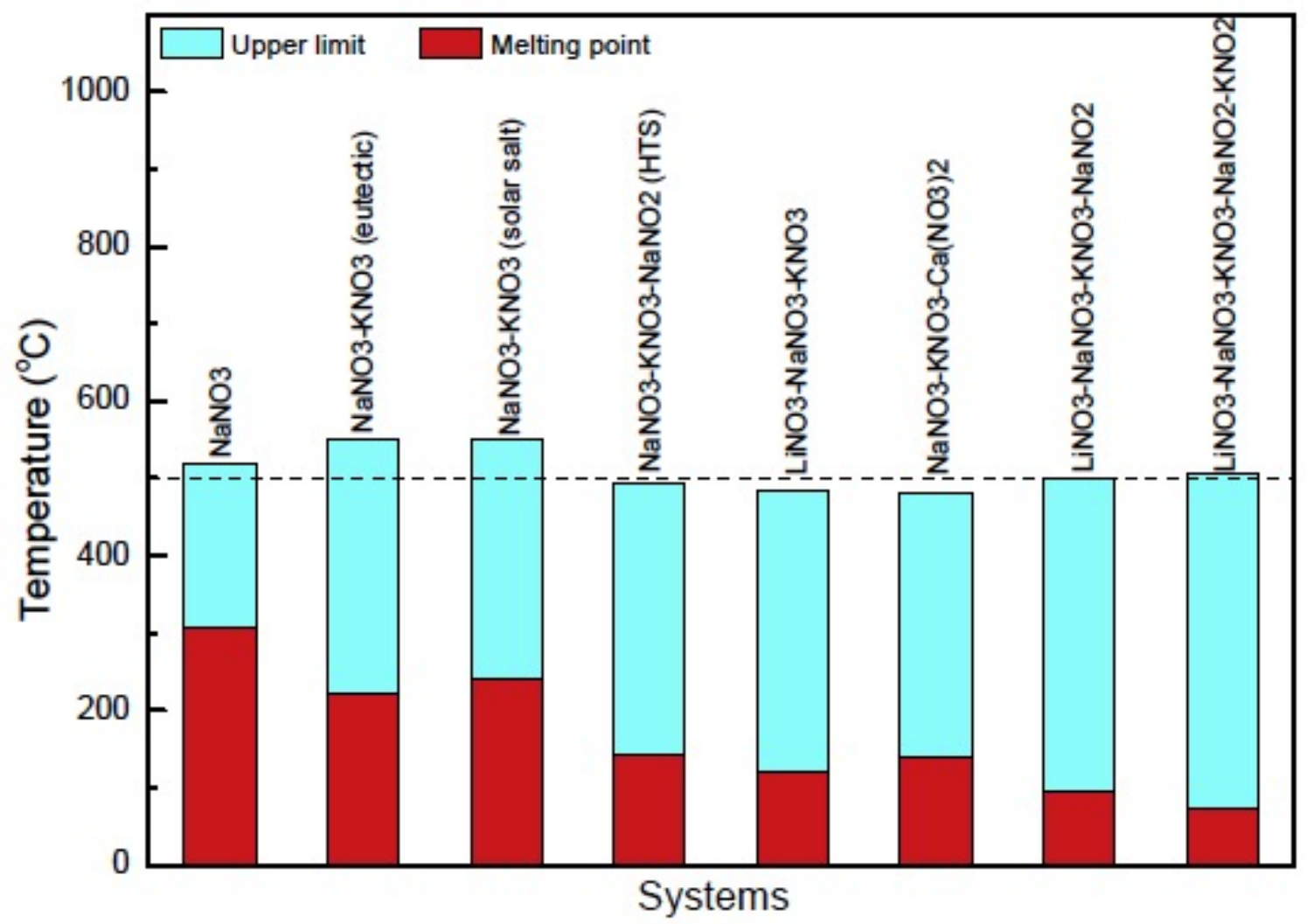

Figure 28. Upper limit and melting points of various salts from [77]. 


\subsubsection{Thermal Oil}

Thermal oils are compounds designed to store and move heat effectively at low to medium temperature ranges. A common thermal oil, Therminol ${ }^{\circledR} 66$ maintains a stable operation range from $-3^{\circ} \mathrm{C}$ to $345^{\circ} \mathrm{C}$ [80]. Another thermal oil company, Duratherm, maintains a variety of oils capable of operating from low temperatures to $315^{\circ} \mathrm{C}$ or more [81]. Oil costs are higher than salt for the same volume and energy capacity of storage given sufficiently high temperature changes. This is due to higher prices per unit mass and lower densities that higher heat capacities do not overcome [82]. Some thermal oil properties are shown in Table 8. Additional investigation may be needed for lower temperature applications as the possible temperature difference for thermal oils may be higher than salts. Thermal oils also have higher environmental impact concerns than salts, affecting their selection [82].

Properties of Possible TES Fluids at $\sim 260^{\circ} \mathrm{C}\left(500^{\circ} \mathrm{F}\right)$

\begin{tabular}{|c|c|c|c|}
\hline Heat Transfer Fluid & Boiling Point & Heat Storage & Operating Range \\
\hline Therminol 8 -66 (Ref. 17) & $358^{\circ} \mathrm{C}\left(678^{\circ} \mathrm{F}\right)$ & $1039 \mathrm{~W} \cdot \mathrm{h} / \mathrm{m}^{3} \cdot{ }^{\circ} \mathrm{C}\left(576.95 \mathrm{~W} \cdot \mathrm{h} / \mathrm{m}^{3} \cdot{ }^{\circ} \mathrm{F}\right)$ & $-2.7^{\circ} \mathrm{C}$ to $343.3^{\circ} \mathrm{C}\left(27^{\circ} \mathrm{F}\right.$ to $\left.650^{\circ} \mathrm{F}\right)$ \\
Therminol 8 -68 (Ref. 18) & $307^{\circ} \mathrm{C}\left(586^{\circ} \mathrm{F}\right)$ & $1013 \mathrm{~W} \cdot \mathrm{h} / \mathrm{m}^{3} \cdot{ }^{\circ} \mathrm{C}\left(563.03 \mathrm{~W} \cdot \mathrm{h} / \mathrm{m}^{3} \cdot{ }^{\circ} \mathrm{F}\right)$ & $-25.5^{\circ} \mathrm{C}$ to $360^{\circ} \mathrm{C}\left(-14^{\circ} \mathrm{F}\right.$ to $\left.680^{\circ} \mathrm{F}\right)$ \\
Therminol $8-75$ (Ref. 19) & $342^{\circ} \mathrm{C}\left(649^{\circ} \mathrm{F}\right)$ & $992 \mathrm{~W} \cdot \mathrm{h} / \mathrm{m}^{3} \cdot{ }^{\circ} \mathrm{C}\left(551.54 \mathrm{~W} \cdot \mathrm{h} / \mathrm{m}^{3} \cdot{ }^{\circ} \mathrm{F}\right)$ & $79.44^{\circ} \mathrm{C}$ to $385^{\circ} \mathrm{C}\left(175^{\circ} \mathrm{F}\right.$ to $\left.725^{\circ} \mathrm{F}\right)$ \\
\hline
\end{tabular}

Table 8. Various heat transfer fluids for potential TES selection, from [73].

In operating concentrated solar power plants that also use TES, it is common for both thermal oils and molten salts to be used. The oils are used as the heat transfer fluid moving heat from the collection tower into the power generation train or to storage. The storage portion then uses molten salt.

\subsection{Steam Accumulators}

Steam accumulators are very well understood components of manufacturing systems. Accumulators are often used when there is a cyclical requirement for a large steam input where using a boiler that could dispatch the needed heat would be overly expensive. An accumulator allows for the boiler to operate at lower power outputs, storing energy in the accumulator. Accumulators do not primarily store steam, but instead a water-steam mixture that is saturated. Spirax Sarco advises that steam accumulators are about $90 \%$ liquid by volume when fully charged [83].

Accumulators resemble submarines in their design shape, designed to withstand a large range of operating pressures. The liquid water fills a majority of the control volume, with steam pressurizing the vessel at the top. The mixture equilibrates at saturation conditions and is kept that way via the steam charging method. Steam is inserted in the bottom of an accumulator directly via nozzles arranged along the bottom. The charging steam is then immediately mixed, and the increased energy will increase the system pressure. Figure 29 shows the design of a sliding pressure accumulator. 


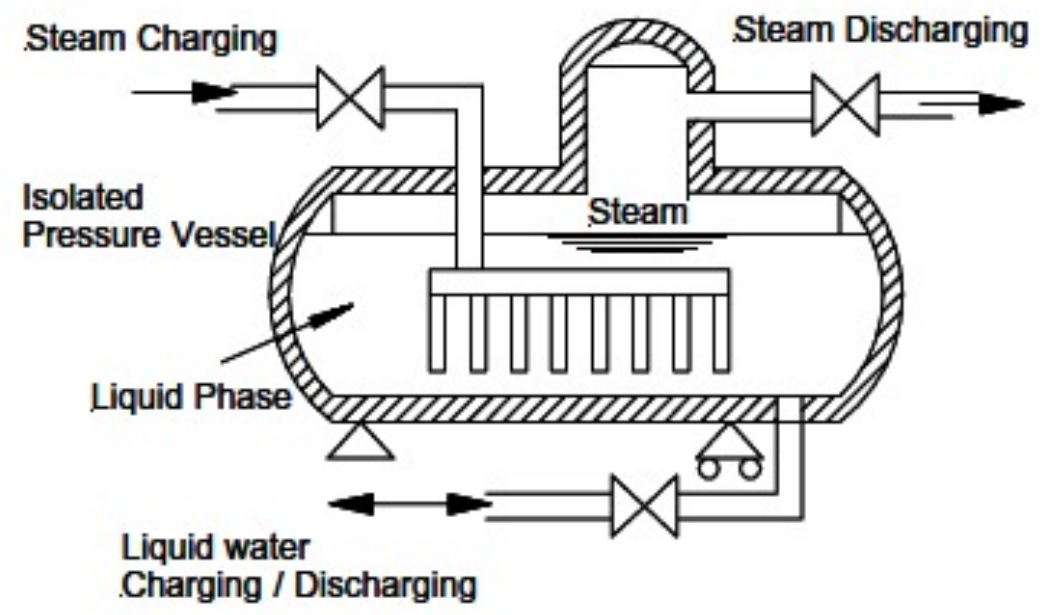

Figure 29. Steam accumulator design as shown in [84].

Steam accumulators store energy at around $20-30 \mathrm{kWh} / \mathrm{m}^{3}$ via the pressurized and saturated water [84]. During discharge, the release valve is opened and the steam evacuates, lowering the vessel pressure. As the pressure decreases and thus the saturation temperature, some of the liquid flashes to steam and subsequently releases as well. Steam accumulators alone are named Ruthstype steam accumulators and have sliding pressure due to this phenomenon [84]. Figure 30 shows some of the pressure curves and the density of steam that is discharged. The plot shows the $p_{\text {start }}$ curves, showing the pressure rise of the system during discharge.

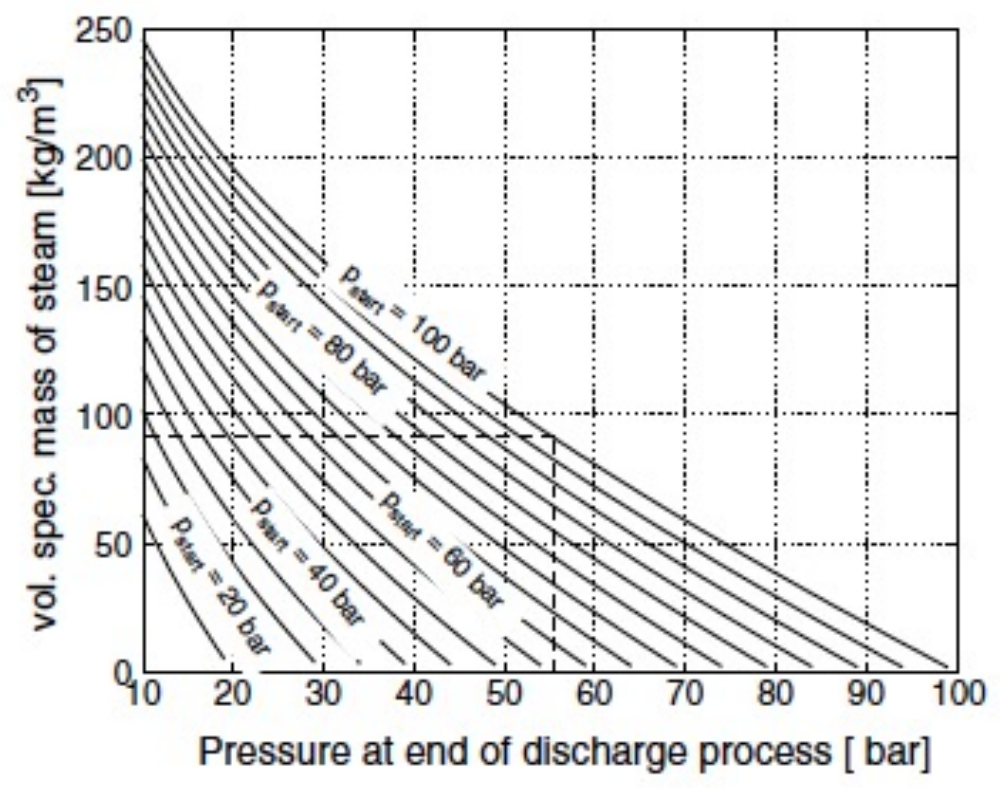

Figure 30. Density of steam discharged versus starting and ending pressure [84].

Steam accumulators serve clear purposes in manufacturing processes, allowing for the delayed and potentially sudden release of steam despite constant steam production. The energy density of steam accumulators is reasonably high, and is much higher than simply storing the steam itself in the vapor phase. Steam accumulators do face size limitations, as hoop stresses begin to limit the 
vessel size. To integrate as the primary TES medium, steam accumulators would need to be connected in parallel to store grid-sized quantities of energy (hundreds of MWh). Further, standard steam accumulators have sliding pressure discharge, which may not be desirable depending on the system application. 


\section{Results and Analysis}

This section first describes the Figure of Merit scoring system developed from the PIRT table outlined in section 2 for the analysis, followed by an in-depth scoring analysis of each thermal storage technology.

\subsection{Figures of Merit}

Thirteen categories have been identified for inclusion in the figure of merit study based on the fourteen PIRT questions identified in section 2. These include: technology readiness, charging and discharging compatibility, ancillary services market application, system capacity, ramp time, cycle frequency, realignment frequency, cost, lifetime, geographical requirements, environmental concerns, and thermal support requirements. The figures of merit assigned for each category along with scaling justification are discussed.

1. Technology readiness level (TRL) is extremely important to JUMP, as the system must be fully designed in the next few years to be licensed and deployed by late 2026. To give the proper weight, the FOM value equals the TRL (0-9 scale).

2. Experienced technology integration with nuclear steam pressures and temperatures. The $\mathrm{NuScale}$ reactor maintains steam pressure of $2.7 \mathrm{MPa}$ and $300^{\circ} \mathrm{C}$. Being able to directly use this steam achieves a FOM of 2, having to somewhat downgrade this steam gives a FOM of 1 , and a FOM of 0 indicates no direct use of this steam.

3. Capability to discharge high quality heat. The TES must be able to discharge its energy capacity at consistent high quality heat. A system capable of discharging its entire store at above $175^{\circ} \mathrm{C}$ was given a FOM of 2 . A system capable of either sliding pressure discharge with some above $175^{\circ} \mathrm{C}$ or a system capable of discharging between $100-175^{\circ} \mathrm{C}$ was given a FOM of 1 . Otherwise, the FOM was 0 for this category.

4. United States electrical grid ancillary services market potential. If a TES allows for participation in the frequency regulation market, a FOM of 2 was given. If a TES allows for participation in the reserves market, a FOM of 1 was given. Otherwise, a 0 was given for this category.

5. Total energy capacity for this system is estimated at $400 \mathrm{MWh}$ of heat. A system must therefore be able to manage that much energy. A system capable of this size was given a FOM of 2. One that could store $100 \mathrm{MWh}$ but not $400 \mathrm{MWh}$ was given a 1 , and a 0 was given otherwise.

6. Ramp time is associated with category 4 , as well as energy arbitration and load following. Due to the most restrictive reserve market restrictions of 10 minutes, a ramp time to maximum power of 10 minutes or less was given a FOM of 2. A ramp time of less than one hour is assigned a 1 , and any ramp longer than that is given a 0 .

7. Cycle frequency, defined as the system's capability to charge and discharge. If a system can charge and discharge at will, a FOM of 2 was given. A system that could cycle only daily is given a FOM of 1 , and a 0 to systems with longer cycles.

8. Realignment frequency is the need of a system to either wait on some phenomenon or correct a non-ideal process and leads to a reduction in capacity factor. If no realignment is required, a FOM of 2 is given. If realignment is required every cycle, a FOM of 0 is given, and a FOM of 1 is given for values in the middle. 
9. TES cost per $\mathrm{kWh}$. This value is evaluated after the total FOM is calculated, to be used as a selection method later.

10. Technology lifetime refers to the time before the TES would need self-replacement. Like cost, this factor is considered after the FOM is calculated.

11. Geographical insensitivity. Because it is desired for SMRs with TES to be deployed globally with as little re-design as possible, geographical needs are considered. A FOM of 0 is given to a geography-specific technology, and a FOM of 1 is given to a TES without those requirements.

12. Environmental concerns are important and can appear in multiple stages of TES use: construction, direct use, and during deconstruction. A FOM of 1 is given to a technology that does not have any significant environmental concerns, and a FOM of 0 was given to a technology with environmental concerns.

Minimum turndown or thermal support requirements. A system that needs heat tracing or a constant supply of heat is given a FOM of 0 . A system that faces no concerns if heat is not constantly supplied is given a FOM of 1.

\subsection{Results and Analysis}

This section details how each technology discussed in Chapter 4 evaluates, based on the FOM, discussed in the previous section. The section will begin with composite score rankings in Table 9, and then detail how each technology's score was developed. The eleven FOM categories that have numerical rankings are reported separately from capital cost and lifetime values. Finally, a qualitative and quantitative section comparing the technologies with the highest composite FOM scores will complete this section.

Table 9 presents the overall results of this investigation. Two-tank sensible heat systems have the highest FOM value. Solid media and steam accumulators also have FOM values very close to two-tank sensible heat systems. These technologies will be included in the pared down list later in this section. The maximum FOM score is shown in Table 10.

\begin{tabular}{|c||r||c|c|}
\hline \multicolumn{1}{|c||}{ Technology } & & Technology & FOM \\
\hline \hline Borehole UTES & 14 & Aquifer UTES & 14 \\
\hline \hline Hot and Cold Water & 18 & Solid Media (Concrete) & 20 \\
\hline \hline Firebrick & 14 & Geothermal & 11 \\
\hline \hline Thermochemicals & 12 & PCMs & 16 \\
\hline \hline Molten Salt - Thermocline & 17 & Thermal Oil - Thermocline & 17 \\
\hline \hline Molten Salt - Two-Tank & 23 & Thermal Oil - Two-Tank & 23 \\
\hline Steam Accumulators & 22 & AVERAGE: & 17.0 \\
\hline
\end{tabular}

Table 9. Evaluation of Thermal Energy Storage Options. 


\begin{tabular}{cccc}
\hline Category & FOM & Category & FOM \\
\hline Technology Readiness Level & 9 & $\begin{array}{c}\text { Charging Compatibility with } \\
\text { LWRs }\end{array}$ & 2 \\
\hline Discharge High Quality Heat & 2 & $\begin{array}{c}\text { Ancillary Electrical Grid } \\
\text { Services Market Potential }\end{array}$ & 2 \\
\hline Energy Capacity & 2 & Ramp Time & 2 \\
\hline Cycle Frequency & 2 & Realignment Requirements & 2 \\
\hline Geographic Insensitivity & 1 & Environmental Concerns & 1 \\
\hline $\begin{array}{c}\text { Minimum Turndown } \\
\text { Requirements }\end{array}$ & 1 & TOTAL SCORE: & 26 \\
\hline
\end{tabular}

Table 10. Maximum FOM score for each category.

\subsubsection{Borehole and Aquifer UTES}

Both forms of underground thermal energy storage scored an overall 15 in the FOM evaluation, and due to their similarities, they can be addressed together. Both forms of energy storage are used for seasonal storage, and their active and large system use indicates that they are fully developed technology with a TRL of 9 [44]. Because the pressure in UTES is very near atmospheric, the water stored in these systems has a standard boiling point. While it may be directly possible to use very high temperature and pressure steam for charging, current systems charge with liquid atmospheric water [45][44]. Therefore, a FOM of 0 is assigned for charging compatibility. For the same reason, the discharge FOM is 0 as well. Liquid water without elevation change cannot directly generate electricity, so a FOM of 0 is assigned for ancillary services potential. The aquifer and borehole systems can be quite large, and thus there is no limitation on the energy capacity of one of these systems, resulting in an FOM of 2 for energy capacity [44]. The ramp time is not estimated to be very high. The systems are designed with seasonal storage in mind, and the ability to ramp has not been a priority, thus meriting a FOM of 0 for ramp time. The seasonal cycle frequency also achieved a FOM of 0 [43]. The system locations are identified well to avoid realignment requirements, and thus a FOM of 2 is assigned in that category. Finding an appropriate underground location is necessary, so a FOM of 0 for geographic requirements is assigned [44]. Underground siting and potential groundwater impacts affect the environmental score, leading to a FOM of 0 with the large intrusions UTES creates [44]. The system should, however, be able to continue operating without constant input, giving a FOM of 1 for the minimum turndown requirements [45]. UTES FOM results are summarized in Table 11. 


\begin{tabular}{cccc}
\hline Category & FOM & Category & FOM \\
\hline Technology Readiness Level & 9 & $\begin{array}{c}\text { Charging Compatibility with } \\
\text { LWRs }\end{array}$ & 0 \\
\hline Discharge High Quality Heat & 0 & $\begin{array}{c}\text { Ancillary Electrical Grid } \\
\text { Services Market Potential }\end{array}$ & 0 \\
\hline Energy Capacity & 2 & Ramp Time & 0 \\
\hline Cycle Frequency & 0 & Realignment Requirements & 2 \\
\hline Geographic Insensitivity & 0 & Environmental Concerns & 0 \\
\hline $\begin{array}{c}\text { Minimum Turndown } \\
\text { Requirements }\end{array}$ & 1 & TOTAL SCORE: & 14 \\
\hline
\end{tabular}

Table 11. UTES FOM Scoring Table.

\subsubsection{Hot and Cold Water Storage}

Hot and cold water storage (HCWS) was evaluated to have a total FOM of 19. The large amount of experience using hot and cold water storage even in very large quantities (100's of MWh) indicates that the technology if fully developed at-scale, and thus the TRL is a 9 [86]. The systems do not take LWR steam as an input, as designs take at maximum $1100 \mathrm{kPa}$ (165 psia) steam, and typically use around $210 \mathrm{kPa}$ (30 psia) steam [87]. The low level of steam compatibility leads to a FOM of 1 for HCWS. The outgoing discharge does not have a great deal of specific energy, and the FOM for discharge is subsequently 0 . This also leads to a FOM for ancillary market potential of 0 . An application of using chilled water to cool turbines and boost output in that fashion is outside the purview of this report. Large HCWS systems are possible, and so a FOM of 2 is assigned to HCWS [86]. Discharge is accomplished via pumping systems and therefore ramp time should be short, so a FOM of 2 is assigned for ramp time. Presently, the highest cycle frequency used in HCWS systems is daily, which indicates a FOM of 1 . The demands put on HCWS is currently cyclical daily as well. Realignment requirements depend on the tank formations of the HCWS system. In stratified tanks, thermocline layers naturally degrade, creating a tank that is not stratified at all and needs correction [47]. Therefore, a FOM of 1 is assigned for realignment. Tanks can be located in anywhere, so a FOM of 1 is assigned for geographic insensitivity. Additionally, these systems are environmentally very clean, so a FOM of 1 is assigned for environmental concerns. At just $1-2 \%$ daily insulation losses, there is not a minimum turndown requirement on the system, so the FOM in this category is a 1 . Hot and cold water storage FOM evaluation values are summarized in Table 12. 


\begin{tabular}{cccc}
\hline Category & FOM & Category & FOM \\
\hline Technology Readiness Level & 9 & $\begin{array}{c}\text { Charging Compatibility with } \\
\text { LWRs }\end{array}$ & 0 \\
\hline Discharge High Quality Heat & 0 & $\begin{array}{c}\text { Ancillary Electrical Grid } \\
\text { Services Market Potential }\end{array}$ & 0 \\
\hline Energy Capacity & 2 & Ramp Time & 2 \\
\hline Cycle Frequency & 2 & Realignment Requirements & 1 \\
\hline Geographic Insensitivity & 1 & Environmental Concerns & 1 \\
\hline $\begin{array}{c}\text { Minimum Turndown } \\
\text { Requirements }\end{array}$ & 1 & TOTAL SCORE: & 19 \\
\hline
\end{tabular}

Table 12. Hot and Cold Water FOM Scoring Table.

\subsubsection{Concrete}

Concrete thermal energy storage was evaluated to have a total FOM of 20. Current concrete storage is described well by TRL level 5: "a laboratory scale, similar system validation in relevant environment" [85]. Experiments have shown concrete should be able to charge using LWR steam directly without need to depressurize or preliminarily cool the steam, evaluating a FOM of 2 for this feature [57] [58]. Unfortunately, the power reduction during discharge is present, reducing the discharge quality heat FOM to a value of 1 [57] [58]. Due to the relatively fast response of the system, it is expected that concrete storage can be used in the electrical reserves market, and receives a FOM of 1 in this category. The energy capacity FOM is a 2, given the simple and bydesign modularity of concrete TES modules [56] [89]. Modules should be able to ramp from zero power to maximum output very quickly, and thus a FOM of 2 is assigned for ramp time [56]. The cycle should not have any limitations, and studies already have been conducted with bi-daily cycles, hence the cycle frequency FOM is evaluated at 2 [57]. The system should not need realignment as long as cycles are sufficiently long, and so a FOM of 2 for realignment requirements is assigned. The storage is cast on-site, so there are no geographic requirements, and concrete is not environmentally taxing, so FOMs of 1 are assigned in both categories. Finally, the system should not have need for minimum heat transfer fluid (HTF) flow as long as the thermal expansion coefficients are well designed between the tubing and the material, so a FOM of 1 is assigned for minimum turndown. FOM evaluation of concrete storage is summarized in Table 13. 


\begin{tabular}{cccc}
\hline Category & FOM & Category & FOM \\
\hline Technology Readiness Level & 5 & $\begin{array}{c}\text { Charging Compatibility with } \\
\text { LWRs }\end{array}$ & 2 \\
\hline Discharge High Quality Heat & 1 & $\begin{array}{c}\text { Ancillary Electrical Grid } \\
\text { Services Market Potential }\end{array}$ & 1 \\
\hline Energy Capacity & 2 & Ramp Time & 2 \\
\hline Cycle Frequency & 2 & Realignment Requirements & 2 \\
\hline Geographic Insensitivity & 1 & Environmental Concerns & 1 \\
\hline $\begin{array}{c}\text { Minimum Turndown } \\
\text { Requirements }\end{array}$ & 1 & TOTAL SCORE: & 20 \\
\hline
\end{tabular}

Table 13. Concrete FOM Scoring Table.

\subsubsection{Firebrick}

Firebrick thermal energy storage was evaluated to have a total FOM of 14 . Reviewing the current status of firebrick use, the TRL was evaluated as a 3 due to a lack of relatable technology relative to thermal energy storage. The goal of firebrick TES is to use resistance heaters to heat the brick and then to use a. sweep gas to extract the heat in order to power a gas turbine [53] [54] [55]. The local house-heating units that the technology has some basis in are only used up to $850^{\circ} \mathrm{C}$, which is the low temperature in the proposed firebrick storage range [55]. Resistance heaters are typically operated to $1000-1200^{\circ} \mathrm{C}$, leading to some large technical challenges in joining the technologies in such a way that would merit a higher TRL [53]. The use of electrical heaters to generate the heat stored in firebrick leads to a charging compatibility FOM value of 0 , as the connection point is electrical rather than thermal, reducing efficiency from a nuclear plant [54]. Despite the drop off in output temperature during a system discharge (Figure 17), given the theoretically very high temperatures that this system would be capable of, a FOM of 2 for high quality discharge heat was assigned [53]. The system would be able to participate in the nonspinning reserves market, which is smaller than the spinning reserves market, if needed as the discharge gas would necessitate a separate Brayton cycle from the nuclear Rankine cycle [16]. The energy capacity is theoretically as large as needed, and thus a FOM of 2 is assigned in this area for firebrick [54]. The system should also be able to ramp quickly, constrained by the time constant of the fan to move the discharge air [55]. Cycle frequency of FIRES would be determined by the size of the individual bricks and the geometry of the system. Current studies have shown discharge times that would force a full cycle to take about a day, indicating a FOM of 1 assigned for cycle frequency [53]. A FOM of 1 was also assigned for realignment requirements, due to a lack of clarity on how the temperature profiles in different discharge paths will lead to different recharge characteristics, and how that would be adjudicated. Firebrick can be easily set and shipped with common and environmentally friendly materials, leading to a FOM of 1 for both geographic insensitivity and environmental concerns [53]. Finally, the reported 5\% heat loss per day merits a minimum turndown requirement FOM of 0 [53]. Table 14 presents the FOM evaluation of firebrick energy storage. 


\begin{tabular}{cccc}
\hline Category & FOM & Category & FOM \\
\hline Technology Readiness Level & 3 & $\begin{array}{c}\text { Charging Compatibility with } \\
\text { LWRs }\end{array}$ & 0 \\
\hline Discharge High Quality Heat & 2 & $\begin{array}{c}\text { Ancillary Electrical Grid } \\
\text { Services Market Potential }\end{array}$ & 1 \\
\hline Energy Capacity & 2 & Ramp Time & 2 \\
\hline Cycle Frequency & 1 & Realignment Requirements & 1 \\
\hline Geo & 1 & Environmental Concerns & 1 \\
\hline graphic Insensitivity & & TOTAL SCORE: & 14 \\
\hline $\begin{array}{c}\text { Minimum Turndown } \\
\text { Requirements }\end{array}$ & 0 & & \\
\hline
\end{tabular}

Table 14. Firebrick FOM Scoring Table.

\subsubsection{Geothermal}

Geothermal energy storage was evaluated and assigned a total overall FOM score of 11. Geothermal TES was evaluated as a TRL of 2, as current research can be well described as "practical applications can be invented. Examples are still limited to analytic studies" [42]. At 1200 meters, the pressure is sufficient to maintain liquid water at $250^{\circ} \mathrm{C}$, which has a saturation pressure around 3.96MPa (575 psia), below the steam pressure generated in LWR systems [42]. Therefore, a FOM of 1 is assigned to the charging compatibility of this system. There should be no limits on the ability of this kind of TES to discharge its stored heat at temperatures above $175^{\circ} \mathrm{C}\left(350^{\circ} \mathrm{F}\right)$, so a discharge quality heat FOM of 2 is assigned. Without information about the response time, a grid services market potential FOM of 0 is assigned. The energy capacity would be site limited, but there is no immediate technological restriction, so the capacity is assigned a FOM of 2 [51]. As far as ramping time, there is insufficient information to indicate the ramp capabilities of such a system would be less than ten minutes, so the FOM for ramp time is assigned a 1. Research thus far has only been for daily charging cycles, but there is no indication that the frequency would be limited in this system, so a FOM of 2 is assigned for frequency. Thermal charging thus far is assumed, and thus some realignment may be required on the system and a FOM of 1 is assigned for this category [51]. Due to the depth of the reservoir used, there are geographic requirements as well as environmental concerns associated with storage pressure, and thus FOM values of 0 are assigned for both categories [51]. Finally, a FOM of 0 is assigned to the turndown requirements as a precaution in case there are material heating and cooling concerns due to the length of materials required in this system. FOM evaluation of geothermal energy storage is summarized in Table 15. 


\begin{tabular}{cccc}
\hline Category & FOM & Category & FOM \\
\hline Technology Readiness Level & 2 & $\begin{array}{c}\text { Charging Compatibility with } \\
\text { LWRs }\end{array}$ & 1 \\
\hline Discharge High Quality Heat & 2 & $\begin{array}{c}\text { Ancillary Electrical Grid } \\
\text { Services Market Potential }\end{array}$ & 0 \\
\hline Energy Capacity & 2 & Ramp Time & 1 \\
\hline Cycle Frequency & 2 & Realignment Requirements & 1 \\
\hline Geographic Insensitivity & 0 & Environmental Concerns & 0 \\
\hline $\begin{array}{c}\text { Minimum Turndown } \\
\text { Requirements }\end{array}$ & 0 & TOTAL SCORE: & 11 \\
\hline
\end{tabular}

Table 15. Geothermal energy storage FOM Scoring Table.

\subsubsection{Thermochemicals}

Thermochemical energy storage was evaluated and received an overall FOM score of 14 . With so many potential thermochemical reactant options, it is difficult to give a single evaluation of thermochemical technology. An evaluation of TRL shows that the most advanced thermochemical studies are still in small-scale component laboratory stages, which matches a TRL of 4 [66] [67] [69] [70] [71]. Due to the uncertainty involved in this process, it is difficult to know that there will be a thermochemical reaction that will match with LWR temperatures and pressures, and so charging compatibility FOM is evaluated as 1 . The discharge FOM would ideally be a 2 in a system that uses flowing reactants and products with adequate cooling. The design of such a system is difficult, and the reaction rate (and thus power) can easily degrade in these systems [66]. Without additional knowledge of precise system setups, it is unknown if ramp rates will allow for any ancillary market participation, and FOMs of 0 are assigned in each category. This is influenced by the current studies focusing on seasonal storage, and lack of detail in other research [67] [70]. The energy capacity should be very high, aided by the high energy density of thermochemicals, and so making a high capacity system should be possible. A FOM of 2 is assigned in this category. The cycle frequency could theoretically be faster in different reactor designs, but currently the full charge/discharge cycle takes more than a day, leading to a FOM of 0 [66]. Even with such long cycles, some realignment may be necessary as there are reversibility concerns with thermochemicals, leading to a FOM of 1 for this category. The materials should not be geographically sensitive, and should be picked to be environmentally friendly, leading to 1's in both of these FOM sections. Finally, there should be few minimum turndown requirements in these systems as the products and reactants are kept in separate locations, but the reactions may require some heat tracing in order to move the operational temperature to an ideal range. Thus, a FOM of 0 is assigned for turndown requirements. Table 16 summarizes the FOM evaluation of thermochemical storage. 


\begin{tabular}{cccc}
\hline Category & FOM & Category & FOM \\
\hline Technology Readiness Level & 4 & $\begin{array}{c}\text { Charging Compatibility with } \\
\text { LWRs }\end{array}$ & 1 \\
\hline Discharge High Quality Heat & 2 & $\begin{array}{c}\text { Ancillary Electrical Grid } \\
\text { Services Market Potential }\end{array}$ & 0 \\
\hline Energy Capacity & 2 & Ramp Time & 0 \\
\hline Cycle Frequency & 0 & Realignment Requirements & 1 \\
\hline Geographic Insensitivity & 1 & Environmental Concerns & 1 \\
\hline $\begin{array}{c}\text { Minimum Turndown } \\
\text { Requirements }\end{array}$ & 0 & TOTAL SCORE: & 12 \\
\hline
\end{tabular}

Table 16. Thermochemicals FOM Scoring Table.

\subsubsection{Phase Change Materials}

Phase change material storage was evaluated and received an overall FOM score of 16. While PCMs are widely regarded as highly efficient thermal storage methods, the lack of definitive materials and systems leads to many challenges. Due to the large number of various single-point studies listed across, the TRL is evaluated at 4, where some pieces of future phase change systems are constructed [59]-[65]. It should be noted that for the sake of this study, ice thermal energy storage is neglected due to its sole use as cooling. Some PCMs, such as $\mathrm{LiNO}_{3}$ for example, would be theoretically capable of charging using LWR steam temperatures, as it melts at $250^{\circ} \mathrm{C}$, but as the structure of the heat exchangers is highly uncertain and thus pressure considerations cannot even be projected, only a FOM of 1 is assigned with respect to charging compatibility [59] [64]. Without information to the contrary, a FOM of 2 is assigned to whether PCMs can discharge high quality heat, as it should be a constant temperature, and thus constant power, process. Initiating discharge would only depend on the movement of heat by the HTF in the system, and thus the system should respond in a short time frame, allowing for participation in the reserves market and an ancillary market potential FOM of 1 . Energy capacity should not be an issue as the energy density in PCMs should be very high, and so a FOM of 2 for capacity is assigned [60] [64]. Ramp time for PCMs to full power is conservatively estimated as being between 10 minutes to an hour, for a FOM value of 1 [65]. This is affected in part due to the fact that a solid-liquid PCM may exhibit phenomena that prohibit a consistent high heat discharge from the system [64]. FOM scores for cycle frequency and realignment were both 1, as the either slow or complicated mechanisms by which the system would completely change phase would likely drive to longer cycles in the system as well as potentially require some system mixing and realignment between cycles [61] [63]. The system does not need any specific geography, so a 1 is assigned for that FOM category. While a 1 was assigned for environmental concerns, it would be highly material dependent and could be a 0 depending on what is selected. PCMs by nature must be designed to operate while in solid or liquid phase, and so there is no danger to the system if the system overcools, and so the lack of minimum turndown makes the PCMs have a 1 for that FOM category. Table 17 presents the FOM results for PCMs. 


\begin{tabular}{cccc}
\hline Category & FOM & Category & FOM \\
\hline Technology Readiness Level & 4 & $\begin{array}{c}\text { Charging Compatibility with } \\
\text { LWRs }\end{array}$ & 1 \\
\hline Discharge High Quality Heat & 2 & $\begin{array}{c}\text { Ancillary Electrical Grid } \\
\text { Services Market Potential }\end{array}$ & 1 \\
\hline Energy Capacity & 2 & Ramp Time & 1 \\
\hline Cycle Frequency & 1 & Realignment Requirements & 1 \\
\hline Geographic Insensitivity & 1 & Environmental Concerns & 1 \\
\hline $\begin{array}{c}\text { Minimum Turndown } \\
\text { Requirements }\end{array}$ & 1 & TOTAL SCORE: & 16 \\
\hline
\end{tabular}

Table 17. PCMs FOM Scoring Table.

\subsubsection{Molten Salt and Thermal Oil Thermocline}

Sensible heat storage using a thermocline with either molten salt or a thermal oil was evaluated, receiving a total FOM of 17. Experiments with molten salt thermoclines are at advanced stages, and stratified water storage is already accomplished in this way [73] [76]. Therefore, a TRL of 5 is assigned to thermocline technology. The charging of a thermocline uses an intermediate heat exchanger, and molten salt and thermal oils are selected due to their temperature compatibilities with SMR generated steam, so a FOM of 2 was assigned for this category. Thermoclines suffer from differences in discharge capability and charging capability [74] [75]. Additionally, before the thermocline is completely discharged, the temperature and heat output of a thermocline decreases, and so a FOM of 1 was assigned for discharging quality heat [74]. The response time of a thermocline should be sufficient for reserves market participation, thus meriting a FOM of 1 for ancillary grid potential [76]. The energy capacity of thermoclines is solely dependent on vessel size, but there is no mention of restrictive limits, so a FOM of 2 was assigned for capacity [75]. The ramp time should be short, as the system discharges via pumped fluid, and so a FOM of 2 is assigned for ramp time as well. An ideal thermocline should be able to cycle as frequently as necessary, a FOM of 2 is assigned for this category. However, thermocline degradation causes significant issues in these systems and must be addressed frequently, forcing a FOM of 0 to be assigned for realignment requirements [76]. The system is a tank built on site, and there are no geographic needs for this system (FOM of 1 assigned). Molten salts exhibit fewer environmental concerns, earning a FOM of 1 for this section but due to the high liquidus temperature, heat tracing forces the minimum turndown FOM to also be a 1. Thermal oils have more significant environmental concerns, both with leakage and deposition after use, and so a FOM of 0 is assigned in this category, but their more optimal temperature operating range does not force any additional turndown requirements [82]. Table 18 presents the FOM results for thermocline sensible heat systems. 


\begin{tabular}{cccc}
\hline Category & FOM & Category & FOM \\
\hline Technology Readiness Level & 5 & $\begin{array}{c}\text { Charging Compatibility with } \\
\text { LWRs }\end{array}$ & 2 \\
\hline Discharge High Quality Heat & 1 & $\begin{array}{c}\text { Ancillary Electrical Grid } \\
\text { Services Market Potential }\end{array}$ & 1 \\
\hline Energy Capacity & 2 & Ramp Time & 2 \\
\hline Cycle Frequency & 2 & Realignment Requirements & 0 \\
\hline $\begin{array}{c}\text { Geographic Insensitivity } \\
\text { Minimum Turndown } \\
\text { Requirements }\end{array}$ & 1 & Environmental Concerns & $1 / 0$ \\
\hline
\end{tabular}

Table 18. Thermocline FOM Scoring Table.

\subsubsection{Two-Tank Molten Salt and Thermal Oil}

Two-tank sensible heat systems using molten salt or thermal oil scored identically in the FOM evaluation with a total of 23 . Both technologies are in use in some capacity in solar power plant systems, and so the TRL is a 9 for compatibility with nuclear generated steam systems. Due to the use of an intermediate heat exchanger, two-tank systems should easily be able to use LWR steam and temperatures at full mass flow rates, achieving a FOM of 2 for this area [73]. Likewise, the ondemand pumping of heating fluid during discharge allows for the system to completely discharge high quality heat during this operational phase, and so a FOM of 2 for this category is assigned. The system should be able to ramp quickly enough for the TES to be considered an ancillary grid reserve, so a FOM of 1 for this category is assigned. $400 \mathrm{MWh}+$ two-tank systems are already operating, so a FOM of 2 for capacity is assigned [72]. The ramp time should be less than 10 minutes for this system, so another FOM of 2 is assigned in this area. The system should be able to cycle as frequently as necessary with few realignment requirements, gaining FOMs of 2 and 1 for these two categories [73]. Two-tank systems are geographically insensitive as they are above ground, so a 1 is assigned. The split between environmental concerns and minimum turndown requirements is identical for 2-tank systems as thermoclines for molten salts and thermal oils, as each split a 0 and 1 in these two FOM categories. The oil has more environmental concern while the molten salts must be kept from freezing [82]. Table 19 presents the FOM values for two-tank sensible heat systems using molten salts or thermal oils. 


\begin{tabular}{cccc}
\hline Category & FOM & Category & FOM \\
\hline $\begin{array}{c}\text { Technology Readiness } \\
\text { Level }\end{array}$ & 9 & $\begin{array}{c}\text { Charging Compatibility with } \\
\text { LWRs }\end{array}$ & 2 \\
\hline $\begin{array}{c}\text { Discharge High Quality } \\
\text { Heat }\end{array}$ & 2 & $\begin{array}{c}\text { Ancillary Electrical Grid } \\
\text { Services Market Potential }\end{array}$ & 1 \\
\hline Energy Capacity & 2 & Ramp Time & 2 \\
\hline Cycle Frequency & 2 & Realignment Requirements & 1 \\
\hline $\begin{array}{c}\text { Geographic Insensitivity } \\
\text { Minimum Turndown } \\
\text { Requirements }\end{array}$ & 1 & Environmental Concerns & $1 / 0$ \\
\hline
\end{tabular}

Table 19. Two-Tank Molten Salt/Thermal Oil FOM Scoring Table.

\subsubsection{Steam Accumulators}

Steam accumulator storage was evaluated and assigned a total FOM score of 22. The technology has been in use for an extended period of time, linked to boilers of various sizes across different industries. Thus, the technology is evaluated as fully developed and at a TRL of 9 [54]. The experience using high temperature steam input in steam accumulators shows that integration with LWR steam should be straightforward, giving a FOM of 2 in this category. Accumulators in general are of the Ruths type and have sliding pressure, meaning that the discharge pressure and thus temperature would not be constant, and thus the high quality heat FOM was assigned a 1 [84]. The inconsistent discharge could be disadvantageous for certain processes. Steam accumulators working on grid-regulated release valves are likely the closest mechanisms to batteries and flywheels to frequency regulation, but their response time is still not instantaneous [83]. That being said, the response time should be fast enough to operate in the reserves market, and therefore a FOM of 1 is assigned for ancillary grid market potential [83]. Energy capacity is a significant concern with steam accumulators. Most steam accumulators are not built very large due to mechanical stresses of maintaining high-pressure steam. Internal volume of steam accumulators is around 10,000 gallons, or about $38 \mathrm{~m}^{3}$. At an energy density between $20 \mathrm{kWh} / \mathrm{m}^{3}$ and $30 \mathrm{kWh} / \mathrm{m}^{3}$, this leads to around $0.75 \mathrm{MWh} / \mathrm{unit}$ to $1.1 \mathrm{MWh} / \mathrm{unit}$ [84]. Therefore, due to the significant amount of non-standard arranging and combining that would be required to use accumulators in a NuScale TES system, a FOM of 1 was assigned for energy capacity. Steam accumulators can begin steam discharge very quickly by opening of the steam release valve, and thus ramp time should be no issue, assigning a FOM of 2 [83]. The system mechanics are straightforward, and there is effectively no concern of losing ability to cycle on demand (that is typically how accumulators are used), and so cyclability is evaluated at 2 [88]. The realignment requirement is only evaluated at a FOM of 1 due to the potential need to inject cooled water periodically to ensure proper pressure is maintained in the accumulator. Accumulators score perfectly on the final items of geographic insensitivity, environmental concerns, and minimum turndown rate as there is no concern in these categories. Accumulators are shipped on trucks for installation and thus can be located anywhere, are made of standard steel materials, and do not require trace heating to maintain pressure during down time. Table 20 presents the FOM values of steam accumulators. 


\begin{tabular}{cccc}
\hline Category & FOM & Category & FOM \\
\hline Technology Readiness Level & 9 & $\begin{array}{c}\text { Charging Compatibility with } \\
\text { LWRs }\end{array}$ & 2 \\
\hline Discharge High Quality Heat & 1 & $\begin{array}{c}\text { Ancillary Electrical Grid } \\
\text { Services Market Potential }\end{array}$ & 1 \\
\hline Energy Capacity & 1 & Ramp Time & 2 \\
\hline Cycle Frequency & 2 & Realignment Requirements & 1 \\
\hline Geographic Insensitivity & 1 & Environmental Concerns & 1 \\
\hline $\begin{array}{c}\text { Minimum Turndown } \\
\text { Requirements }\end{array}$ & 1 & TOTAL SCORE: & 22 \\
\hline
\end{tabular}

Table 20. Steam Accumulators FOM Scoring Table.

In the results section, each technology has had an item-by-item investigation of the PIRT criteria and evaluated based on the system as described in the decision tool development section. The complete results are summarized in Table 21. A two-tank system is evaluated as the option with the highest FOM total of all TES technologies investigated. The next section will include additional factors to compare between the best performers - concrete, two-tank systems, and steam accumulators - from this quantitative comparison of the technologies. 


\begin{tabular}{|c|c|c|c|c|c|c|c|c|c|c|c|c|}
\hline Tech & TRL & Charge & Discharge & $\begin{array}{l}\text { Ancillary } \\
\text { Market }\end{array}$ & Capacity & Ramp & $\begin{array}{c}\text { Cycle } \\
\text { Frequency }\end{array}$ & Realignment & $\begin{array}{c}\text { Geography } \\
\text { Reqs. }\end{array}$ & $\begin{array}{c}\text { Environment } \\
\text { Impacts }\end{array}$ & $\begin{array}{l}\text { Turndown } \\
\text { Reqs. }\end{array}$ & Total \\
\hline UTES & 9 & 0 & 0 & 0 & 2 & 0 & 0 & 2 & 0 & 0 & 1 & 14 \\
\hline Hot/Cold Water & 9 & 0 & 0 & 0 & 2 & 2 & 2 & 1 & 1 & 1 & 1 & 19 \\
\hline Concrete & 5 & 2 & 2 & 1 & 2 & 2 & 2 & 1 & 1 & 1 & 1 & 20 \\
\hline Firebrick & 3 & 0 & 2 & 1 & 2 & 2 & 1 & 1 & 1 & 1 & 0 & 14 \\
\hline Geothermal & 2 & 1 & 2 & 0 & 2 & 1 & 2 & 1 & 0 & 0 & 0 & 11 \\
\hline $\begin{array}{l}\text { Therm. } \\
\text { Chemicals }\end{array}$ & 4 & 1 & 2 & 0 & 2 & 0 & 0 & 1 & 1 & 1 & 0 & 12 \\
\hline $\begin{array}{c}\text { Phase Change } \\
\text { Materials }\end{array}$ & 4 & 1 & 2 & 1 & 2 & 1 & 1 & 1 & 1 & 1 & 1 & 16 \\
\hline $\begin{array}{c}\text { Thermocline } \\
\text { Molten } \\
\text { Salt/Thermal Oil }\end{array}$ & 5 & 1 & 2 & 1 & 2 & 2 & 2 & 0 & 1 & $1 / 0$ & $0 / 1$ & 17 \\
\hline $\begin{array}{c}\text { Two-Tank } \\
\text { Molten } \\
\text { Salt/Thermal Oil }\end{array}$ & 9 & 2 & 2 & 1 & 2 & 2 & 2 & 1 & 1 & $1 / 0$ & $0 / 1$ & 23 \\
\hline $\begin{array}{c}\text { Steam } \\
\text { Accumulators }\end{array}$ & 9 & 2 & 1 & 1 & 1 & 2 & 2 & 1 & 1 & 1 & 1 & 22 \\
\hline
\end{tabular}

Table 21. Complete FOM table for all TES technologies. 


\subsubsection{Qualitative and Comprehensive Analysis}

Two-tank TES systems, steam accumulators, and concrete were the only three technologies to achieve a FOM score of at least 20 and are the technologies that will continue to be considered. From this point forward, molten salt TES and thermal oil TES are considered as separate from each other and exclusively refer to a two-tank configuration. To continue making evaluations of these technologies, a project cost must be estimated. The upper bound of the cost estimation may need to be expanded to accommodate the lower $\Delta \mathrm{T}$ that will be inherent in nuclear integrated systems. This is particularly true when compared with concentrated solar facilities. The power densities of other systems are expected to be higher than what is available to LWRs. Table 22 compares the capital costs per unit of energy and power, round trip efficiencies, and energy densities of these technologies.

\begin{tabular}{ccccc}
\hline Technology & $\begin{array}{c}\text { Energy Cost } \\
\mathbf{( \$ / k W h e )}\end{array}$ & $\begin{array}{c}\text { Power Cost } \\
\mathbf{( \$ / k W e )}\end{array}$ & $\begin{array}{c}\text { Est. Round Trip } \\
\text { Efficiency } \mathbf{( \% )}\end{array}$ & $\begin{array}{c}\text { Energy } \\
\text { Density } \\
\left(\mathbf{k w h e} / \mathbf{m}^{\mathbf{3}} \mathbf{)}\right.\end{array}$ \\
\hline Concrete & $25-150[4][47]$ & $500-3000[4]$ & $\begin{array}{c}50 \%-92 \%[4] \\
{[89]}\end{array}$ & $\begin{array}{c}22-82.5[4] \\
{[89]}\end{array}$ \\
\hline Molten Salt & $5-30[4]$ & $400-2100[4]$ & $40-93 \%[4]$ & $170-420[4]$ \\
\hline Thermal Oil & $8-16[4][90]$ & $600-1400[4][90]$ & $40-93 \%$ & $100-300[73]$ \\
\hline $\begin{array}{c}\text { Steam } \\
\text { Accumulators }\end{array}$ & $130-400$ (Estimate) & 1200 (Estimate) & $70-90 \%[88]$ & $20-30[84]$ \\
\hline
\end{tabular}

Table 22. Energy and Power Cost Estimates for Potential TES technologies.

Concrete costs are estimated from multiple sources [4] [56] [89]. The cost would ideally be as low as $\$ 25 / \mathrm{kWhe}$ for energy capacity; however, this does not take into account the lower temperature changes available from LWR systems. Costs will also depend on the local fabrication costs for these systems. All these sources agree that the lowest realistic cost for concrete storage will be around $\$ 25 / \mathrm{kWhe}$. However, due to the low power density in concrete, the minimum power cost is around a factor of 20 higher. A project cost estimate can be found as the greater of:

$$
\frac{\$}{k W h e} * 400 M W h t * 0.35^{9} \quad \text { or } \quad \frac{\$}{k W e} * 80 M W t * 0.35
$$

The cost estimate of using concrete storage, using the low and high ends of these estimates, is around \$14$\$ 84$ million. Without further deployment of concrete TES, it is too early to tell which end of the cost range is more accurate for JUMP.

Molten salt TES costs are a bit more available and based on existing experiences. Around half of the cost of molten salt storage systems is in the salt itself [90]. Prices quoted in literature exclusively have to do with using relatively cheap salts (solar salt, HITEC) under large temperature deltas. Solar salt and HITEC have liquidus temperatures of $220^{\circ} \mathrm{C}$ and $142^{\circ} \mathrm{C}$ respectively, leading to maximum JUMP temperature

${ }^{9}$ An assumed thermal to electric conversion efficiency 
storages (using saturation temperature at NuScale secondary steam pressure) of $22^{\circ} \mathrm{C}$ and $99^{\circ} \mathrm{C}$, much lower than the often used $295^{\circ} \mathrm{C}$ temperature changes found in literature. Salt choice will have a significant impact on the cost of the system, and the percentage of cost of salt may grow to more than $50 \%$ of the cost. Even so, minimum costs for molten salt are around $\$ 5 / \mathrm{kWhe}$, and some basic estimations see nuclear cost at around $\$ 13 / \mathrm{kWhe}$ [3]. The upper limit on salt is raised from literature by a factor of 3 to account for the smaller temperature changes that JUMP will be able to use. The upper power cost estimate is similarly altered. The cost estimate for molten salts is then between $\$ 11-\$ 56$ million.

Thermal oils are noted as being around $40-45 \%$ more expensive than molten salt for concentrated solar power applications [90]. Thermal oil costs more per unit of mass-energy in storage and the maximum temperatures of thermal oils are lower than salts. In a nuclear system, however, the maximum thermal oil temperature is no longer the limiting factor, and the lower available temperatures lead to larger temperature changes available in thermal oil systems. By uprating the cost of thermal oil directly from the molten salt costs, an estimate of about $\$ 8 / \mathrm{kWhe}$ to $\$ 16 / \mathrm{kWhe}$ is reached. The minimum power cost is expected to be high as well, around $\$ 600 / \mathrm{kW}$, with a maximum of $\$ 1400 / \mathrm{kW}$. The total capital cost of this system then would be between $\$ 17-\$ 39$ million.

Finally, steam accumulators are not typically used in a large-scale manner, and the cost of steam accumulators is highly dependent on pressures, locations, capacity, and discharge rates. The cost of steam accumulators is generally regarded as inhibitive and is typically only beneficial if the presence of an accumulator can reduce the size of a corresponding boiler and its fuel consumption [54]. A low-end capital cost estimate for accumulators is around $\$ 15 /$ gallon. With accumulator energy density is generally around 20-30 kWht $/ \mathrm{m}^{3}$, this leads to a range of $\$ 53-\$ 80$ million as the low-end estimate for a 400MWht system [84]. The requirements for power would actually be even higher, as it could take around 6,200,000 gallons to meet power requirements, and the price per unit power is estimated at $\$ 1200 / \mathrm{kWe}$ [88]. Low-end and high-end project costs, along with cost uncertainties are presented in Table 23.

\begin{tabular}{|c|c|c|c|}
\hline Technology & $\begin{array}{l}\text { Low-End Project } \\
\text { Cost (\$ million) }\end{array}$ & $\begin{array}{l}\text { High-End Project } \\
\text { Cost (\$ million) }\end{array}$ & Biggest Uncertainty \\
\hline Concrete & 14 & 84 & Cost per unit power \\
\hline Molten Salt & 11 & 56 & $\begin{array}{c}\text { Impact of low } \Delta \mathrm{T} \text {, new } \\
\text { salt selection }\end{array}$ \\
\hline Thermal Oil & 17 & 39 & Specific oil pricing \\
\hline Steam Accumulators & 53 & $95+$ & $\begin{array}{l}\text { Cost of steam } \\
\text { accumulator unit, units } \\
\text { needed to meet power } \\
\text { requirements }\end{array}$ \\
\hline
\end{tabular}

Table 23. TES project capital cost estimations for JUMP.

Overall, steam accumulators are significantly more expensive than concrete, molten salt, or thermal oil storage for nuclear plants. This expense prohibits their use. Concrete has the highest of the high-end project cost estimations due to uncertainties in the amount of power that concrete can provide during discharge. Molten salt is potentially the lowest cost TES option at approximately $\$ 11$ million, but how well prior molten salt estimations will hold up when nuclear temperatures are considered has not yet been investigated, and this uncertainty leads to the increased high-end cost estimation. Thermal oil storage, noted in molten salt research as being relatively expensive, has the smallest potential capital cost range due to its simpler integration with LWR temperatures. 
Project costs are one of the final items needed to fully compare the separate technologies for TES deployment. The other FOM item that has not yet been discussed is the technology lifetime. The expected lifetime for concrete systems is around 50 years if the temperature is kept below $400^{\circ} \mathrm{C}$. Molten salt systems do not have a listed lifetime and should last indefinitely with good material selection [4]. Thermal oil lifetime depends on the amount of thermal cycling and how closely the system is operated to the oil boiling temperature. With proper tank buffering and maintaining temperatures $100^{\circ} \mathrm{C}$ below boiling point, oils should last at least 30 years. Finally, steam accumulators are very robust machines whose lifetime depends on the purity of the water being used. As it is currently proposed to use the nuclear systems water supply, which goes through extensive chemical cleaning, accumulator lifetime is also assumed to be sufficient. Technology lifetime is considered a tie for all of these technologies.

One goal of the TES RD\&D in the JUMP module is to demonstrate as much flexibility for nuclear heat applications as possible. Power peaking and high temperature steam electrolysis are projects that are intended to be demonstrated using JUMP, and other technologies may follow in the future. Power peaking requires high quality heat discharge, with the highest pressures possible, in order to either supplement an over-sized turbine or to power a separate turbine. HTSE does not have steam pressure requirements, but higher discharge temperatures would lead to increases in system efficiency by reducing the amount of required electrical topping heat. Of the thermal storage technologies still considered, only molten salt and thermal oils securely provide high-temperature and high-pressure heat in a technology that is highly developed. Both technologies would operate via a tertiary storage loop connected to the nuclear power conversion system via an intermediate heat exchanger, as depicted in Figure 31. This indirect connection is also considered advantageous for the RD\&D at JUMP due to the thermal buffering between the first-of-akind nuclear interconnection with storage and the storage discharge mechanisms. It should also lead to simpler mechanisms for changing the auxiliary energy conversion process (power peaking, HTSE, chemical processing, etc.), as the buffer layer should isolate the processes during construction and testing. 


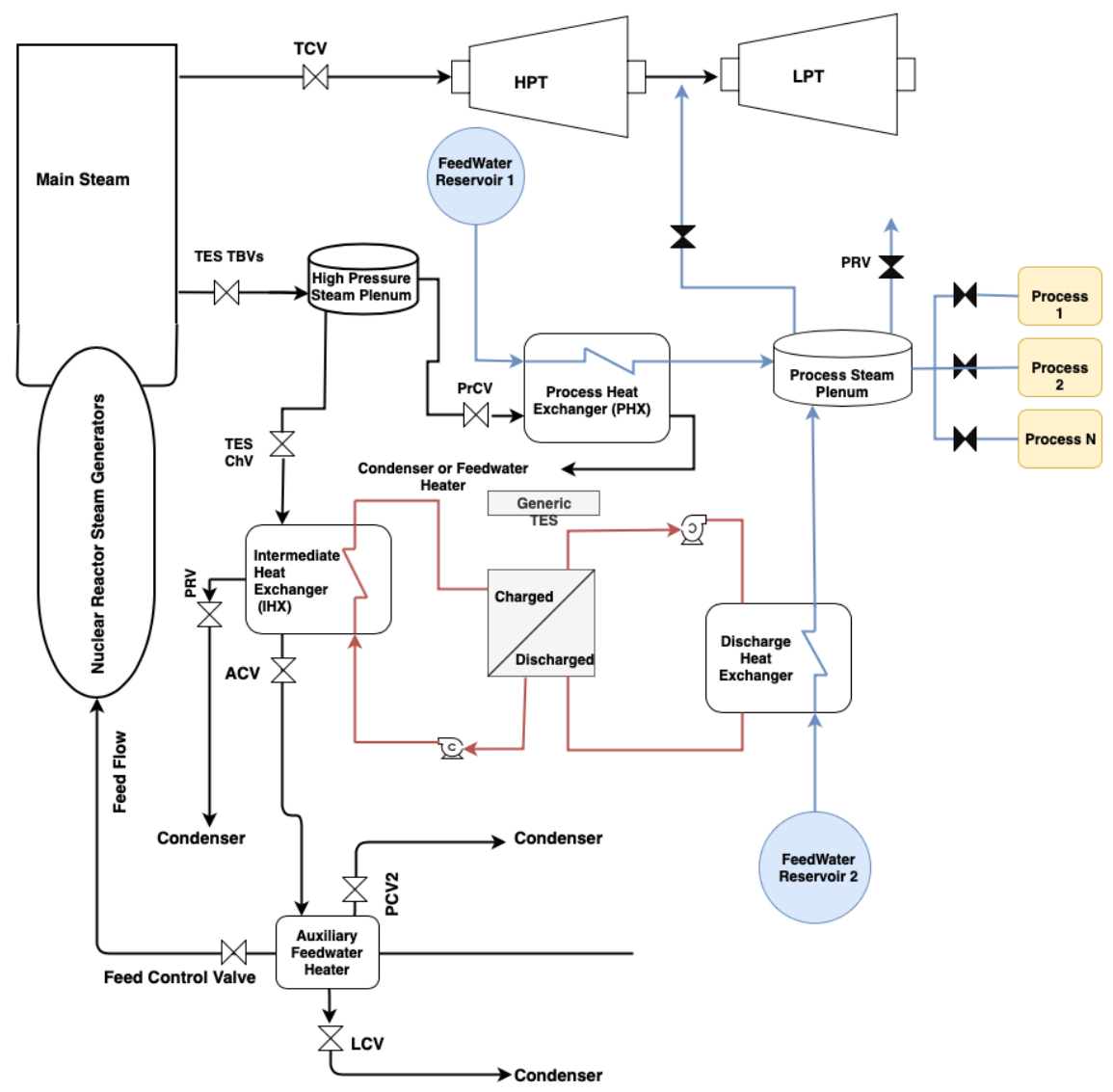

Figure 31: Conceptual TES integration for JUMP project. ${ }^{10,11,12,13}$

It is the opinion of the author that an in-depth analysis of the relative costs of thermal oil and molten salt two tank sensible heat storage systems must be completed. The analysis should include various research benefits of choosing salt and thermal oils. These include, but are certainly not limited to, investigation of new low temperature salts or a demonstration of the largest thermal oil storage. Potential future developments for each technology (further salt discoveries or reductions in cost of either medium) should also be considered in this decision.

\footnotetext{
${ }^{10}$ HPT - High Pressure Turbine, LPT - Low Pressure Turbine, OTSG - Once through Steam Generator

${ }^{11}$ PCV - Pressure Control Valve, TCV - Turbine Control Valve, FCV - Flow Control Valve

${ }^{12}$ PRV - Pressure Relief Valve, ACV - Auxiliary Control Valve, FDCV - Feed Control Valve

${ }^{13} \mathrm{LCV}$ - Level control valve, $\mathrm{ChV}$ - Charge Valve, PrCV - Process control valve
} 


\section{Conclusion}

This report has analyzed ten thermal energy storage technologies, with thirteen specific systems discussed in detail regarding their potential to integrate with LWR technology. A ranking tool identified important characteristics of thermal storage and ranked each of the technologies. Concrete, molten salt, and thermal oil sensible heat storage, and steam accumulators evaluated highly. After including cost estimations and qualitatively comparing these technologies, it is recommended that either molten salt or thermal oil be used for TES implementation in the JUMP module. The TES project cost will likely cost between $\$ 14,000,000$ and $\$ 50,000,000$. The potential flexibility of a two-tank sensible heat storage system should be able to demonstrate various new uses for nuclear heat. From power peaking via steam or liquid air heat topping to process heat applications, a two-tank system should be able to best provide a constant power transfer capability to the auxiliary energy consumer.

Further research is needed in two significant areas regarding the TES. First, as previously stated, a complete economic analysis should be conducted to assess the benefits of molten salts and thermal oils. Second, specific configuration, optimal sizing, and operational techniques need to be investigated in order to maximize the research opportunity provided by JUMP. The decisions made herein could have significant impact on the growth of the nuclear power industry globally, potentially opening a variety of nuclear applications with successful TES and SMR integration.

This work will limit the number of models that will be finally translated in modelica and made available in the hybrid repository. Moreover, the ranking system developed here will be used also to perform screening for future applications.

\section{Acknowledgements}

This research was supported by the U.S. Department of Energy Office of Nuclear Energy via the Crosscutting Technologies Development Integrated Energy Systems Program, conducted at Idaho National Laboratory under U.S. Department of Energy contract DE-AC-07-05ID14517. 


\section{REFERENCES}

[1] Patrick Morilhat, Stéphane Feutry, Christelle Le Maitre, Jean Melaine Favennec, "Nuclear power plant flexibility at EDF," 2019. Ffhal-01977209. Available; https://hal-edf.archives-ouvertes.fr/hal-01977209/document

[2] Margaret Harding, “\#12 - nuclear flexibility,” Nuclear Economics Consulting Group, Sep. 2015. http://nucleareconomics.com/12-nuclear-flexibility/

[3] United States Energy Information Agency, "Levelized cost and levelized avoided cost of new generation sources in the Annual Energy Outlook 2019," Feb. 2019. Available: https://www.eia.gov/outlooks/aeo/pdf/electricity_generation.pdf

[4] Advanced Reactor Technologies (2019), Hybrid energy system, Available: https://art.inl.gov/hybridenergy/SitePages/Home.aspx

[5] Hatch, C. (2019, March 20). JUMP presents big opportunities for nuclear scientists, industry. Available: https://inl.gov/article/advanced-reactors/

[6] K Frick, S Bragg-Sitton, C Rabiti, "Development of a NuScale Power Module in the Modelica Framework" Nuclear Science and Technology, Idaho National Laboratory, Idaho Falls, ID. INL/LTD-19-56694, November 2019.

[7] OECD Nuclear Energy Agency for the Generation IV International Forum, "Technology roadmap update for generation IV nuclear energy systems," Januarty 2014. Available: https://www.gen4.org/gif/upload/docs/application/pdf/2014-03/gif-tru2014.pdf

[8] J. Coleman, S. Bragg-Sitton, E. Dufek, S. Johnson, J. Rhodes, T. Davidson, and M. Webber, "An evaluation of energy storage options for nuclear power," Nuclear Science and Technology, Idaho National Laboratory, Idaho Falls, ID. INL/EXT-17-42420, June 2017.

[9] NuScale (2019), Comprehensive Safety Features, Available: https://www.nuscalepower.com/benefits/safety-features

[10] NuScale (2019), History, Available: https://www.nuscalepower.com/about-us/history

[11] S. Bailey, "NuScale Power," June 11, 2014. Available: https://www.google.com/url?sa=t\&rct=j\&q=\&esrc=s\&source=web\&cd=1\&cad=rja\&uact=8\&ved=2ahUKEwjG1I SL5vDiAhWwHjQIHQULDl0QFjAAegQIABAC\&url=https\%3A\%2F\%2Fnupic.com\%2FNUPIC\%2FGetFile.aspx\%3F ID\%3D43\%26tbl\%3DHOME_HOT_TOPICS_DOCS\%26idFN\%3Did\%26fileFN\%3Dfile_name\&usg=AOvVaw0tekm Ew7gQlfID4SkUrxXs

[12] NuScale (2019), Technology Overview, Available: https://www.nuscalepower.com/technology/technologyoverview

[13] D. Mikkelson, K. Frick, J. M. Doster, S. Bragg-Sitton, E. Worsham “Thermal Energy Storage Selection for Near Term Nuclear Integration," Transaction American nuclear Society Winter Meeting 2019, Washington DC, November 2019.

[14] Nuscale Standard Plant Design Certification Application (2019, August), "Introduction and general description of the plant," Available: https://www.nrc.gov/docs/ML1831/ML18310A314.pdf

[15] Nuscale Standard Plant Design Certification Application (2019, August), "Steam Power and Conversion System," Available: https://www.nrc.gov/docs/ML1831/ML18310A332.pdf

[16] Z. Zhou, T. Levin, and G. Conzelmann, "Survey of U.S. Ancillary Services Market,” Center for Energy, Environmental, and Economic Systems Analysis, Energy Systems Division, Argonne National Laboratory, Lemont, IL. ANL/ESD-16/1, January 2016.

[17] A. Dicks and D. Rand, Fuel Cell Systems Explained, Wiley, Glasgow, UK: John Wiley \& Sons LTD, 2018.

[18] United States Department of Energy. "A national vision of America's transition to a hydrogen economy - to 2030 and beyond." February 2002. Available: https://www.hydrogen.energy.gov/pdfs/vision_doc.pdf

[19] J. Kim, S. Bragg-Sitton, and R. Boardman, "Status report on the high-temperature steam electrolysis model developed in the Modelica framework (FY2017)," Nuclear Science and Technology, Idaho National Laboratory, Idaho Falls, ID. INL/EXT-17-43056, August 2017.

[20] K. Frick, P. Talbot, D. Wendt, R. Boardman, C. Rabiti, S. Bragg-Sitton, D. Levie, B. Frew, M.Ruth, A. Elgowainy, T. Hawkins. Evaluation of Hydrogen Production Feasibility for a Light Water Reactor in the Midwest. Idaho National Laboratory, September 2019. INL/EXT-19-55395.

[21] S. Patel. "Three More Nuclear Plant Owners will Demonstrate Hydrogen Production." September 11, 2019. https://www.powermag.com/three-more-nuclear-plant-owners-will-demonstrate-hydrogen-production/.

[22] A. Vostrikov, S. Psarov, D. Yu. Dubov, O. Fedyaeva, and M. Sokol, "Kinetics of coal conversion in supercritical water," Energy \& Fuels, vol. 21. pp 2840-2845, Sep. 2007.

[23] Z. Ou, H. Jin, Z. Ren, S. Zhu, M. Song, L. Guo, "Mathematical modeling for coal conversion in supercritical water: reacting multiphase flow with conjugate heat transfer," International Journal of Hydrogen Energy vol. 44, pp 15746-15757, June 2019. Available: https://doi.org/10.1016/j.ijhydene.2018.09.139

[24] Office of Energy Efficiency \& Renewable Energy, "U.S. manufacturing energy use and greenhouse gas emissions analysis," pp 69-83, 2012. Available:

https://www.energy.gov/sites/prod/files/2013/11/f4/energy_use_and_loss_and_emissions_petroleum.pdf 
[25] Office of Energy Efficiency and Renewable Energy. "Steam System Opportunity Assessment for the Pulp and Paper, Chemical Manufacturing, and Petroleum Refining Industries Main Report," Oct. 2002. D0E/G0-1020021639. Available: https://www.osti.gov/servlets/purl/1215927

[26] J. Chen, H. Garcia, J. Kim, S Bragg-Sitton, “Operations optimization of nuclear hybrid energy systems,” Nuclear Technology vol. 195, pp. 143-156, Aug. 2016.

[27] H. Garcia, J. Chen, J. Kim, R. Vilim, W. Binder, S. Bragg-Sitton, R. Boardman, M. McKeller, C. Paredis, "Dynamic performance analysis of two regional nuclear hybrid energy systems," Energy vol. 107, pp. 234-258, Jul. 2016. Available: https://doi.org/10.1016/j.energy.2016.03.128

[28] U.S. Energy Information Administration. "Manufacturing Energy Consumption Survey Consumption of Energy For All Purposes Table 1.2," 2017. Available: https://www.eia.gov/consumption/manufacturing/data/2014/

[29] U.S. Energy Information Administration. "Manufacturing Energy Consumption Survey Offsite-Produced Fuel Consumption. Table 4.2,” 2017. Available: https://www.eia.gov/consumption/manufacturing/data/2014/

[30] C. McMillan, R. Boardman, M. McKellar, P. Sabharwall, M. Ruth, and S. Bragg-Sitton, "Generation and use of thermal energy in the U.S. industrial sector and opportunities to reduce its carbon emissions," Technical Report, NREL/TP-6A50-66763, INL/EXT-16-39680, December 2016. Available: https://www.nrel.gov/docs/fy17osti/66763.pdf

[31] United Nations World Water Assessment Programme, "Global water resources under increasing pressure from rapidly growing demands and climate change, according to new UN World Water Development Report," Colombella, Italy. Available:

http://www.unesco.org/new/fileadmin/MULTIMEDIA/HQ/SC/pdf/WWDR4\%20Background\%20Briefing\%20 Note_ENG.pdf

[32] H. Tran and E. Vakkilainnen, "The kraft chemical recovery process.” Available: https://www.tappi.org/content/events/08kros/manuscripts/1-1.pdf.

[33] E. Jones, M. Qadir, M. van Vleet, V. Smakhtin, and S. Kang, "The state of desalination and brine production: A global outlook," Science of the Total Environment, vol. 657, pp 1343-1356, Mar. 2019. Available: https://doi.org/10.1016/j.scitotenv.2018.12.076

[34] A. Stillwell and M. Webber, "Predicting the specific energy consumption of reverse osmosis desalination," Water, vol. 8, issue 12, Dec. 2016. Available: https://doi.org/10.3390/w8120601

[35] Kucera, Jane, Reverse Osmosis - Industrial Processes and Applications (2nd Edition) - 9. Design Considerations, John Wiley \& Sons, 2015. Available: https://app.knovel.com/hotlink/pdf/id:kt011BIG05/reverse-osmosis-industrial/design-considerations

[36] H. Rabiee, K. Khalilpour, J. Betts, N. Tapper, "Energy-Water Nexus: Renewable-Integrated Hybridized Desalination Systems," Cambridge, MA: Academic Press, 2019, pp. 409-458. Available: https://doi.org/10.1016/B978-0-12-813306-4.00013-6

[37] Highview Power (2019), Plants, Available: https://www.highviewpower.com/plants/

[38] R. Morgan, S. Nelmes, E. Gibson, and G. Brett, "Liquid air energy storage - Analysis and first results from a pilot scale demonstration plant," Applied Energy vol. 137, pp 845-853, Jan. 2015. Available: https://doi.org/10.1016/j.apenergy.2014.07.109

[39] H. Peng, X. Shan, Y. Yang, and X. Ling, "A study on performance of a liquid air energy storage system with packed bed units," Applied Energy vol. 211, pp 126-135, Feb. 2018. Available: https://doi.org/10.1016/j.apenergy.2017.11.045

[40] Y. Li, D. Li, H. Cao, X. Wang, S. Wang, Y. Jin, and Y. Ding, "Load shifting of nuclear power plants using cryogenic energy storage technology," Applied Energy vol. 113, pp 1710-1716, Jan. 2014. Available: https://doi.org/10.1016/j.apenergy.2013.08.077

[41] M. Antonelli, S. Barsali, U. Desideri, R. Giglioli, F. Paganucci, and G. Pasini, "Liquid air energy storage: Potential and challenges of hybrid power plants," Applied Energy vol. 194, pp 522-529, May 2017. Available: https://doi.org/10.1016/j.apenergy.2016.11.091

[42] A. Sciacovelli, A. Vecchi, and Y. Ding, "Liquid air energy storage (LAES) with packed bed cold thermal storage From component to system level performance through dynamic modeling," Applied Energy vol. 190, pp 84-98, Mar. 2017. Available: https://doi.org/10.1016/j.apenergy.2016.12.118

[43] Underground Energy (2018), ATES - Aquifer thermal energy storage, Available: http://undergroundenergy.com/our-technology/ates/

[44] Snijders, Aart, "Aquifer thermal energy storage technology development and major applications in europe," IFTech. Avialable: http://www.trca.on.ca/dotAsset/16551.pdf

[45] Drake Landing Solar Community (2018), Borehole thermal energy storage. Available: https://dlsc.ca/borehole.htm.

[46] Underground Energy (2018), BTES - Borehole thermal energy storage, Available: http://undergroundenergy.com/our-technology/btes/

[47] C. Misenheimer and S. Terry, "Modeling hybrid nuclear systems with chilled-water storage," J. Energy Resource Technologies, vol. 139, issue 1, Jan. 2017. Available: https://www.osti.gov/servlets/purl/1367861 
[48] K. Frick, C. Misenheimer, J. Doster, S. Terry and S. Bragg-Sitton, “Thermal energy storage configurations for small modular reactor load shedding," Nuclear Technology, vol. 202, issue 1, pp 53-70, Apr. 2018.

[49] Office of Sustainability, "Stanford University Energy and Climate Plan," Stanford University, 2015. Available: http://sustainable.stanford.edu/sites/default/files/E\%26C\%20Plan\%202016.6.7.pdf.

[50] Sandia National Laboratories, DOE Office of Electricity. DOE Global Energy Storage Database. Available: https://www.energystorageexchange.org/projects.

[51] D. Wendt, H. Huang, G. Zhu, P. Sharan, J. McTigue, K. Kitz, S. Green, and J. McLennan, “Geologic thermal energy storage of solar heat to provide a source of dispatchable renewable power and seasonal energy storage capacity," GRC Transactions, vol. 43, pp unassigned, 2019. (upcoming INL submission)

[52] J. McTigue, J. Castro, G. Mungas, N. Kramer, J. King, C. Turchi, G. Zhu, "Hybridizing a geothermal power plant with concentrating solar power and thermal storage to increase power generation and dispatchability," Applied Energy, vol. 228, pp 1837-1852, Oct. 2018. Available: https://doi.org/10.1016/j.apenergy.2018.07.064

[53] D. Stack, D. Curtis, and C. Forsberg. "Performance of firebrick resistance-heated energy storage for industrial heat applications and round trip electricity storage," Applied Energy, vol. 242, pp 782-796, May 2019. Available: https://doi.org/10.1016/j.apenergy.2019.03.100

[54] C. Forsberg, S. Brick, and G. Haratyk. "Coupling heat storage to nuclear reactors for variable electricity output with baseload reactor operation," The Electricity Journal, vol. 31. pp 23-31, Apr 2018. Available: https://doi.org/10.1016/j.tej.2018.03.008

[55] C. Forsberg, D. Stack, D. Curtis, G. Haratyk, and N. Sepulveda, “Converting excess low-price electricity into hightemperature stored heat for industry and high-value electricity production," The Electricity Journal, vol. 30, pp 42-52, July 2017. Available: https://doi.org/10.1016/j.tej.2017.06.009

[56] EnergyNest The Thermal Battery Company (2018) Applications, Available: https://energynest.com/applications/

[57] N. Hoivik, C. Greiner, E. Tirado, J. Barragan, P. Bergan, G. Skele, P. Blanco, and N. Calvet, "Demonstration of EnergyNest thermal energy storage (TES) technology," AIP Conference Proceedings 1850, 080011, 2017. Available: https://doi.org/10.1063/1.4984432

[58] D. Laing, C. Bahl, T. Bauer, M. Fiss, N. Breidenbach, and M. Hempel, "High temperature solid-media thermal energy storage for solar thermal power plants," Proceedings of the IEEE vol. 100, no. 2. pp 516-524, Feb. 2012. Available: 10.1109/JPROC.2011.2154290

[59] K. Pielichowska and K. Pielichowski. "Phase change materials for thermal energy storage," Progress in Materials Science, vol. 65, pp 67-123, Aug. 2014. Available: https://doi.org/10.1016/j.pmatsci.2014.03.005

[60] J. Pereira de Cunha and P. Eames, "Thermal energy storage for low and medium temperature applications using phase change materials - a review," Applied Energy, vol. 177. pp. 227-238, Sep. 2016.

[61] R. Bradshaw and N. Siegel, "Molten nitrate salt development for thermal energy storage in parabolic trough solar power systems," Sandia National Laboratories SAND2008-4727C, ES2008-54174, Aug. 2008. Available: https://www.osti.gov/servlets/purl/1142924

[62] P. Donkers, L. Sögütoglu, H. Huinink, H. Fischer, and O. Adan, "A review of salt hydrates for seasonal heat storage in domestic applications," Applied energy, vol. 199, pp 45-68, Aug. 2017. Available: https://doi.org/10.1016/j.apenergy.2017.04.080

[63] W. Su, J. Darkwa, and G. Kokogiannakis, "Review of solid-liquid phase change materials and their encapsulation technologies," Renewable and Sustainable Energy Reviews vol. 48, pp 373-391, Aug. 2015. Available: https://doi.org/10.1016/j.rser.2015.04.044

[64] S. Mohamed, F. Al-Sulaiman, N. Ibrahim, H. Zahir, A. Al-Ahmed, R. Saidur, B. Yilbas, and A. Sahin, "A review on the current status and challenges of inorganic phase change materials for thermal energy storage systems," Renewable and Sustainable Energy Reviews, vol. 70, pp 1072-1089, Apr. 2017. Available: https://doi.org/10.1016/j.rser.2016.12.012

[65] P. Donkers. L. Pel, and O. Adan, "Experimental studies for the cyclability of salt hydrates for thermochemical heat storage," Journal of Energy Storage vol. 5. pp 25-32. Feb. 2016. Available: https://doi.org/10.1016/j.est.2015.11.005

[66] B. Michel, N. Mazet, and P. Neveu, "Experimental investigation of an innovative thermochemical process operating with a hydrate salt and moist air for thermal storage of solar energy: Global performance," Applied Energy, vol. 129 pp 179-186. Sep. 2014. Available: https://doi.org/10.1016/j.apenergy.2014.04.073

[67] A. de Jong, F. Trausel, C. Finck, L. van Vliet, and R. Cuypers, "Thermochemical heat storage - system design issues," Energy Procedia, vol. 48, pp 309-319, 2014. Available: https://doi.org/10.1016/j.egypro.2014.02.036

[68] G. Krese, R. Koželj, V. Butala, U. Stritih, "Thermochemical seasonal solar energy storage for heating and cooling of buildings," Energy and Buildings, vol. 164, Pages 239-253, Apr. 2018. Available: https://doi.org/10.1016/j.enbuild.2017.12.057

[69] X. Chen, Z. Zhang, C. Qi, X. Ling, and H. Peng, "State of the art on the high temperature thermochemical energy storage systems," Energy Conversion and Management vol. 177, pp. 792-815, Dec. 2018. Available: https://doi.org/10.1016/j.enconman.2018.10.011 
[70] Angerer, M. Becker, S. Härzschel, K. Kröper, S. Gleis, A. Vandersickel, and H. Spliethoff, “Design of a MW scale thermo-chemical energy storage," Energy Reports, vol. 4, pp 507-519, Nov. 2018. Available: https://doi.org/10.1016/j.egyr.2018.07.005

[71] D. Yadav and R. Banerjee, "A review of solar thermochemical process," Renewable and Sustainable Energy Reviews, vol. 54, pp 497-532. Feb. 2016. Available: https://doi.org/10.1016/j.rser.2015.10.026

[72] Office of Electricity (2019), “Department of energy global energy storage database," Sandia National Laboratory. Available: https://energystorageexchange.org

[73] K. Frick, J. Doster, and S. Bragg-Sitton. "Design and operation of a sensible heat peaking unit for small modular reactors," Nuclear Technology, vol. 205, pp 415-441, Jun. 2018.

[74] G. Angelini, A. Lucchini, and G. Manzolini, "Comparison of thermocline molten salt storage performances to commercial two-tank configuration,” Energy Procedia, vol. 49, pp 694-704, 2014. Available: https://doi.org/10.1016/j.egypro.2014.03.075

[75] Z. Yang and S. Garimella, "Cyclic operation of molten-salt thermal energy storage in thermoclines for solar power plants," Applied Energy vol. 103, pp 256-265, Available: https://doi.org/10.1016/j.apenergy.2012.09.043

[76] Z. Yang and S. Garimella, "Thermal analysis of solar thermal energy storage in a molten-salt thermocline," Solar Energy, vol. 84, pp 974-985, Jun. 2010. Available: https://doi.org/10.1016/j.solener.2010.03.007

[77] X. Li, Y. Wang, S. Wu, and L. Xie, "Preparation and investigation of multicomponent alkali nitrate/nitrite salt for low temperature thermal energy storage," Energy vol. 160. pp 1021-1029, Oct. 2018. Available: https://doi.org/10.1016/j.energy.2018.07.078

[78] T. Delise, A. Tizzoni, M. Ferrara, N. Corsaro, C. D’Ovatti, S. Sau, and S. Licoccia, “Thermophysical, environmental, and compatibility properties of nitrate and nitrite containing molten salts for medium temperature CSP applications: A critical review," Journal of the European Ceramic Society, vol. 39, pp 92-99, Available: https://doi.org/10.1016/j.jeurceramsoc.2018.07.057

[79] R. Jacob, W. Saman, and F. Bruno, "Capital cost expenditure of high temperature latent and sensible thermal energy storage systems," AIP Conference Proceedings, vol. 1850, 080012, June 2017.

[80] Eastman (2019),Technical data sheet Therminol ${ }^{\circledR} 66$ heat transfer fluid. Available: https://www.therminol.com/heat-transfer-fluids

[81] Duratherm (2019). Thermal Fluids. Available: https://durathermfluids.com/heat-transfer-fluid/

[82] E. Batuecas, C. Mayo, R. Díaz, and F. Pérez, "Life cycle assessment of heat transfer fluids in parabolic trough concentrating solar power technology," Solar Energy Materials and Solar Cells vol. 171, pp 91-97, Nov. 2017. Available: https://doi.org/10.1016/j.solmat.2017.06.032

[83] Spirax Sarco, (2019) Steam Accumulators. Available: https://beta.spiraxsarco.com/learn-about-steam/theboiler-house/steam-accumulators

[84] W.-D. Steinmann and M. Eck, "Buffer storage for direct steam generation," Solar Energy, vol. 80, pp. 1277-1282, Oct. 2006. Available: https://doi.org/10.1016/j.solener.2005.05.013

[85] Department of Energy, "Technology readiness assessment guide," DOE G 413.3-4A, Sep 2001. Available: https://www2.lbl.gov/dir/assets/docs/TRL\%20guide.pdf

[86] Office of Electricity (2019), “TAS Texas Cooperative," Sandia National Laboratory. Available: https://energystorageexchange.org/projects/995

[87] U.S. Department of Energy (2012) “Energy tips: steam,” Energy Efficiency \& Renewable Energy, Advanced Manufacturing Office. Available: https://www.energy.gov/sites/prod/files/2014/05/f16/steam14_chillers.pdf.

[88] M. Daniels, "Integration of large-scale steam accumulators for energy storage in nuclear hybrid energy systems," North Carolina State University Master's Thesis, 2017.

[89] B. Capp, “Transforming nuclear generation plants with thermal energy storage," June 17, 2019.

[90] International Renewable Energy Agency, "Renewable energy technologies: cost analysis series, concentrating solar power," International Renewable Energy Agency, June 2012. Available: https://www.irena.org/documentdownloads/publications/re_technologies_cost_analysis-csp.pdf

[91] NuScale (2019), Cost Competitive, Available: https://www.nuscalepower.com/benefits/cost-competitive 
